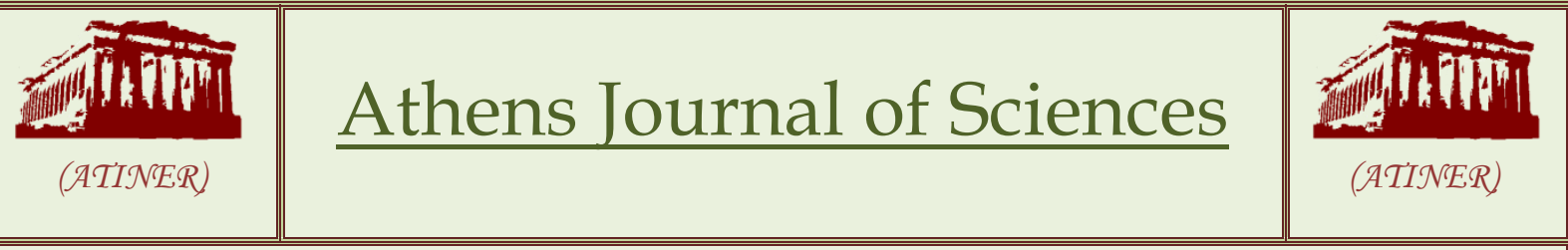 \\ Volume 6, Issue 2, June 2019
}

Articles

Front Pages

FRANCISCO JAVIER DELGADO CEPEDA

Assembling Large Entangled States in the Rényi-Ingarden-Urbanik Entropy Measure under the SU(2)-Dynamics Decomposition for Systems Built from Two-Level Subsystems

SARAH HAINES, MICHAEL KRACH, ARKHADI PUSTAKA, QING LI E LAILA RICHMAN

The Effects of Computational Thinking Professional Development on STEM Teachers' Perceptions and Pedagogical Practices

FAISAL ABDALLA SINADA \& MANAL ELSAYED ABDELRAHMAN The Phytoplankton and Water Quality of Sennar and Roseires Reservoirs, Sudan

ALI ABDALLA MOHAMMED, ASIM OSMAN ELZUBEIR, MUAWIA ELBEDAWI HAMAD \& ABDALLA IBRAHIM ELHAGWA Effect of Irrigation Canal Sediments, Humate Fertilizer and Irrigation Interval on Wheat Performance in Desert Soils 


\section{Mission}

ATINER is a World Non-Profit Association of Academics and Researchers based in Athens. ATINER is an independent Association with a Mission to become a forum where Academics and Researchers from all over the world can meet in Athens, exchange ideas on their research and discuss future developments in their disciplines, as well as engage with professionals from other fields. Athens was chosen because of its long history of academic gatherings, which go back thousands of years to Plato's Academy and Aristotle's Lyceum. Both these historic places are within walking distance from ATINER's downtown offices. Since antiquity, Athens was an open city. In the words of Pericles, Athens"... is open to the world, we never expel a foreigner from learning or seeing". ("Pericles' Funeral Oration", in Thucydides, The History of the Peloponnesian War). It is ATINER's mission to revive the glory of Ancient Athens by inviting the World Academic Community to the city, to learn from each other in an environment of freedom and respect for other people's opinions and beliefs. After all, the free expression of one's opinion formed the basis for the development of democracy, and Athens was its cradle. As it turned out, the Golden Age of Athens was in fact, the Golden Age of the Western Civilization. Education and (Re)searching for the 'truth' are the pillars of any free (democratic) society. This is the reason why Education and Research are the two core words in ATINER's name. 
The Athens Journal of Sciences

ISSN NUMBER: 2241-8466- DOI: 10.30958/ajs

Volume 6, Issue 2, June 2019

Download the entire issue ( $\underline{\mathrm{PDF}})$

Front Pages

i-viii

Assembling Large Entangled States in the Rényi81 Ingarden-Urbanik Entropy Measure under the SU(2)Dynamics Decomposition for Systems Built from Two-Level Subsystems

Francisco Javier Delgado Cepeda

The Effects of Computational Thinking Professional

Development on STEM Teachers' Perceptions and Pedagogical Practices

Sarah Haines, Michael Krach, Arkhadi Pustaka, Qing Li \& Laila Richman

The Phytoplankton and Water Quality of Sennar and

Roseires Reservoirs, Sudan

Faisal Abdalla Sinada \& Manal Elsayed Abdelrahman

Effect of Irrigation Canal Sediments, Humate Fertilizer and Irrigation Interval on Wheat Performance in Desert $\underline{\text { Soils }}$

Ali Abdalla Mohammed, Asim Osman Elzubeir, Muawia Elbedawi Hamad \& Abdalla Ibrahim Elhagwa 


\section{Athens Journal of Sciences Editorial and Reviewers' Board}

\section{Editors}

- Dr. Nicolas Abatzoglou, Head, Environment Unit, ATINER; Professor, Department of Chemical \& Biotechnological Engineering, Université de Sherbrooke, Canada; Chair Pfizer, Processes and Analytical Technologies in Pharmaceutical Engineering; Director of GRTP-C \& P (Groupe de recherches sur les technologies et procédés de conversion et pharmaceutiques); Fellow of Canadian Academy of Engineering.

- Dr. Christopher Janetopoulos, Head, Biology Unit, ATINER \& Associate Professor, University of the Sciences, USA.(Biology)

- Dr. Ethel Petrou, Academic Member, ATINER \& Professor and Chair, Department of Physics, Erie Community College-South, State University of New York, USA.

- Dr. Ellene Tratras Contis, Head, Chemistry Unit, ATINER \& Professor of Chemistry, Eastern Michigan University, USA.(Chemistry)

\section{Editorial Board}

- Dr. Colin Scanes, Academic Member, ATINER \& Emeritus Professor, University of Wisconsin Milwaukee, USA.

- Dr. Dimitris Argyropoulos, Professor, North Carolina State University, USA.

- Dr. Cecil Stushnoff, Emeritus Professor, Colorado State University, USA.

- Dr. Hikmat Said Hasan Hilal, Academic Member, ATINER \& Professor, Department of Chemistry, An-Najah N. University, Palestine.

- Dr. Jean Paris, Professor, Polytechnique Montreal, Canada.

- Dr. Shiro Kobayashi, Academic Member, ATINER \& Distinguished Professor, Kyoto Institute of Technology, Kyoto University, Japan.

- Dr. Jose R. Peralta-Videa, Academic Member, ATINER \& Research Specialist and Adjunct Professor, Department of Chemistry, The University of Texas at El Paso, USA.

- Dr. Jean-Pierre Bazureau, Academic Member, ATINER \& Professor, Institute of Chemical Sciences of Rennes ICSR, University of Rennes 1, France.

- Dr. Mohammed Salah Aida, Professor, Taibah University, Saudi Arabia.

- Dr. Zagabathuni Venkata Panchakshari Murthy, Academic Member, ATINER \& Professor/Head, Department of Chemical Engineering, Sardar Vallabhbhai National Institute of Technology, India.

- Dr. Alexander A. Kamnev, Professor, Institute of Biochemistry and Physiology of Plants and Microorganisms, Russian Academy of Sciences, Russia.

- Dr. Carlos Nunez, Professor, Physics Department, University of Wales Swansea, UK.

- Dr. Anastasios Koulaouzidis, Academic Member, ATINER \& Associate Specialist and Honorary Clinical Fellow of the UoE, The Royal Infirmary of Edinburgh, The University of Edinburgh, UK.

- Dr. Francisco Lopez-Munoz, Professor, Camilo Jose Cela University, Spain.

- Dr. Panagiotis Petratos, Professor, California State University-Stanislaus, USA.

- Dr. Yiannis Papadopoulos, Professor of Computer Science, Leader of Dependable Systems Research Group, University of Hull, UK.

- Dr. Joseph M. Shostell, Professor and Department Head, Math, Sciences \& Technology Department, University of Minnesota Crookston, USA.

- Dr. Ibrahim A. Hassan, Professor of Environmental Biology, Faculty of Science, Alexandria University, Egypt \& Centre of Excellence in Environmental Studies, King Abdulaziz University, Saudi Arabia.

- Dr. Laurence G. Rahme, Associate Professor, Department of Surgery, Microbiology and Immunobiology, Harvard Medical School, Boston, Massachusetts \& Director of Molecular Surgical Laboratory, Burns Unit, Department of Surgery, Massachusetts General Hospital, USA.

- Dr. Stefano Falcinelli, Academic Member, ATINER \& Associate Professor, Department of Civil and Environmental Engineering, University of Perugia, Italy.

- Dr. Mitra Esfandiarei, Academic Member, ATINER \& Assistant Professor, Midwestern University, USA

- Dr. Athina Meli, Academic Member, Academic Member, ATINER, Visiting Scientist and Research Scholar, University of Gent \& University of Liege, Belgium and Ronin Institute Montclair, USA.

- Vice President of Publications: Dr Zoe Boutsioli

- General Managing Editor of all ATINER's Publications: Ms. Afrodete Papanikou

- ICT Managing Editor of all ATINER's Publications: Mr. Kostas Spyropoulos

- Managing Editor of this Journal: Ms. Olga Gkounta ( $\underline{\text { bio })}$

\section{Reviewers' Board}

Click Here 


\section{President's Message}

All ATINER's publications including the e-journals are open access without any costs (submission, processing, publishing, open access paid by authors, open access paid by readers etc.) and are independent of the presentations made at any of the many small events (conferences, symposiums, forums, colloquiums, courses, roundtable discussions) organized by ATINER throughout the year. The intellectual property rights of the submitted papers remain with the author.

Before you submit, please make sure your paper meets some basic academic standards, which include proper English. Some articles will be selected from the numerous papers that have been presented at the various annual international academic conferences organized by the different divisions and units of the Athens Institute for Education and Research.

The plethora of papers presented every year will enable the editorial board of each journal to select the best ones, and in so doing, to produce a quality academic journal. In addition to papers presented, ATINER encourages the independent submission of papers to be evaluated for publication.

The current issue of the Athens Journal of Sciences (AJS) is the second issue of the sixth volume (2019). The reader will notice some changes compared with the previous issues, which I hope is an improvement. An effort has been made to include papers which extent to different fields of the Natural and Formal Sciences.

Gregory T. Papanikos, President

Athens Institute for Education and Research 


\section{Athens Institute for Education and Research}

\section{A World Association of Academics and Researchers}

\section{$7^{\text {th }}$ Annual International Conference on Chemistry \\ 22-25 July 2019, Athens, Greece}

The Chemistry Unit of ATINER, will hold its $7^{\text {th }}$ Annual International Conference on Chemistry, 22-25 July 2019, Athens, Greece sponsored by the Athens Journal of Sciences. The aim of the conference is to bring together academics and researchers of all areas of chemistry and other related disciplines. You may participate as stream organizer, presenter of one paper, chair a session or observer. Please submit a proposal using the form available (https://www.atiner.gr/2019/FORMCHE.doc).

Academic Members Responsible for the Conference

- Dr. Ellene Tratras Contis, Head, Chemistry Unit, ATINER \& Professor of Chemistry, Eastern Michigan University, USA.

- Dr. Nicolas Abatzoglou, Head, Environment Unit, ATINER \& Professor, Department of Chemical \& Biotechnological Engineering, University of Sherbrook, Canada, Chair Pfizer, PAT in Pharmaceutical Engineering, Director GREEN-TPV and GRTP-C \& Pwelcomes.

- Abstract Submission: 10 June 2019

- Acceptance of Abstract: 4 Weeks after Submission

- Submission of Paper: 24 June 2019

\section{Social and Educational Program}

The Social Program Emphasizes the Educational Aspect of the Academic Meetings of Atiner.

- Greek Night Entertainment (This is the official dinner of the conference)

- Athens Sightseeing: Old and New-An Educational Urban Walk

- Social Dinner

- Mycenae Visit

- Exploration of the Aegean Islands

- Delphi Visit

- Ancient Corinth and Cape Sounion

\section{Conference Fees}

Conference fees vary from $400 €$ to $2000 €$ Details can be found at: https://www.atiner.gr/2019fees 


\section{Athens Institute for Education and Research}

A World Association of Academics and Researchers

\section{$7^{\text {th }}$ Annual International Conference on Physics \\ 22-25 July 2019, Athens, Greece}

The Physics Unit of ATINER, will hold its $7^{\text {th }}$ Annual International Conference on Physics, 22-25 July 2019, Athens, Greece sponsored by the Athens Journal of Sciences. The aim of the conference is to bring together academics and researchers of all areas of physics and other related disciplines. You may participate as stream organizer, presenter of one paper, chair a session or observer. Please submit a proposal using the form available (https://www.atiner.gr/2019/FORM-PHY.doc).

\section{Important Dates}

- Abstract Submission: 10 June 2019

- Acceptance of Abstract: 4 Weeks after Submission

- Submission of Paper: 24 June 2019

\section{Academic Member Responsible for the Conference}

- Dr. Ethel Petrou, Academic Member, ATINER \& Professor and Chair, Department of Physics, Erie Community College-South, State University of New York, USA.

- Dr. Bala Maheswaran, Head, Electrical Engineering Unit, ATINER \& Professor, Northeastern University, USA.

\section{Social and Educational Program}

The Social Program Emphasizes the Educational Aspect of the Academic Meetings of Atiner.

- Greek Night Entertainment (This is the official dinner of the conference)

- Athens Sightseeing: Old and New-An Educational Urban Walk

- Social Dinner

- Mycenae Visit

- Exploration of the Aegean Islands

- Delphi Visit

- Ancient Corinth and Cape Sounion

More information can be found here: https://www.atiner.gr/social-program

\section{Conference Fees}

Conference fees vary from $400 €$ to $2000 €$

Details can be found at: https://www.atiner.gr/2019fees 



\title{
Assembling Large Entangled States in the Rényi- Ingarden-Urbanik Entropy Measure under the $S U(2)$-Dynamics Decomposition for Systems Built from Two-Level Subsystems
}

\author{
By Francisco Javier Delgado Cepeda*
}

\begin{abstract}
Quantum Information is a discipline derived from Quantum Mechanics which uses quantum systems to exploit their states as information recipients. Normally, these states are conformed by two-level systems to reproduce the binary nature underlying the classical computation structure. Quantum evolution is then controlled to reproduce convenient information processing operations. Evolution could be hard to be controlled. $S U(2)$ decomposition procedure lets to set a binary structure of processing when a convenient basis is selected to set the dynamics description. In this work, we exploit this procedure for a generic Hamiltonian in order to set the process to reduce arbitrary states into simplest ones. For this work, we use customary SU(2) operations on local and entangled states. These operations are described in the development. They involve 1, 2 and 4-local operations meaning the number of quantum parties involved, in agreement with the decomposition procedure scope. This task is complex in spite the difficulty to set a general way to manipulate the entanglement in the system. We are particularly interested on the application of stochastic procedures based in SU(2) decomposition operations to achieve that goal. In order to have a measure of the advancement of the last task, we use the RényiIngarden-Urbanik entropy to describe the whole spectrum of entanglement in the large systems through the assembling/disassembling of the state.
\end{abstract}

Keywords: Entanglement, Quantum Information, Quantum Processing, Rényi-IngardenUrbanik Entropy, States Design.

\section{Introduction}

Quantum information is pursuing novel approaches to set information and processing on physical systems exhibiting quantum properties, such as superposition and entanglement. There, normally two-level systems are combined to scale them into large physical systems being able to hold large amounts of complex Information. Due to the entangling interactions among them, which are mandatory as part of the improved processing, these composed systems exhibit a complex dynamics hard to control under a universal set of operations as in classical computing, normally in the form of gates. In the most of cases, the whole evolution matrices for the composed system have their entries different from zero. This aspect does hard to fit them in controlled operations, normally involving two informational parts in the physical systems (remember that normally, those states are expressed in the eigenstates of the

"Professor, Tecnológico de Monterrey, Mexico. 
physical parameters composing such subsystems). Thus, the clue is to select an adequate basis to re-express the dynamics in order to reduce the complexity of such evolution. Nevertheless, the physical meaningful of those states are not assured, it is only informational unlinked from the physical parameters.

$S U(2)$ decomposition (Delgado 2017a) is a procedure recently developed for certain architectures and interactions (three interactions and set-ups denoted by Type $\mathrm{I}_{1} \mathrm{II}_{\mathrm{ab}}$ and III are able to set this kind of controllable operations; despite could be generalizable on a wider spectrum of quantum systems and non-only as $S U(2)$ reduction, instead having another group structure). There, generic $S U(2)$ operations can be settled in order to design states and to process information in terms of the Di Vincenzo criteria (Di Vincenzo 1997). Such procedure could be useful to reach processing gates in terms of the Gates Based Quantum Computation (GBQC), control in quantum information, entanglement quantification, quantum error correction, etc. In the current work, we exploit this approach to set key operations to transform random large quantum states in order to analyse if they are able to carry out the state through the entire spectrum of entanglement.

The aim of this paper is focused in the complexity to get general quantum states departing from the most simple ones, particularly those possibly exhibiting several types of entanglement (really, from separable to the genuine entangled states as a spectrum). The second section summarizes the details of $S U(2)$ decomposition procedure. Third section depicts the general processing operations being possible to reach in such procedure. Fourth section sets several findings about entanglement already reached under the $S U(2)$ decomposition operations. Fifth section presents the Rényi-Ingarden-Urbanik (RIU) entropy (Ingarden and Urbanik 1962) and finally sets several automated procedures to show the evolution processing of large quantum states transiting from separable to entangled states. Last section set the conclusions and future work.

\section{$S U(2)-D y n a m i c s$ Decomposition}

In this section, we set the generalities of $S U(2)$ reduction procedure as it has been developed in (Delgado 2015), together with the Hamiltonian being considered in such development. This procedure was first applied in the Heisenberg-Ising Hamiltonian for two particle spin together with external magnetic fields in a fix direction. By using the Bell states basis to describe the dynamics, it was discovered that the $S U(4)$ dynamics for the entire system became split in two evolution subspaces, each one with a $S U(2)$ dynamics. This block structure in the evolution matrix was useful to set the most common quantum processing operations. After, it was realized this procedure could be generalizable to any system integrated by several interacting two level systems being combined in only one bigger system. 


\section{A General Hamiltonian in $S U\left(2^{2 \mathrm{~d}}\right)$}

Thus, the current analysis of the $S U(2)$ decomposition departs from the general Hamiltonian for $n=2 d$ qubits (Delgado 2017a):

$$
\tilde{H}=\sum_{\left\{i_{k}\right\}} h_{\left\{i_{k}\right\}} \bigotimes_{k=1}^{n} \sigma_{i_{k}}=\sum_{\mathcal{I}=0}^{4^{n}-1} h_{\mathcal{I}_{4}^{n}} \bigotimes_{k=1}^{n} \sigma_{\mathcal{I}_{4, k}^{n}}
$$

where matrices $\sigma_{i}, i=0,1,2,3$ are the Pauli matrices (and the identity), and symbol $\otimes$ is the tensor product. The two-biased notation in the subscripts of the Hamiltonian coefficients and Pauli matrices are common in quantum information: $\left\{i_{1}, i_{2}, \ldots, i_{n}\right\}$ are a set of subscripts as reference of each coefficient and each physical part of the system, but alternatively $I$ is an equivalent number to those subscripts considered as its expression in base 4 with $n$ digits. Thus, $I_{4, k}^{n}=i_{k}$ is its $k$ digit in such base. We switch both notations under convenience.

\section{The Generalized Bell Basis (GBS)}

The last expression is settled on the Hilbert space $\mathcal{H}^{2 d}$ of spin states for each one of the $2 d$ subsystems being combined, a space with $2^{2 d}$ complex dimensions (or $4^{2 \mathrm{~d}-1}$ parametric dimensions due to the normalization condition). Procedure suggests re-express the dynamics on the Generalized Bell States basis, GBS (Sych and Leuchs 2009):

$$
\begin{aligned}
\left|\Psi_{\mathcal{L}_{d}^{d}}\right\rangle & =\bigotimes_{s=1}^{d} \frac{1}{\sqrt{2}} \sum_{\epsilon_{s}, \delta_{s}=0}^{1}\left(\tilde{\sigma}_{i_{s}}\right)_{\epsilon_{s}, \delta_{s}}\left|\epsilon_{s} \delta_{s}\right\rangle \\
& =\frac{1}{\sqrt{2^{d}}} \sum_{\left\{\epsilon_{j}\right\},\left\{\delta_{k}\right\}}\left(\tilde{\sigma}_{i_{1}} \otimes \ldots \otimes \tilde{\sigma}_{i_{d}}\right)_{\epsilon_{1} \ldots \epsilon_{d}, \delta_{1} \ldots \delta_{d}}\left|\epsilon_{1} \ldots \epsilon_{d}\right\rangle \otimes\left|\delta_{1} \ldots \delta_{d}\right\rangle \\
& =\frac{1}{\sqrt{2^{d}}} \sum_{\mathcal{E}, \mathcal{D}=0}^{2^{d}-1}\left(\tilde{\sigma}_{i_{1}} \otimes \ldots \otimes \tilde{\sigma}_{i_{d}}\right)_{\mathcal{E}_{2}^{d}, D_{2}^{d}}\left|\mathcal{E}_{2}^{d}\right\rangle \otimes\left|\mathcal{D}_{2}^{d}\right\rangle
\end{aligned}
$$

where the tilded $\sigma_{i}$ are the modified Pauli matrices, differing from the classical ones only for $i=2$ by an additional imaginary unit factor, $i$. Scripts follow the same rule that in the Hamiltonian, as instance: $\mathcal{D}^{n}{ }_{2, k}=\delta_{k}$, in this case in base 2 . Then, the Hamiltonian components can be expressed (Delgado 2017a) as:

$$
\left\langle\Psi_{\mathcal{I}_{4}^{d}}|H| \Psi_{\mathcal{K}_{4}^{d}}\right\rangle=\frac{1}{2^{d}} \sum_{\mathcal{J}=0}^{4^{2 d}-1} h_{\mathcal{J}_{4}^{2 d}} \prod_{s=1}^{d} \operatorname{Tr}\left(\tilde{\sigma}_{i_{s}}^{*} \sigma_{j_{d+s}} \tilde{\sigma}_{k_{s}}^{T} \sigma_{j_{s}}^{T}\right)
$$

This expression sets the rules to get the $S U(2)$ decomposition. By taking pairs of the entire set of scripts $I^{d}{ }_{4}$ and $\mathcal{K}^{d}$, in such way that in both corresponding rows of Hamiltonian only the diagonal terms and those with entries having them as subscripts, we will get a $2 \times 2$ block. In the current 
Hamiltonian, we can to get three possible groups of interactions: Types $\mathrm{I}_{\mathrm{a}} \mathrm{II}_{\mathrm{a}, \mathrm{b}}$ and III (Delgado 2017a). All of them contain entangling operations between the pairs $1, d+1 ; 2,4 ; \ldots ; d, 2 d$ (called correspondent pairs), a kind of operations referred as 2-local operations. All of them exhibit Ising-like interactions between correspondent pairs providing the diagonal part of the blocks. Additionally, Ising-like interactions among the non-correspondent parts provide the diagonal-off entries in the blocks. Correspondingly, the Type $\mathrm{II}_{\mathrm{b}}$ and III involve Dzyaloshinskii-Moriya-like interactions (Dzyaloshinskii 1958, Moriya 1960) among non-correspondent parts and correspondent pairs respectively to provide the diagonal-off entries (Delgado 2017a). In any case, all interactions work in only two ways: a) they lets to mix or to exchange the basis states by pairs if they are different in only one script (Type I ad III), or b) they are different in exactly two scripts (Types $\mathrm{II}_{\mathrm{a}, \mathrm{b}}$ ). These exchange rules have been described in detail by Delgado (2017b).

\section{The Block Structure Generated by the SU(2) Reduction}

Last decomposition lets to express the Hamiltonian in the form (by the rearrangement of the basis elements) of $2 \times 2$ blocks:

$$
H=\bigotimes_{i=1}^{2^{n-1}} \mathbb{S}_{H i}=\left(\begin{array}{c|c|c|c}
\mathbb{S}_{H 1} & \mathbf{0} & \ldots & \mathbf{0} \\
\hline \mathbf{0} & \mathbb{S}_{H 2} & \ldots & \mathbf{0} \\
\hline \vdots & \vdots & \ddots & \vdots \\
\hline \mathbf{0} & \mathbf{0} & \ldots & \mathbb{S}_{H 2^{n-1}}
\end{array}\right)
$$

Thus, because the evolution operator can be calculated from the Hamiltonian as the time-ordered integral (Grossman and Katz 1972), basically containing time-ordered products preserving that structure, it inherits the same block structure:

$$
U=\bigotimes_{i=1}^{2^{n-1}} \mathbb{S}_{U i}=\left(\begin{array}{c|c|c|c}
\mathbb{S}_{U 1} & \mathbf{0} & \ldots & \mathbf{0} \\
\hline \mathbf{0} & \mathbb{S}_{U 2} & \ldots & \mathbf{0} \\
\hline \vdots & \vdots & \ddots & \vdots \\
\hline \mathbf{0} & \mathbf{0} & \ldots & \mathbb{S}_{U 2^{n-1}}
\end{array}\right)
$$

Clearly there are $2^{2 d-1}$ blocks in each matrix with a respective phase factor (despite only $2^{2 d-2}$ are independent, thus generating a semi product structure). Only $U$ exhibits the structure $U(1)^{2^{2 d-2}} \times S U(2)^{2^{2 d-1}}$ (Delgado 2017a).

\section{Interactions Generating SU(2) Reduction}

Only the Type $\mathrm{II}_{\mathrm{a}, \mathrm{b}}$ interactions are able to generate extended entanglement in the system because it works on two correspondent pairs (4-local operations), it means on states differing in two elements of the subscripts. Figure 1 depicts those interactions showing $2 d=20$ qubits. The envelope surface depicts the 
permanent entanglement (in some variable degree) between the correspondent pairs maintained by non-local interactions in all three cases (non-crossed and Ising-like). Type I interaction includes only local interactions in each element of only one correspondent pair. Type III interaction includes non-local crossed (Dzyaloshinskii-Moriya-like) interactions between elements of only one correspondent pair. These interactions do not generate more extended entanglement far away than the pair where are applied. Finally, Type $\mathrm{II}_{\mathrm{a}, \mathrm{b}}$ interactions include non-local, and non-crossed (a) or crossed (b) interactions able to generate extended entanglement far away from the correspondent pairs. As a result, under this scheme, we have a group of $S U(2)$ based operations through the whole matrix evolution to produce quantum information processing with well identified operations.

Figure 1. Depiction of the Three Types of Interactions Exhibiting SU(2) Reduction in the GBS Basis a) Type I b) Type II $I_{a, b} c$ ) Type III

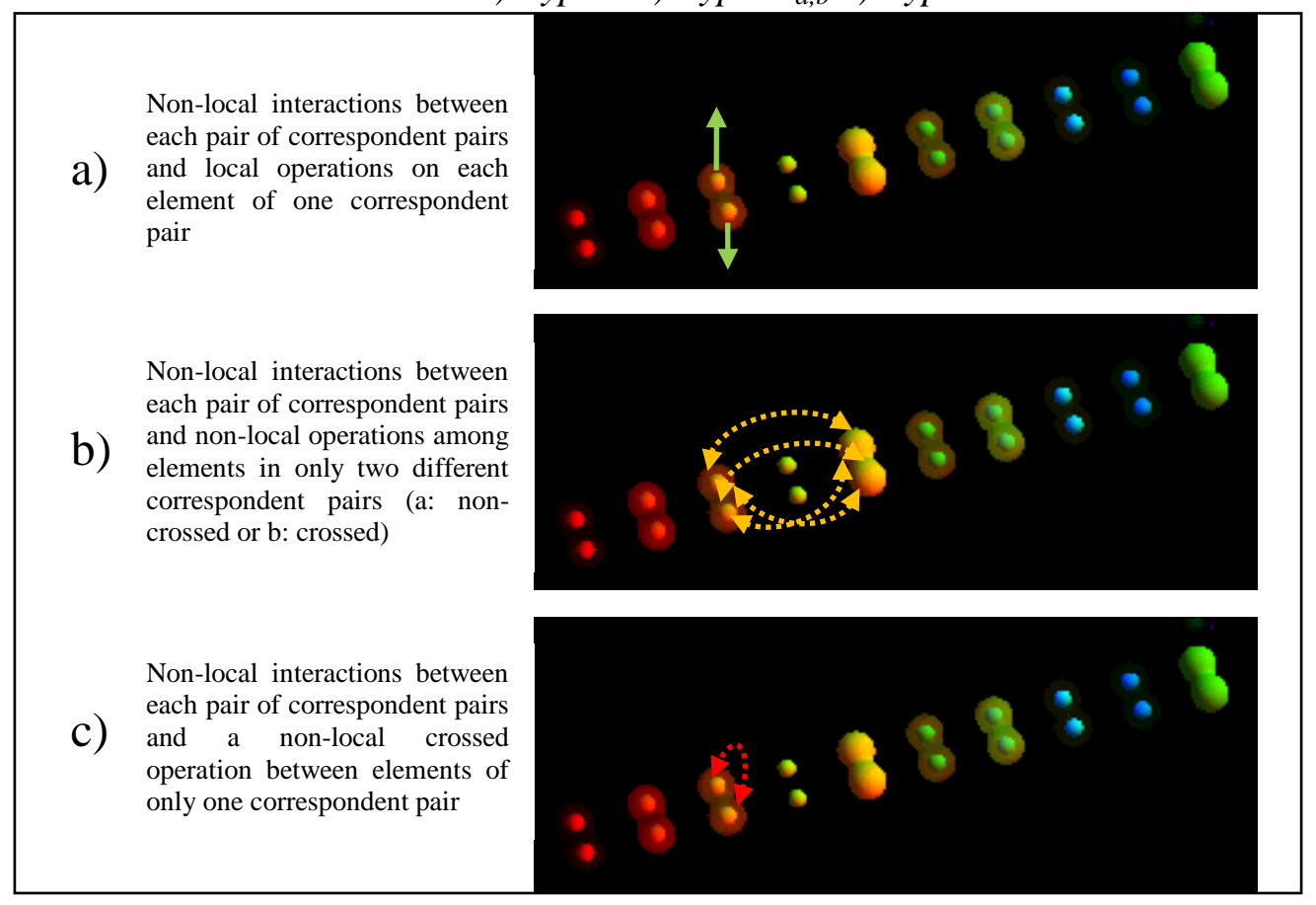

\section{Operations for Quantum Information and their Classification}

This section is devoted to depict some generic operations in quantum processing. In spite of the $S U(2)$ reduction, then each block is able to adopt this form. They are shown able to generate large entangled states departing from basic (separable) or similar quantum information states (as a re-scaling in the number of qubits). Still, the operations presented are not necessarily the most general, instead the most common operations in terms of similitude with those used as traditional gates in GBQC. 


\section{Generic Operations in Quantum Processing}

A general common operation (but not the most general actually) in the previous $S U(2)$ reduction context can be expressed as:

$$
\mathbb{H}_{m}^{c}(\delta, \epsilon)_{\mathcal{I}, \mathcal{I}^{\prime}} \equiv(-1)^{m}\left(\begin{array}{cc}
\epsilon & i^{c} \delta \\
(-i)^{c} \delta & -\epsilon
\end{array}\right)
$$

where $\varepsilon^{2}+\delta^{2}=1 ; m, c \in \mathbf{Z}$. In particular, we can identify there certain archetypical operations (Delgado, 2017b). By instance, Hadamard-like gate:

$$
H_{\mathcal{I}, \mathcal{I}^{\prime}}^{m, c, s_{\epsilon}}=\frac{(-1)^{m}}{\sqrt{2}}\left(\begin{array}{cc}
s_{\epsilon} & i^{c} \\
(-i)^{c} & -s_{\epsilon}
\end{array}\right)
$$

or the exchange gate, responsible to switch the states related in the block:

$$
E_{\mathcal{T}, \mathcal{I}^{\prime}}^{m, c}=(-1)^{m}\left(\begin{array}{cc}
0 & i^{c} \\
(-i)^{c} & 0
\end{array}\right)
$$

and the quasi-identity gate:

$$
e^{i \alpha \pi} \mathbb{I}_{\mathcal{I}, \mathcal{I}^{\prime}} \equiv I_{\mathcal{I}, \mathcal{I}^{\prime}}^{\alpha}
$$

where: $I$ is the identity matrix, $s_{\varepsilon}$ is a sign, $\alpha \in \mathbf{R}$. In all cases, $I, I$ ' in $\left[0,2^{2 d}\right]$ depict the rows (or columns) where the block is allocated. Despite (6) is a more general gate under the $S U(2)$ decomposition able to be adapted into other necessities. Delgado (2017b, 2017c) has presented several results about the use of these operations in order to get special extended entangled states as Greenberger-Horne-Zeilinger states $(G H Z)$ and $W$ states. Despite, they are very limited cases of large entangled states and they are easy because contain a reduced number of terms (despite of their importance). In the current approach, we are interested on the analysis of general processes to reach states with arbitrary degrees of entanglement. Normally, it has been probed that while size of the combined system becomes larger, the number of entangled states grows, thus a random state in $\mathcal{H}{ }^{2 d}$ becomes normally an entangled state, and particularly exhibiting a large value of entanglement (Enriquez et al. 2015).

\section{Reaching General States with 1, 2 and 4-Local Operations}

In this section, we describe some previous works developing the generation of maximal entangled states in the context of $S U(2)$ reduction operations, despite limited because they are special cases, they have set probes about how basic processing operations are able to generate large entangled states. The aim of 
this section is to prepare the reader for a stochastic process to reduce (or alternatively to construct) arbitrary large quantum states into other simpler. Operations being presented should be responsible to assemble or to disassemble each state considered in each step of the process. Each operation has a group of parameters to be selected, we are interested in the best selection able to reduce or to increase the entanglement as a roadmap.

\section{Processes Generating Entanglement under SU(2) Reduction Procedures}

2-local operations let to the entanglement inside of the correspondent pairs but no longer that it. Particularly, in this context, the absolute local operations (the 1-local), are a special case of 2-local ones. While, 4-local operations generate entanglement involving more than two pairs. Note no longer exchange of entanglement is directly allowed at a time in the nature because physical interactions are between pairs of physical particles. Because the $S U(2)$ reduction sets the interaction architecture in the system and there the GBS basis works as a universal basis still if the three types of interactions are combined, then is few recommendable as first instance to change the structure of correspondent pairs because it will destroy the stable basis on which the dynamics is being analysed.

Particularly, by using the Partial Trace criterion for pure states (Nielsen and Chuang 2000) to measure the entanglement degree between two basis elements of the entire system:

$$
\left|\phi_{\mathcal{I} \mathcal{J}}\right\rangle=\alpha_{\mathcal{I}}\left|\Psi_{\mathcal{I}}\right\rangle+\alpha_{\mathcal{J}}\left|\Psi_{\mathcal{J}}\right\rangle
$$

Concretely, we are interested mainly on the effect of one of the 4-local operations exchanging the indexed $I$ and $J$ (assuming they are different in a couple of digits in base 4). Then, under such criterion, the concurrence is:

$$
\mathcal{C}^{2}\left(\operatorname{Tr}^{S}\left(\rho_{\mathcal{I} \mathcal{J}}\right)\right)=2\left(1-\operatorname{Tr}^{S}\left(\rho_{\mathcal{I} \mathcal{J}}^{2}\right)\right)
$$

where $S$ is the set of scripts left after to take the partial trace (Ulhmann 2000). We assume they are $k, k$ '. If $m=\min \left(m_{1}, m_{2}\right)$, where $m_{1}, m_{2}$ are the dimensions of each part in the partial trace, then concurrence values ranges from 0 (for separable states) to $2(m-1) / m$ (maximal entangled states). For our case, $m=m_{1}=m_{2}=4$ because we are comparing the entanglement between one corresponding pair with another. By expressing conveniently the state coefficients as:

$$
\alpha_{\mathcal{I}}=\cos \theta / 2, \alpha_{\mathcal{J}}=e^{i \phi} \sin \theta / 2
$$


Then, we get by computing the density matrix and then the concurrence $C^{2}$ :

$$
\frac{3}{2}-\frac{1}{2} \sin ^{2} \theta\left(\cos ^{2} \phi^{\prime} \delta_{i_{k^{\prime}} j_{k^{\prime}}} \delta_{i_{k^{\prime \prime}} j_{k^{\prime \prime}}}+\sin ^{2} \phi^{\prime}\left(1-\delta_{i_{k^{\prime}} j_{k^{\prime}}} \delta_{i_{k^{\prime \prime}} j_{k^{\prime \prime}}}\right)\right)
$$

clearly denoting the possible maximum value $3 / 2$. In this case:

$$
\begin{array}{r}
\tilde{\sigma}_{i} \equiv e^{i \phi_{i}} \sigma_{i} \\
\phi^{\prime}=\phi+\phi_{i_{k}^{\prime}}-\phi_{j_{k}^{\prime}}
\end{array}
$$

Nevertheless, this is important only for the case $i=2$ and those cases involving it (there, $\phi_{i}=\pi / 2$ ). This result exhibits how entanglement is exchanged between two correspondent pairs under the 4-local operation generating the linear combination (10). This fact appoints on the generation of extended entanglement, which can be continued if interactions consider now other noncorrespondent pairs. This aspect will be fundamental in this work because it is the source of extended entanglement.

Several cases have been developed (Delgado 2017b, 2017c) for specific cases of interest: a) the reaching of $G H Z$ and $W$ states departing from separable states (Delgado 2017c), and b) the enlargement of those states departing from their shorter versions with two less qubits by the integration of an additional separable pair (Delgado 2017b). Nevertheless, those cases have a low complexity due to their reduced number of terms. In the $S U(2)$ reduction, despite of simplicity of the operations, still remains the complexity on the large number of blocks operating in the entire state. In addition, the number of different $S U(2)$ blocks (not including their $U(1)$ phase component) is reduced, the most of them are identical. This fact reflects the underlying complexity of entanglement (Gurvits 2003), particularly when the number of parts grows.

\section{Process to Generate Extended Entanglement in the SU(2) Reduction Scheme}

In this subsection, we address with the problem to generate (or to reduce, with the inverse operations, due to the reversibility of quantum mechanics), larger entanglement from separable states, as instance. By departing from the 2-separable basic state $\left|\Psi_{0}\right\rangle^{2 d}=\left|\Psi_{0}, . ., \Psi_{0}\right\rangle$ (the tensor product of $d$ Bell states $\left|\Psi_{0}\right\rangle$ ), a general procedure (but non unique) to generate the sixteen terms in a general state involving two correspondent pairs (four single qubits) could be stated in the following way. If $i, j, k$ is a permutation of $1,2,3$, then we apply first a 2-local operation with associated direction $i$ on the first correspondent pair $s$, then another on the second correspondent pair $s$ in the direction $j$. After, we apply a 4-local operation on both pairs in the direction $k$ (generating entanglement between the two pairs). Finally, we apply a 2-local operation on the first pair $s$ in the direction $j$. This procedure gives the sixteen possible terms and certain degree of entanglement: 


$$
\begin{aligned}
& \left|\Psi_{0}\right\rangle^{2 d} \quad \frac{H_{I}^{(i, s)}}{O_{I}^{(i,\{s\})}} \sum_{t \in\{0, i\}} \alpha_{t, 0}^{s}\left|\Psi_{0, \ldots, t, \ldots, 0, \ldots, 0}\right\rangle \frac{H_{I}^{\left(j, s^{\prime}\right)}}{O_{I}^{\left(j,\left\{s^{\prime}\right\}\right)}} \sum_{\substack{t \in\{0, i\} \\
t^{\prime} \in\{0, j\}}} \alpha_{t, 0}^{s} \alpha_{t^{\prime}, 0}^{s^{\prime}}\left|\Psi_{0, \ldots, t, \ldots, t^{\prime}, \ldots, 0}\right\rangle
\end{aligned}
$$

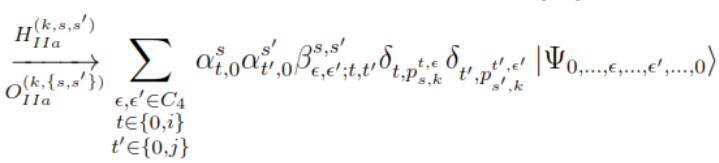

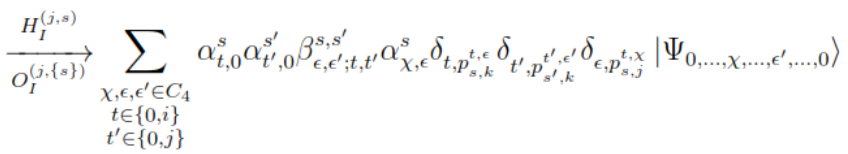

where $C_{4}=\{0,1,2,3\}$ and $p^{t, \varepsilon}$ is the extension of the inverse exchange rule (Delgado, 2017b), but specifying the rule $j$ as function of the direction of the interaction involved and the script $t \in\{0, i\}$ is a label specifying each possible inverse. It means, if $j$ is the characteristic direction of interaction: $p^{0, i}{ }_{s, j}=k=p^{0, k}{ }_{s, j}$ , $p^{0,0}{ }_{s, j}=0=p_{s, j}^{0, j}$ and $p_{s, j}^{i, i}=i=p_{s, j}^{i, k}, p_{s, j}^{i, 0}=j=p_{s, j}^{i, j}$. By increasing the number of additional intermediate operations (1-local, 2-local or 4-local), it is possible to extend the coverage on the elements of $S U(2)$ for each evolution operator in each subspace. Alternatively, other possible procedures to generate larger entangled states could give more extended entanglement as those cases presented in Delgado (2017b) to generate the $G H Z$ and $W$ states with genuine entanglement. In any case, the way (clearly the ways) to reach some state by construction departing from a very simple state as $\left|\Psi_{0}\right\rangle^{2 d}$ is still open. The last fact suggests how to address a quantum information processing to generate some general states from simpler ones or otherwise, reducing an arbitrary state into another with low entanglement (1 or 2-separable in the current scheme).

But the process will not become sufficiently obvious when the complexity grows together with the size of the system. For an arbitrary state is not always clear how it can be reduced into a separable state, despite from the analysis becomes true it requires both, 1 or 2-local operations, but necessarily, 4-local operations to decompose the possible entangled structure in an arbitrary state. In addition, the advancement on the process is difficult to be continuously monitored because the lack of a universal entanglement measure. We will try to compensate that lack in the next section with the Rényi-Ingarden-Urbanik entropy.

\section{Analysis to Reduce the RIU Entropy through the $S U(2)$ Reduction with 1, 2 and 4-Local Operations}

In this section we finally analyze how a series of operations based on $S U(2)$ reduction are able to transform arbitrary states into simple ones. We use the Rényi-Ingarden-Urbanik entropy to depict the process in terms of the global entropy of the state. 


\section{Rényi-Ingarden-Urbanik Entropy}

A measure of entanglement for arbitrary number of qubits ( $q$-dits in fact) is the RIU entropy (Ingarden and Urbanik 1962) defined as:

$$
S_{p}(|\psi\rangle)=\frac{1}{1-p} \log \left(\sum_{i=1}^{n}\left|\alpha_{i}\right|^{2 p}\right), \quad \text { with : } \quad|\psi\rangle=\sum_{i=1}^{n} \alpha_{i}\left|\phi_{i}\right\rangle
$$

We will consider the most common case $p=1$ as a measure of the entanglement of larger states as those presented in the context of the $S U(2)$ reduction process:

$$
S_{1}(|\psi\rangle)=-\sum_{i=1}^{n}\left|\alpha_{i}\right|^{2} \log \left|\alpha_{i}\right|^{2}, \quad \text { with : } \quad|\psi\rangle=\sum_{i=1}^{n} \alpha_{i}\left|\phi_{i}\right\rangle
$$

The Shannon entropy; clearly these quantities depend on the representation of the states and the basis being used in it, despite they can be minimized through optimal local operations into the minimal RIU entropy (Enríquez, Puchala and Życzkowski 2015). RIU entropy with $p=1$ for $2 d$ qubits exhibits values ranging from 0 (for separable states) to $\log \left(2^{2 d}\right)$ (for certain maximal entangled states).

Despite this entanglement measure could be useful to provide a dial to sense the entanglement degree, it is not clear how it relates with the inner structures of entanglement. Thus, it will work to have a general and a side-toside quantification for the entanglement. We are particularly interested on the big picture of the transit from an arbitrary state (commonly entangled) into another finally separable, using only 1,2, 4-local operations as they could be provided by the $S U(2)$ decomposition scheme.

\section{Stochastic Process Reducing RIU Entropy with SU(2) Reduction Operations}

Following the ideas previously presented, it has been automated a process to reduce the entropy of arbitrary states. It begins by generating a random state in the Haar's measure in $2^{2 d-1}$ dimensions (Diestel and Spalsbury 2014). Then, the state is first processed with 1-local operations to reduce optimally its RIU entropy. After, a stochastic process begins by selecting a 2-local or a 4-local operation, together with a characteristic direction for it. In any case, an optimization problem is solved in order to select the best parameters of such operation in order to minimize its RIU entropy with it. Then, process is always followed with the application of an optimal 1-local operation to reduce again the entropy ( 2 and 4-local operations includes by extension the 1-local operations in the $S U(2)$ reduction scheme). Clearly, this step process only is able to reduce it in a limited strength because the residuary entanglement involving more complex structures (Gurvits 2003). Thus, the process continues 
alternating those 2 or 4-local operations followed with a 1-local operation optimally to reduce the RIU entropy (Figure 2).

As was stated, the selection of the local order of operations, the associated direction together with the pairs involved, are completely stochastic in each step. Last process is hard to simulate because the large number of parameters associated to be optimized on each step. Each one lasts out around of two minutes to be numerically processed (for utmost six qubits on an Intel Xeon $3.40 \mathrm{GHz}$ ). The process was followed by certain number of operations tracking its RIU entropy. For the six-qubits, we are working with basis of size 64 . Figure 3 depicts such basis elements and their relations under the $S U(2)$ reduction combining 2 and 4-local operations, reflecting the complexity in the interactions for this system (only six qubits!). Each script exhibits their composition in terms of Bell states if it is expressed in base 4 .

Figure 2. Stochastic Process to Reduce the RIU Entropy

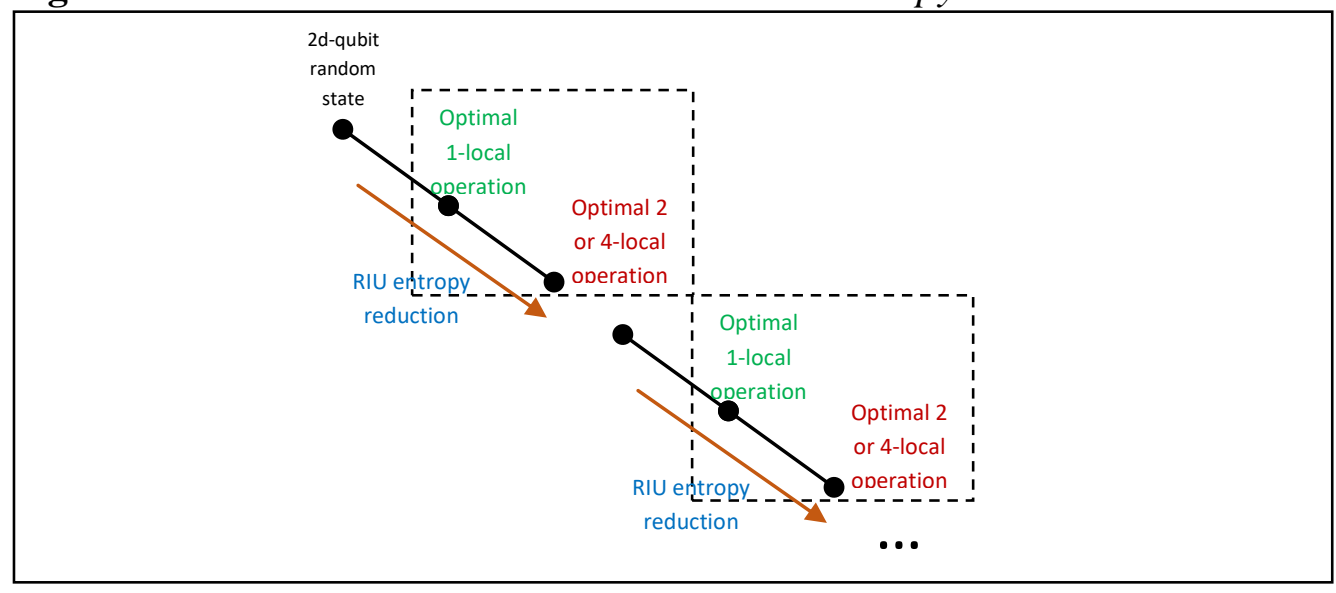

Blue arrows match the overall relations settled by any 2-local operation in all possible associated directions and parts (between those basis elements differing in only one digit in the base 4 representation of scripts). Green arrows relate the relations settled by any 4-local operation considering all possible directions and parts (differing in two digits in the scripts). 
Figure 3. Basis Elements for the $2 d=6$ Case for the $S U(2)$ Reduction and Relations for a) 2-Local Operations (blue), and b) 4-Local Operations (green)

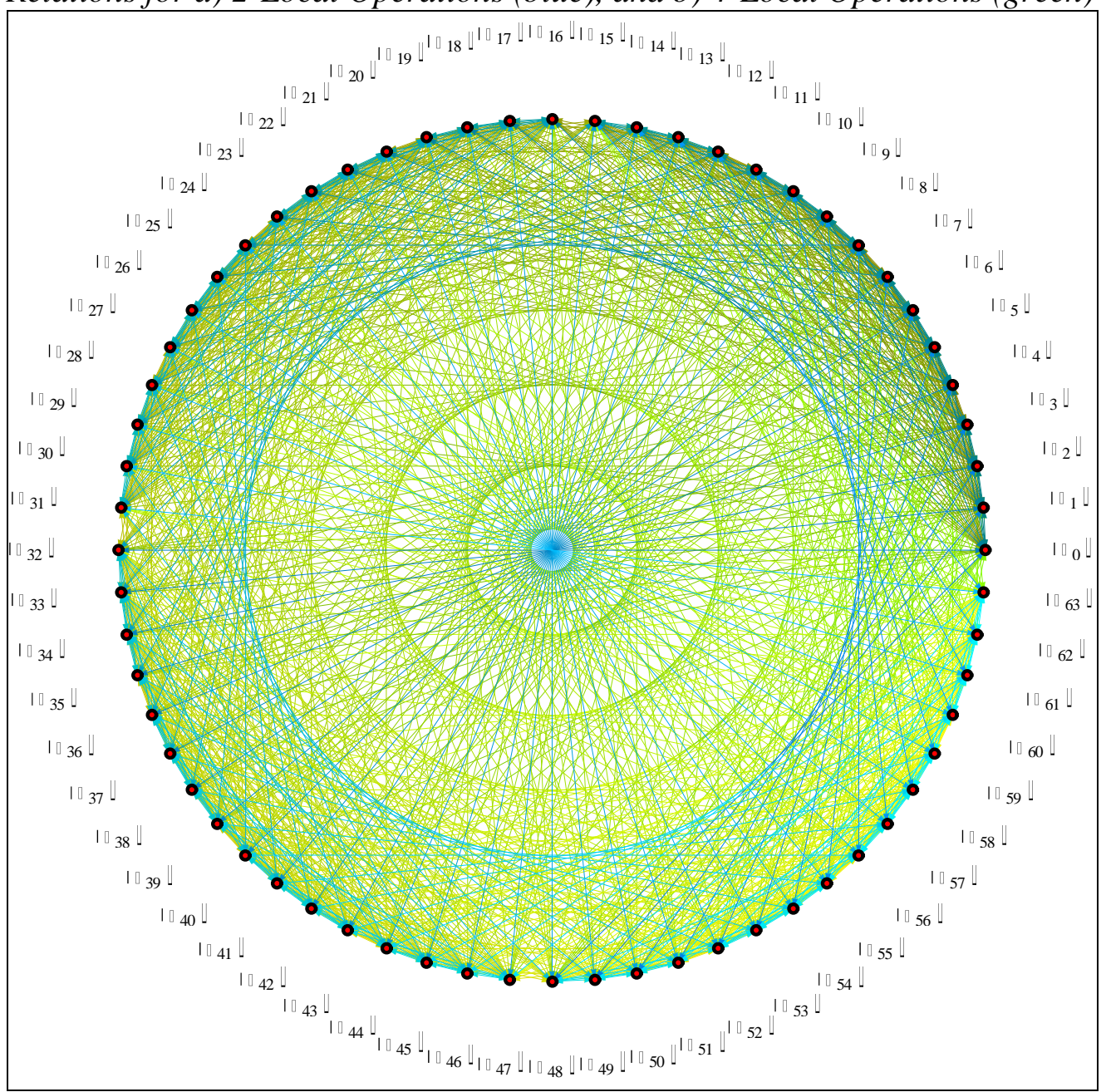

Figure 4 shows ten simulation experiments with a six-qubits system processed with the last procedure with 300 steps of such optimal operations each one. Note how the RIU entropy reduces rapidly in the first steps. After, the process slows until a casual operation finally reaches a deep reduction of the entropy (resembling a thermodynamic change of state) to then remain almost static until a new remarked reduction. Some of those experiments reach a zero entropy indicating the achievement of a separable state. Clearly, the inverse process can be attained reversing the quantum operations. In any case, we note it is possible to disassemble (or assemble) arbitrary states reaching (or departing from) single separable states. 
Figure 4. Ten Random States Evolving through a Series of 300 Steps of the Stochastic Process Combining 2-Local and 4-Local Optimal Operations to Decrease their RIU Entropy

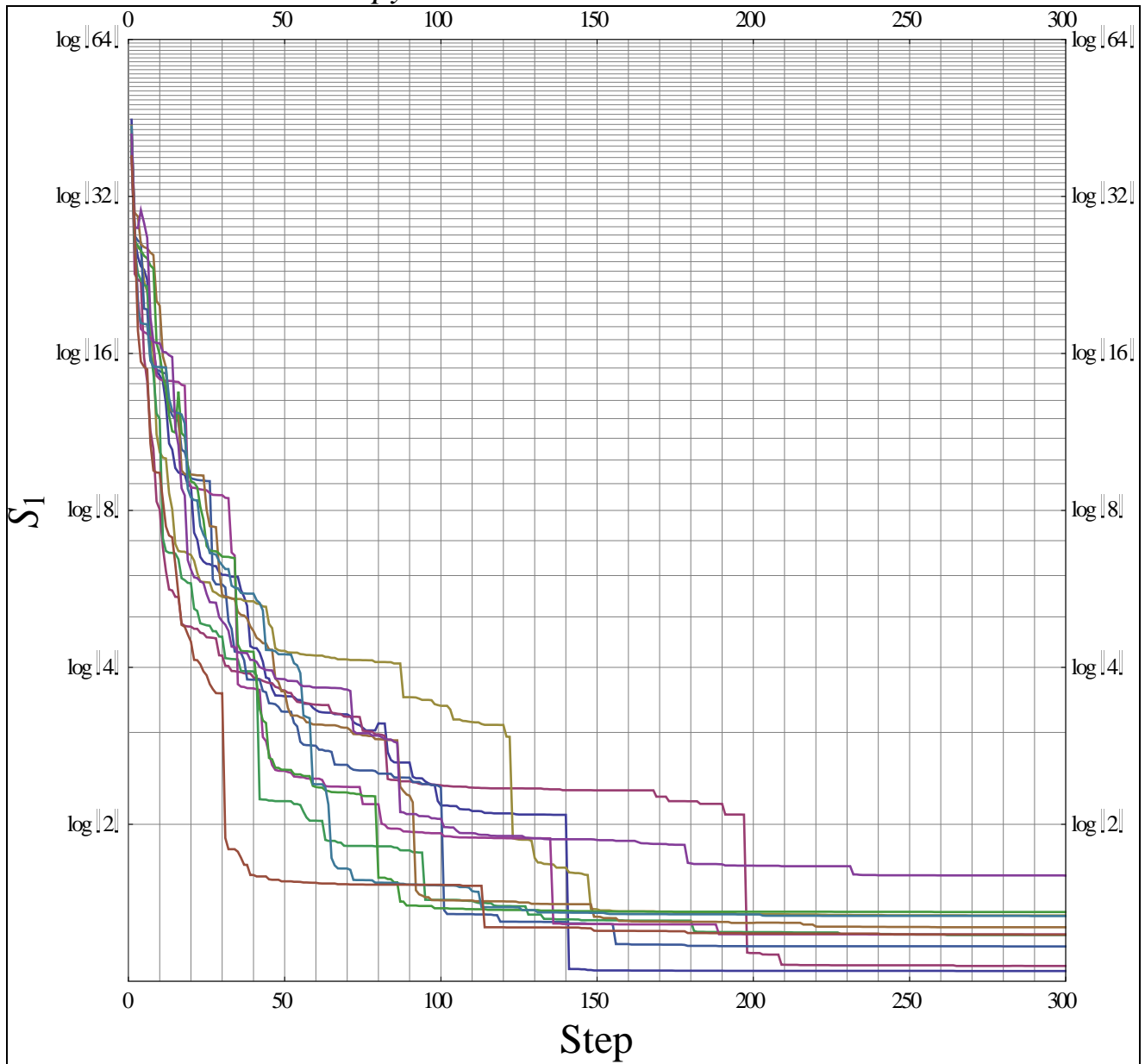

The process is not direct, to see that it is important understand how the use of information states (more than physical states) works. The evolution by blocks works in parallel on large number of states, instead independently. It means, for the 2-local interactions, there are only two different blocks at the time. In fact, all blocks are of two types, both exchanging one digit in the script of states while other remain unchanged: a) those exchanging 0 and the digit $j$ (the associated direction to the interaction; in the crossed interaction the Type III, both coordinates involved defines that direction as a permutation of $1,2,3$ ), and $\mathrm{b}$ ) those exchanging $i, j$, the remaining scripts. For the Type $\mathrm{II}_{\mathrm{a}, \mathrm{b}}$ interactions, the situation is similar, but there are eight different blocks related with the exchanges (Delgado 2017a). Despite the complexity, the RIU entropy works as an indicator in the process. The processes depicted in the Figure 4 deeply suggest a certain order in the decreasing of the RIU entropy under this stochastic roadmap. Still more numerical data are precise to reach statistical meaningful in such quantification. Other findings in the last plot are suggested in the deceleration of the RIU entropy reduction around of $\log (4)$. Further evolution departing from this point is erratic in terms of optimality in the reduction of the 
residual entropy. Six-qubits case is only the beginning. Note other works have attempted similar approaches in the comprehension of the structure of large entangled states by identifying inner structures of partial entanglement (Guhne and Toth 2009, Kraus 2010, Zangi et al. 2018).

\section{Conclusions}

The comprehension of entanglement, constitution and measurement are aspects closely related. In addition, limitations associated with the formation of entangled states for large systems suppose a high quest being able to reach or manipulate arbitrary quantum states, because it is closely related with the system and the associated Hamiltonian. Quantum information theory is widely based on this fact, thus the importance to learn about control and processing in many body systems.

In the current work, the use of $S U(2)$ reduction as analysis element to identify and to classify the entangling operations based on the concrete possibilities for the Hamiltonian has becoming valuable to set an automated road to analyze the possibility of processing. In addition, it has been useful to set a common grammar for a group of possible related interactions. Despite the complexity becomes exacerbated by the lack of a general measurement and quantification of entanglement, the use of RIU entropy is still useful to appoint the beginning and the goal of the entire processing, nevertheless it does not give a clear and complete compass in the middle of the road, particularly in terms of optimality. A future work opportunity in this context is a customary factorization for a direct $S U\left(2^{2 d}\right)$ matrix resembling the processing transforming a state into another, which could be uniquely factorized in terms of a matrix basis being formed with the $S U(2)$ blocks present in the reduction formalism.

In the last outcome (Figure 4), it is barely clear there is a notable reduction in the RIU entropy in the first steps of the process by the use of combined 2 and 4-local operations. The decided reduction stops approximately in $\log (4)$ to then going on a slower reduction with only casual and sudden entropy fallings. This region appears as the most unclear and complex processing in terms of the RIU entropy reduction with the available operations. Despite, the processing seems going to zero-RIU entropy as a function of time (or the number of steps needed). Still more research and improvements in the computer simulations of this proposed process appears as necessary to get some statistical insights about its qualities, which could be associated in general as the processing of quantum states for large systems. Statistical analysis is suggested in terms of other approaches as invariants (Eltschka et al. 2011), customized factorization (Luo et al. 2014), rank of coefficient matrix ( $\mathrm{Li}$ and $\mathrm{Li}$ 2012), generalized singular value decomposition (De Lathauwer et al. 2000), etc. In any case, still there are many facts to explore in the understanding of entanglement and its quantification, together with the general dominion of quantum processing, in particular when the size of systems grows. 


\section{Acknowledgments}

Support for research activity is acknowledged to CONACYT. Economic support to disseminate the current results through NOVUS grants initiative is acknowledged to Tecnológico de Monterrey.

\section{References}

De Lathauwer L, De Moor B, Vandewalle J (2000) A Multilinear Singular Value Decomposition, SIAM J. Matrix Anal. Appl. 21(4): 1253-1278. DOI = https://epubs. siam.org/doi/10.1137/S0895479896305696.

Delgado F (2015) Algebraic and Group Structure for Bipartite Anisotropic Ising Model on a Non-Local Basis. International Journal of Quantum Information 13(7). DOI = https://doi.org/10.1142.

Delgado F (2017a) Modelling the Dynamics of Multipartite Quantum Systems Created Departing from Two-Level Systems using General Local and Non-Local Interactions. Journal of Physics: Conference Series 936(Conference 1-Feb). DOI = https://doi.org/ 10.1088/1742-6596/936/1/012070.

Delgado F (2017b) Generalized Bell States Map Physical Systems' Quantum Evolution into a Grammar for Quantum Information Processing. Journal of Physics: Conference Series 936(1). DOI = https://doi.org/10.1088/1742-6596/936/1/012083.

Delgado F (2017c) Generation of Large Quantum Entangled States in 2d-Partite Systems using SU(2) Decomposition. In Quantum Information and Measurement. OSA Technical Digest.

Di Vincenzo DP (1997) Mesoscopic Electron Transport. In NATO Advanced Study Institute, Series E: Applied Sciences 345, 657. Edited by Lydia L Sohn, Leo P Kuwenhoven, Gerd Schoen. DOI = http://doi.acm.org/10.1145/10.1007/978-94-0158839-3.

Diestel J, Spalsbury A (2014) The Joys of Haar Measure. Graduate Studies in Mathematics 150, Providence, RI: American Mathematical Society.

Dzyaloshinskii I (1958) A Thermodynamic Theory of "Weak" Ferromagnetism of Antiferromagnetics. Journal of Physics and Chemistry of Solids 4(4): 241-255. DOI $=$ https://doi.org/10.1016/0022-3697(58)90076-3.

Eltschka C, Bastin T, Osterloh A, Siewert J (2011) Multipartite-Entanglement Monotones and Polynomial Invariants. Phys. Rev. A 85(2). DOI = https://doi.org/10.1103/Phys RevA.85.022301.

Enríquez M, Puchała Z, Życzkowski K (2015) Minimal Rényi-Ingarden-Urbanik Entropy of Multipartite Quantum States. Entropy 17(7). DOI = https://doi.org/10.3390/e170 75063.

Grossman M, Katz R (1972) Non-Newtonian Calculus. Pigeon Cove, MA: Lee Press.

Guhne O, Toth G (2009) Entanglement Detection. Phys. Rep. 474(1-6): 1-75. DOI = https://doi.org/10.1016/j.physrep.2009.02.004.

Gurvits L (2003) Classical Deterministic Complexity of Edmonds' Problem and Quantum Entanglement. In Proceedings of the $35^{\text {th }}$ ACM Symposium on Theory of Computing. ACM Press, New York (2003). DOI = https://doi.org/10.1142/10.1016/j.jcss.2004. 06.003 .

Ingarden RS, Urbanik K (1962) Quantum Informational Thermodynamics. Acta Phys. Pol. 21, 281-304. 
Kraus B (2010) Local Unitary Equivalence and Entanglement of Multipartite Pure States. Phys. Rev. A 82(May). DOI = https://doi.org/10.1103/PhysRev A.82.032121.

Li X, Li D (2012) Classification of General n-Qubit States under Stochastic Local Operations and Classical Communication in terms of the Rank of Coefficient Matrix, Phys. Rev. Lett. 108(May) 180502.

Luo M, Chen X, Yang Y, Wang X (2014) Geometry of Quantum Computation with Qudits. Nature Scientific Reports 4(Feb). DOI = https://doi.org/10.1038/srep04044.

Moriya T (1960) Anisotropic Superexchange Interaction and Weak Ferromagnetism. Physical Review 120(Oct) 91. DOI = https://doi.org/10.1103/ PhysRev.120.91.

Nielsen M, Chuang I (2000) Quantum Computation and Quantum Information. Cambridge University Press.

Sych D, Leuchs G (2009) A Complete Basis of Generalized Bell States. New Journal of Physics 11(Jan). DOI = http://www.njp.org/doi:10.1088/1367-2630/11/1/013006.

Uhlmann A (2000) Fidelity and Concurrence of Conjugated States. Phys. Rev. A 62(3). DOI = https://doi.org/10.1103/PhysRevA.62.032307.

Zangi S, Li J, Qiao C (2018) Quantum State Concentration and Classification of Multipartite Entanglement. Phys. Rev. A 97(1). 012301. 


\title{
The Effects of Computational Thinking Professional Development on STEM Teachers' Perceptions and Pedagogical Practices
}

\author{
By Sarah Haines ${ }^{*}$, Michael Krach ${ }^{\dagger}$, Arkhadi Pustaka ${ }^{*}$, \\ Qing $\mathrm{Li}^{\star} \&$ Laila Richman ${ }^{* *}$
}

The authors investigated the impact of exposure to computational thinking activities and professional development on inservice teachers' perceptions and teaching practices in elementary and secondary school education. The participants of this 2017/2018 research study were STEM teachers from the Baltimore County (Maryland) Public Schools in the United States of America. The major focus of this study was on the impact of professional development activities on the inclusion of computational thinking activities in the k-12 mathematics and science classrooms. The analysis of the data indicated that most of the participating teachers felt that the professional development activities were valuable and made a positive impact on the quality and quantity of computational thinking activities they implemented in their classrooms. Most of these teachers stated that they would implement computational thinking activities on a weekly or monthly basis. Based on the analysis of the data and the results of this study, a list of future research questions is included.

Keywords: Computational Thinking, Mathematics Education, Science Education, STEM, Professional Development.

\section{Introduction}

In order for CT integration into k-12 mathematics and science classrooms to be successful, teachers at both the preservice and inservice levels must be provided with the appropriate coursework and professional development (PD) to allow them to master the pedagogical skills involved. Barr and Stephenson (2011) recommend the inclusion of a CT class across disciplines in teacher preparation programs. They further recommend providing inservice teachers with PD opportunities in the use of CT in k-12 classrooms. Research shows that education majors' views toward CT are more favorable if they are exposed to CT during their undergraduate careers. Additionally, they are more likely to use CT in their own classrooms, and see the applications to k-12 education more readily than those not exposed to $\mathrm{CT}$ in their teacher preparation programs (Yadav et al. 2011, Yadav et al. 2014).

Wozney et al. (2006) state that one of the greatest predictors of the extent of teachers' technology use and integration of CT in the classroom is their

\footnotetext{
*Professor, Towson University, USA.

${ }^{\dagger}$ Professor, Towson University, USA.

†Towson University, USA.

'Professor, Towson University, USA.

**Associate Dean, College of Education, Towson University, USA.
} 
belief that they can reach their instructional goals using this approach. This finding suggests that providing PD that assists teachers in gaining successful personal experiences in CT will help in this endeavor. We designed our PD based on best practices in the literature:

- Giving teachers time to use technology and to become comfortable with the CT approach through the online modules (Somekh 2008).

- Focusing new uses on teachers' immediate needs (Kanaya et al. 2005, Zhao and Cziko 2001).

- Starting with small successful experiences, through the online modules and in person PD (Ottenbreit-Leftwich 2007).

- Establishing a professional learning community (Putnam and Borko 2000).

- Situating professional development programs within the context of teachers' ongoing work (Cole et al. 2002, Snoeyink and Ertmer 2001/ 2002).

The focus of this study is on professional development in computational thinking for inservice teachers of science and mathematics. Our primary focus is to answer the following research question:

What is the impact of professional development activities on the inclusion of CT activities in k-12 mathematics and science classrooms?

\section{Literature Review}

According to Wing's seminal manuscript on computational thinking (2006), "computational thinking is a fundamental skill for everyone, not just for computer scientists. Computational thinking involves solving problems, designing systems, and understanding human behavior, by drawing on the concepts fundamental to computer science. Computational thinking includes a range of mental tools that reflect the breadth of the field of computer science" (p. 33). Over the past few decades, advances in computer technology have revolutionized the STEM fields. The application of computer technology to virtually every field of study has changed the way STEM research is done today. Wing observes that the application of computer technology in the STEM fields facilitates the spread of (and the need for) computational thinking (CT) skills in the STEM disciplines. Barr et al. (2011) expand upon this foundational definition of CT, providing educators with an operational definition of CT that can be used to build on skills across grade levels and content areas. They define CT as a problem-solving process involving several steps: formulating a problem in such a way that the use of computer technology can help us solve it; analyzing data and representing that data through models or simulations, identifying possible solutions to the problem posed, and generalizing this process to a wide variety of situations and issues. 
Following the premise of teaching STEM content as the STEM disciplines are practiced in real-world settings, it then makes sense that STEM teaching practices must also evolve. In the United States, many states have adopted the Next Generation Science Standards (NGSS, National Research Council 2013). The NGSS are k-12 science content standards. These standards set the expectations for what students should know and be able to do. The standards are designed to give local educators the flexibility to create classroom learning experiences that will stimulate student interest in science and prepare them for college, careers, and citizenship. The NGSS include the science and engineering practice of "Using Mathematics and Computational Thinking". According to the NGSS, the integration of quality mathematical and computational thinking can (and should) enhance science instruction. Scientists and engineers use computational thinking processes as tools for representing relationships between and among variables. Computational thinking can help scientists and engineers accomplish tasks such as simulating phenomena, analyzing data sets, and studying a multitude of quantitative relationships appropriate to the discipline.

The mathematics counterpart to the NGSS in the United States is the Common Core State Standards-Mathematics (CCSS-M). These standards state what each student in grades k-12 should know and be able to do in mathematics. Within the CCSS-M, there are no direct references with respect to integrating CT into the current framework (content clusters) for students in grades k-12 (CCSSI 2010). However, based on an understanding of the CCSS-M and the authors' working definition of CT (see Appendix 4), mastering concepts and skills in the following areas can certainly be considered major contributors to the development of a student's CT skills: generalize and analyze patterns, reason specifically and abstractly (especially with ratios and proportions), represent and interpret data, solve real-world problems. Since the task of integrating CT into existing curricula should be one of the many current teacher responsibilities, the teacher must be extremely knowledgeable with respect to mathematics content as well as how to best integrate CT into the curriculum. Websites, such as http://ctmath.ca/ (Computational Thinking in Mathematics Education), which provide effective classroom-tested CT activities, would be extremely beneficial for teachers in grades k-12 to utilize.

Besides the inclusion of CT in the NGSS science and engineering practices, CT is linked to science in other important ways. For example, Barr and Stephenson (2011) align core computational thinking concepts and capabilities with scientific experimentation. For example, the CT concept of abstraction is aligned with the science skill of building models, and the CT concept of algorithms is aligned with the scientific skill of creating and following sound experimental procedures. Similarly, the authors link data collection with collecting data in a scientific experiment; data analysis by analyzing the data collected during experimentation; automation by using probeware in a scientific setting; parallelization by running two scientific experiments with different parameters at the same time; and simulation by simulating solar system movement.

Sengupta et al. (2013) connect abstractions involved in computational thinking with the thought and skill processes involved in scientific inquiry. The 
authors draw similarities between algorithm design and the scientific process of developing mechanistic reasoning and explanations, or constructing models. In the same manner, test driven software development is seen as a parallel process to the scientific processes of hypothesis testing or validating/testing models.

In k-12 mathematics, many of the definitional components of CT can be directly related/linked to concept and skill areas in the CCSS-M. For example, algorithmic thinking can be linked to the study and analysis of computational algorithms and to the introduction and use of a problem solving protocol, such as Polya's Problem Solving Model (Polya 1957), logical thinking and rigorous argument and proof can be linked to the study, analysis, and construction of both informal and formal proofs, and the collection and analysis of relevant data, and abstraction can be linked to the introduction and study of pattern recognition, creation, and analysis.

Baytak and Land (2011) found that the use of Scratch (scratch.mit.edu) increased computational skills in $5^{\text {th }}$ grade students. Lambert and Guiffre (2009) found that the use of Scratch improved elementary school students' attitudes about computing and computer science.

The eight CCSS-M Standards of Mathematical Practice (SMP) can also be directly linked to CT, especially with respect to solving both traditional and non-traditional problems (see Table 1).

Table 1. Standards of Mathematical Practice

\begin{tabular}{|l|l|}
\hline SMP\#1 & Make sense of problems and persevere in solving them \\
\hline SMP\#2 & Reason abstractly and quantitatively \\
\hline SMP\#3 & $\begin{array}{l}\text { Construct viable arguments and critique the reasoning of } \\
\text { others }\end{array}$ \\
\hline SMP\#4 & Model with mathematics \\
\hline SMP\#5 & Use appropriate tools strategically \\
\hline SMP\#6 & Attend to precision \\
\hline SMP\#7 & Look for and make us of structure \\
\hline SMP\#8 & Look for and express regularity in repeated reasoning \\
\hline
\end{tabular}

Each of these SMPs can be linked to a current definition of CT, of which there are many. If one accepts the authors' working definition of CT, then these eight "habits of mind" can be critical to the understanding of the proposed problem and instrumental to the creation of a solution to the problem.

The use of open-ended problems or scenarios encourages complete and meaningful responses, which requires the understanding of specific mathematical concepts and skills, the use of a problem solving protocol, constructing generalizations and proofs, modeling, and utilizing algorithms, all of which are components of CT.

The authors have established the ways in which CT is connected to the mathematics and science disciplines. Given that this connection exists, are there benefits associated with integrating CT into mathematics and science teaching? The answer to this question is multi-faceted. The nature of CT as described above places this way of thinking and problem-solving into the higher levels of Bloom's taxonomy (Bloom et al. 1956, Gal-Ezer and Stephenson 
2010). Besides encouraging higher level thinking in students, there are several practical reasons for integrating CT into science and mathematics classrooms. Weintrop et al. (2016) found that including CT in science classrooms builds on the interconnected relationship between $\mathrm{CT}$ and science. It also addresses practical concerns of reaching students - students must enroll in a certain number of science classes to graduate, but computer science is most often an elective course. If students are exposed to CT in their science courses, there is no need to worry about lack of computer science course offerings or students not electing to take the course. Moreover, currently, many schools do not have certified teachers in the area of computer science, but most do have teachers certified in the science and mathematics disciplines. These teachers should be more comfortable with the content, since CT aspects are embedded into their content areas. Last, integrating CT into science content courses means that the teaching methodology will more closely mirror the methods used by scientists in the field ("doing science the way it is done in the real world"). Jona et al. (2014) support these arguments. The authors found that CT interest and appeal is higher if the CT content is embedded into STEM courses instead of a standalone computer science course. Further, the integration of CT in science and mathematics classrooms has been shown to enhance the learning of STEM content (National Research Council 2011, Repenning et al. 2010, Sengupta et al. 2013, Wilensky and Reisman, 2006).

The integration of CT can be an effective instructional approach for learning science and mathematical concepts that students traditionally find difficult (Sherin 2001, Hambrusch et al. 2009, Blikstein and Wilensky 2009, di Sessa 2000, Kynigos 2007). Research suggests that programming in context (i.e., within an area of STEM discipline) makes it easier to learn. Hambrusch et al. (2009) found that using CT in college-level science classes with noncomputer science majors resulted in higher learning gains and increased student engagement. Similar results have been reported for k-12 students. For example, Calao et al. (2015) found that in a sixth-grade mathematics class with CT embedded activities (for example, algorithmic thinking), student comprehension increased compared to a control group.

\section{Methodology}

\section{Participants}

At the beginning of the program, the participants consisted of 28 teachers. For various reasons, there was attrition and the final number of participants for this study consisted of 17 teachers. The participants taught in grades Kindergarten $(\mathrm{n}=1), 1^{\text {st }}(\mathrm{n}=1), 2^{\text {nd }}(\mathrm{n}=2), 4^{\text {th }}(\mathrm{n}=1), 5^{\text {th }}(\mathrm{n}=1), 6^{\text {th }}(\mathrm{n}=1)$, $7^{\text {th }}(\mathrm{n}=1), 9^{\text {th }}(\mathrm{n}=1)$; and several taught students in multiple grades: Kindergarten $-5^{\text {th }}(\mathrm{n}=2), 9^{\text {th }}-12^{\text {th }}(\mathrm{n}=4)$, and $10^{\text {th }}-12^{\text {th }}(\mathrm{n}=2)$. The participants taught mathematics $(n=3)$, science $(n=4)$, both mathematics and science $(n=5)$, non-STEM related courses $(n=4)$, and special education $(n=1)$. 


\section{Description of Professional Development}

The PD sessions focused on preparing teachers to integrate computational thinking and computer science activities, aligned with state standards including NGSS \& Maryland College and Career Ready Standards (MCCRS, i.e. Common Core State Standards), into their daily lesson plans. Participants were provided with activities that supported their ability to serve as teacher leaders related to integrating computational thinking and computer science in their schools and district. The professional development sessions consisted of four main parts: 1) Introductory Session, 2) Online Modules, 3) Summer Institute, and 4) Colloquium. The three-hour Introductory Session was conducted faceto-face in early Spring 2017. Then, participants completed three online modules during Spring - Summer 2017 to learn the basics of computational thinking and coding using Star Logo Nova. All of the online modules were offered using EdX, a massive open online course provider. Next, during the Summer Institute 2017, participants attended a series of workshops to work collaboratively on the fourth module in order to apply computational thinking skills learned from the online modules and then to create lesson plans that incorporated CT in their classrooms. In addition, the participants completed a fifth online module focused on enhancing teachers' understanding of the content and pedagogical knowledge related to CT integration. Scratch, another software application, was introduced and used to support diverse learner needs. Finally, the participants were expected to implement their lesson plans and to report on their experiences during the 2018 Spring Colloquium.

\section{Data Analysis}

\section{Discussion Board Posts}

Participants were given access to an edX (for a detailed description see edge.edx.org) course site to access and provide reflections on the modules they were completing. For a sample list of discussion prompts, see Appendix 1. Science and mathematics content specialists, who were also completing the modules at the same time as the participants, responded daily to the discussion board posts with additional probing comments and questions that were intended to elicit further pedagogical ideas from the participants.

The content specialists used a modified version of Hord et al.'s stages of concern for adult learners (1987) to categorize and analyze the discussion posts. Hord et al. identified seven categories in their original study. However, due to the nature of the current study, the authors dropped one category and redefined the remaining six, and included an "Other" category, to better reflect the issues that were being reported in the Discussion Board Posts by the participating teachers (see Appendix 2 for a description of each category). To control for inter-rater differences in reliability, discussion posts were analyzed concurrently by the content specialists. The seven categories are described below. 
- Awareness: teachers have an awareness of CT, but are not yet fully comfortable with it.

- Informational: teachers are comfortable with CT and are more interested in becoming involved with it.

- Management: teachers are fully committed to CT, but their attention is focused on the processes and tasks involved in implementing it.

- Consequence: teachers focus on the impact that CT has on their students' achievement.

- Collaboration: teachers have a need to collaborate and share ideas concerning CT.

- Refocusing: teachers explore current and future ways to incorporate CT into their lesson plans.

- Other: response does not fit into any of the above categories.

\section{$\underline{\text { Professional Development Surveys }}$}

At the conclusion of the summer PD sessions, a seven question Likert-type instrument (referred to as Survey \#1) was administered to the participating teachers. Responses were aggregated and analyzed for emerging trends. Two additional open-ended questions were also included and analyzed with respect to main ideas and experiences participants had during the CT professional development sessions (see Appendix 2).

Participants were surveyed again at the conclusion of the project during two focus group interview sessions; participants attended one of these sessions (referred to as Survey \#2). The interviews were approximately 60-90 minutes long. The groups were semi-structured in that there was a list of questions that were intended to be covered, but the conversation was allowed and encouraged to take its course to include other areas of interest. See Appendix 3 for the focus group interview protocol.

\section{$\underline{\text { Participant Lesson Plans }}$}

Participating teachers were required to write and submit a lesson plan appropriate for the grade level and students that they were currently teaching and were also required to integrate at least one appropriate CT activity into the lesson plan. A modified rubric based on the ISTE Computational Thinking operational definition was utilized to score each of the fourteen lesson plans (ISTE 2011). The iterative development process started with a discussion about various definitions of computational thinking; for example, ISTE's operational definition of computational thinking, from which an initial rubric was created. Using the created rubric, two of the authors independently evaluated five representative lesson plans, which were written and submitted by the participating teachers, and then met in a series of discussions to compare the results of their evaluation. A careful analysis of the inconsistencies and ambiguous aspects of the instrument (with respect to the evaluation process) led to a revision of the initial rubric. The authors then independently evaluated another three 
representative lesson plans using the revised rubric, from which a further refined rubric was created. The final rubric was developed after several rounds of testing in which each category was scrutinized. All five authors met as a team to discuss each category during this "fine tuning" process until reaching a consensus.

Categories used to score the lesson plans included Decomposition, Pattern Recognition, Abstraction, Algorithmic Thinking, Optimization, and Generalization (see Appendix 4 for the detailed scoring rubric). Sample lesson plans can be viewed in Appendix 5.

\section{Results}

Discussion Board Posts

After analyzing the discussion posts, the authors concluded the following:

Awareness: The teachers were aware of CT early in the PD sessions, but were not yet fully comfortable with it. As the teachers interacted with more modules, their comfort level increased, but started to decease as the content of the modules became more complex.

Informational: Many teachers felt comfortable with CT and were more interested in learning more about it as additional modules (that contained more complexity) were provided.

Management: Initially, the teachers were fully committed to CT, but their attention was focused on the processes and tasks involved in implementing it. As additional modules were introduced, the focus on processes lessened, but increased as the modules complexity increased.

Consequence: The teachers' focus on the impact of CT on student achievement was an initial concern, became less so as additional modules were provided, but returned when certain modules refocused their attention.

Collaboration: Based on perusing the 18 modules, the teachers did not seem to indicate that collaboration was important. However, based on the responses to Questions \#8 (Survey \#2), 44\% of the responses indicated that the teachers profited professionally by collaborating with colleagues and/or requested more collaborative PD sessions.

Refocusing: Certain modules (for example, CT \& Mathematics Education and Pattern Recognition) seemed to provide an incentive for teachers to explore current and future ways to incorporate CT into their lesson plans. 


\section{Survey \#1: Overall Feedback Survey Following Summer Professional} Development

Upon examination of the Likert-type scale responses included in the Overall Feedback Survey (Survey \#1), a large majority of participants answered "Strongly Agree" or "Agree" for each question (see Appendix 1).

Based on analysis of the comments provided by the participating teachers on Survey \#1, the authors made the following observations for each question:

Q1 \& Q7: $100 \%$ of the respondents $(n=17)$ felt that the PD was important and worthwhile for their professional growth.

Q2, Q3 \& Q5: 86\% of the respondents felt that the PD activities and discussions were engaging, positively influenced their related content knowledge (mathematics and science content), and positively impacted their teaching of the related content.

Q4 \& Q6: It seems that the PD has positively impacted the attitude of the participating teachers (88\% answered Agree or Strongly Agree). However, 6\% answered Disagree. This positive impact has influenced many of the teachers to apply information learned during the PD sessions on a Daily (12\%), Weekly (47\%), Monthly (35\%), or Every 3 Months (6\%) with their students.

Q8: Below are a few sample responses from Question 8 (a free response question):

I thought that the whole event was helpful as a whole. Going through the programming on SLNova was great because I experienced that it wasn't so hard to do and can pass it along to my students. I think the whole plan was good and each part was important.

The activities and discussions we had regarding how to connect UDL and math/science to CT skills were very helpful.

I really enjoyed learning how to connect computational thinking to science and math curriculum. The brain rules and UDL was extremely interesting. I feel much more comfortable with coding in SLNova. I found code.org and the unplugged lessons extremely beneficial.

It was awesome to hear the different ways to incorporate CT into the classroom. It was nice to learn different ways to teach the students on basic topics.

Q9: Below are a few sample responses from Question 9 (a free response question):

I liked having the opportunity to pair program and partner up to build lessons. 
I really enjoyed the collaborative aspect that the workshop was able to provide. I would have liked to have that same collaboration when working through Modules 1-3.

It was awesome to hear the different ways to incorporate CT into the classroom. It was nice to learn different ways to teach the students on basic topics.

Overall Survey \#1 observations are stated below:

- Teachers learned about CT resources available to them and to their students.

- Teachers felt the collaborative aspect of the PD was positive.

- Teachers suggested more face-to-face meetings (to create lesson plans/ activities/games).

- Overall teacher satisfaction was positive - PD provided helpful/ beneficial experiences.

Survey \#2: Exit Interviews

Of the 17 participating teachers who completed the entire PD sequence, only 5 were available for exit interviews. Exit interviews were transcribed and coded using NVivo. Based on the analysis of the transcribed information from the Exit Interviews (Survey \#2), four main themes emerged: Skill Set, Teacher Attitude, Pedagogical Approach, and Logistics. Skill Set includes new ways of thinking with respect to the participating teachers. Teacher Attitude includes how the participating teachers felt about CT, coding, and the CTforAll project. Pedagogical Approach includes teaching methods, inclusion of CT activities in lesson plans, and administrative issues. Logistics includes issues with the professional development sessions (overall and individual sessions), the individual modules, and lesson plans. Some sample responses taken from the transcript appear below:

But I think it is that mindset shift - kind of like one of those things where I've always known that this stuff is the right way to do it. But now I'm hearing it and I'm learning a few ways to do it-in that way it's helping me as teacher (Skill Set, teacher \#1).

[Students] are interested in being hands on. I had kids that really, it's very hard to get them engaged. But if I tell them I know that with the coding they, they love the games, and the electronics, things like that. And so when you tell them things like, well coding is basically like making your own game. They were like wait, what does that have to do with school? And you know, and that might seem obvious to you or I, but those connections are the ones that get the kids from being not really interested to wanting to get involved and even going above and beyond. So I think it's helpful because a lot of kids know a lot about the stuff and they really want 
to sharpen their skills and they want to be able to explore these things that they may not have access to or opportunity to really learn from. How is it affecting students' learning? I think it gets them, it makes them see a point to their learning and it makes them tie in the classroom to their interests and things like that (Pedagogical Approach, teacher \#2).

And then I think it's also helpful, at least in my mind to think through...you try something and if it doesn't work that debugging or kind of repetitive iteration process for me was a big thing (Logistics, teacher \#3).

I felt at first, I was afraid because when they said you're going to do coding I thought "how did I get into this situation"? And um, and then I thought, well, I'm going to give it a try because I always liked computer science and then I found out it was much more than that (Teacher Attitude, teacher \#4).

\section{Lesson Plans}

Based on the nature of the collected data (categorical and discrete), the mode value was used as the appropriate measure of central tendency for data analysis (see Tables 2 and 3).

Table 2. Overall Ratings for Lesson Plans by Category (see Appendix 4 for a Description of the Lesson Plan Rubric)

\begin{tabular}{|l|l|l|}
\hline Category & Rating & $\underline{\text { Sum }^{+}}$ \\
\hline Decomposition & 1 & 13 \\
\hline Pattern Recognition & 1 & 13 \\
\hline Abstraction & 1 & 13 \\
\hline Algorithmic Thinking & 1 & 14 \\
\hline Optimization & 0 & 4 \\
\hline Generalization & 1 & 10 \\
\hline
\end{tabular}

+ This number is the total number of lesson plans that were rated as " 1 " by the authors for the listed category. The total number of lesson plans that were evaluated was 14 .

\section{Overall Ratings - Lesson Plans by Categories (Mode, Total)}

- The inclusion of Optimization $(0,4)$ \& Generalization $(1,10)$ activities was not overwhelmingly apparent in the lesson plans. Most of the lesson plans did not even incorporate one example of an activity in either of these categories $(71 \%$ of the lesson plans did not include an Optimization activity, $29 \%$ of the lesson plans did not include a Generalization activity).

- Decomposition (1,13), Pattern Recognition (1,13), Abstraction $(1,13)$, and Algorithmic Thinking $(1,14)$ were overwhelmingly apparent $(93 \%$ of the lesson plans included Decomposition, Pattern Recognition, and Abstraction activities, $100 \%$ of the lesson plans included Algorithmic Thinking activities). 
Table 3. Overall Ratings for Lesson Plans

\begin{tabular}{|l|l|l|}
\hline Lesson Plan & Rating & Sum $^{+}$ \\
\hline$\# 1$ & 0 & 1 \\
\hline$\# 2$ & 1 & 6 \\
\hline$\# 3$ & 1 & 5 \\
\hline$\# 4$ & 1 & 5 \\
\hline$\# 5$ & 1 & 5 \\
\hline$\# 6$ & 1 & 5 \\
\hline$\# 7$ & 1 & 6 \\
\hline$\# 8$ & 1 & 4 \\
\hline$\# 9$ & 1 & 4 \\
\hline$\# 10$ & 1 & 5 \\
\hline$\# 11$ & 1 & 4 \\
\hline$\# 12$ & 1 & 6 \\
\hline$\# 13$ & 1 & 5 \\
\hline$\# 14$ & 1 & 6 \\
\hline
\end{tabular}

+ This number is the sum, over categories, for the indicated lesson plan. The maximum number that could be earned is 6 .

\section{Overall Ratings - Lesson Plans (Mode)}

- Thirteen lesson plans (93\%) were rated "1" except for Lesson Plan \#1, which was rated "0", primarily due to the lack of sufficient details in order to be properly evaluated. Totals across categories ranged from 1 to 6 , with " 5 " being the most common rating, which means that the lesson plans were rated " 1 " in all categories except for one. The category that was often rated " 0 " was Optimization (see Table 4).

Table 4. Overall Ratings for Lesson Plans by Content Area

\begin{tabular}{|l|l|l|}
\hline Mathematics & Rating & Sum $^{+}$ \\
\hline Lesson Plan & 0 & 1 \\
\hline$\# 1$ & 1 & 6 \\
\hline$\# 2$ & 1 & 5 \\
\hline$\# 3$ & 1 & 5 \\
\hline$\# 4$ & 1 & 5 \\
\hline$\# 6$ & 1 & 4 \\
\hline$\# 9$ & 1 & 5 \\
\hline$\# 13$ & \multicolumn{2}{|l|}{} \\
\hline Science & Rating & Sum $^{+}$ \\
\hline Lesson Plan & 1 & 5 \\
\hline$\# 5$ & 1 & 6 \\
\hline$\# 7$ & 1 & 4 \\
\hline$\# 8$ & 1 & 5 \\
\hline$\# 10$ & 1 & 4 \\
\hline$\# 11$ & 1 & 6 \\
\hline$\# 12$ & 1 & 6 \\
\hline$\# 14$ & 1 & 7
\end{tabular}

+ This number is the sum, over categories, for the indicated lesson plan. The maximum number that could be earned is 6 . 


\section{Overall Ratings - Lesson Plans by Content Areas (Mode)}

- Mathematics - Six of the seven lesson plans were rated "1", which indicated that $86 \%$ of the lesson plans contained more than three of the six rated categories. The lesson plan that was rated " 0 " did not include enough specific information to be properly evaluated (see Table 5).

- Science - All seven lesson plans were rated "1", which indicated that $100 \%$ of these lesson plans contained more than three of the six rated categories (see Table 5).

Table 5. Overall Ratings for Lesson Plans by Grade Level Band

\begin{tabular}{|c|c|c|}
\hline Mathematics & & \\
\hline Elementary & Rating & Sum $^{++}$ \\
\hline$\# 1$ & 0 & 1 \\
\hline$\# 2$ & 1 & 6 \\
\hline$\# 6$ & 1 & 5 \\
\hline \#8 & 1 & 4 \\
\hline$\# 9$ & 1 & 4 \\
\hline$\# 14$ & 1 & 6 \\
\hline Science & & \\
\hline Secondary $^{+}$ & Rating & $\mathrm{Sum}^{++}$ \\
\hline$\# 3$ & 1 & 5 \\
\hline$\# 4$ & 1 & 5 \\
\hline$\# 5$ & 1 & 5 \\
\hline$\# 7$ & 1 & 6 \\
\hline$\# 10$ & 1 & 5 \\
\hline$\# 11$ & 1 & 4 \\
\hline$\# 12$ & 1 & 6 \\
\hline$\# 13$ & 1 & 5 \\
\hline
\end{tabular}

+ Elementary: grades kindergarten through 5, inclusive

Secondary: grades 6 through 12, inclusive

++ This number is the sum, over categories, for the indicated lesson plan. The maximum number that could be earned is 6 .

\section{Overall Ratings - Lesson Plans by Grade Level Band ${ }^{+}$(Mode)}

- Elementary Level - Five of the six lesson plans were rated "1", which indicated that $83 \%$ of these lesson plans contained more than three of the six rated categories. Lesson plan " 1 " was rated " 0 " mainly due to insufficient details.

- Secondary Level - All eight lesson plans were rated "1", which indicated that $100 \%$ of these lesson plans incorporated more than three of the six rated categories.

- $67 \%$ (4 of 6) of the Elementary Level lesson plans were mathematics lesson plans. 63\% (5 of 8) of the Secondary Level lesson plans were science lesson plans. 


\section{Discussion}

The analysis of the data demonstrated that most of the participants felt that the professional development activities were worthwhile and made a positive impact on the quality and quantity of CT activities they implemented in their k12 mathematics and science classrooms. Most participants stated that they would be implementing CT activities with their students weekly or monthly.

Lesson plan analysis indicated that Optimization and Generalization were not routinely integrated into participants' classroom teaching. Upon further examination of the comments made by the teachers on the online discussion board, it is logical to conclude that this occurred due to the teachers' lack of their own experiences and comfort level with different computational thinking tasks. On the other hand, participants seemed comfortable with integrating decomposition, algorithmic thinking, pattern recognition, and abstraction into their teaching, as these categories were more prevalent in written lesson plans. It seemed easier for teachers to understand these types of activities and, therefore, incorporate them into their lesson plans (more experience with these types of computational thinking activities).

Based on the total sum of ratings across lesson plan categories, the science lesson plans earned a higher rating than the mathematics lesson plans ( 36 points to 31 points, out of a possible 42 points). This may have been due to the mathematics lesson plan that was rated " 0 ". However, three of the science lesson plans earned a total score of " 6 " (the highest possible total), while only one of the mathematics lesson plans earned this total. Perhaps, since the modules were primarily science-based, the science teachers were better prepared to adapt or create lessons that were science-based. It may have been more difficult for the mathematics teachers to adapt and/or create a lesson plan that focused on a purely mathematical concept, such as "how best to conceptually teach the Pythagorean Theorem", with respect to computational thinking. In fact, using aspects of CT to develop a conceptual, as opposed to a procedural, understanding of specific mathematical content may not be the best way to accomplish this goal (Lye and Koh 2014).

Examination of the lesson plan total sum of ratings across categories, reveals that the Secondary Level lesson plans earned a higher rating than the Elementary Level lesson plans $(41 / 48=85 \%$ to $26 / 36=72 \%)$. The authors felt that the Secondary Level teachers were better prepared to incorporate CT activities into their lessons due to their familiarity and consistent use of the scientific method and a mathematics-related problem solving protocol (for example, Polya's Problem Solving Model). This may not have been the case with the Elementary Level teachers, even though a few of these teachers have used both the scientific method and Polya's Problem Solving Model with their students.

Since the research question of this paper focused on the impact of PD on the inclusion of CT activities in the mathematics and science classrooms of participating teachers, the authors only reported on this particular issue under the Pedagogical Approach theme. 
The qualitative analysis of the teacher interview data showed that the following themes were emerged:

- Many teachers used the terms "coding" and "CT" interchangeably, which contributed to the difficulty that most teachers experienced when creating, selecting, and/or implementing appropriate CT activities into their lesson plans.

- After the professional development, the participating teachers had a "mindset" shift. They were more willing to take risks with their students with respect to CT projects/activities (for example, the prosthesis project) and get out of the usual pedagogical routine. Most teachers were optimistic about CT, not only about how well it can be integrated into science content, but other content areas as well.

- The participating teachers also indicated that assigning and completing CT projects/activities were important for their students. Students began to understand the reasons for studying and learning concepts and skills in mathematics and science. There was an increase in engagement with respect to learning content so they could complete the project. The CT projects/activities could be used to illustrate the connection between "school" life and "real" life, sharpen academic skills, provide career opportunities, and create a viable product. According to one participating teacher "Including CT projects/activities in lesson plans will encourage students to think for themselves and isn't that what CT is all about?" By participating in CT projects, teachers reported their students became better problem solvers and became more proficient with the logic of coding. In addition, since many students want to become programmers/ gamers, they were excited about getting more experience in writing code when completing certain $\mathrm{CT}$ activities.

- The teachers realized that CT projects/activities can be used to engage students in the SMPs and NGSS (SMP \#1 \& \#3, scientific process).

- The teachers acknowledge that CT projects/activities can be integrated into the existing curriculum, but not every day and not everywhere. The activities must fit naturally, not be forced. Most students are not currently prepared to write code. Therefore, teachers must provide the opportunity and the necessary steps in order to enhance student success. The incorporation of CT activities/projects will increase the chance of this occurring. Many teachers felt that routinely introducing CT activities into their lesson plans would help students reach a higher level of thinking.

- Many teachers wanted more examples of how to incorporate CT projects/activities into their classrooms, especially with respect to teaching specific content. They would like ideas as to how best to resolve the issue of using more CT activities/projects and teaching specific content that is on the state mandated tests.

- The PD sessions helped the participating teachers learn how to teach their students to write code in StarLogo and Scratch. By participating in the PD sessions, the teachers learned it was okay to make mistakes 
when writing code because this encourages open dialogue between and among teachers and this approach can and should be encouraged with their students. Teachers and students can approach writing code as an adventure that they can share and enjoy together by making and correcting mistakes!

\section{Future Research Questions}

Based on a careful consideration of the original research question, and the data generated from the present study, the following additional questions should be actively pursued in future research studies:

- Does content discipline impact the quantity of CT activities that teachers incorporate into their lesson plans?

- Does content discipline impact the quality of CT activities that teachers incorporate into their lesson plans?

- Do grade-level bands (elementary and secondary) impact the quantity of CT activities that teachers provide their students?

- Do grade-level bands (elementary and secondary) impact the quality of CT activities that teachers provide their students?

- What is the impact of the teachers' CT professional development activities on their students' attitudes and achievement towards mathematics and science?

- Is there a difference in teacher-attitudes toward incorporating CT activities into lesson plans based on grade-level bands (elementary and secondary)?

- Is there a difference in teacher-attitudes toward incorporating CT activities into lesson plans based on content specialty (mathematics and science)?

- What are the most pedagogically effective ways to include more emphasis on classroom integration of Optimization and Generalization activities in order to increase teachers' confidence in their ability to effectively integrate these skills into their current classroom teaching?

\section{Acknowledgments}

The activities conducted in this research study were performed in the State of Maryland in the United States of America from spring 2017 to spring 2018. 


\section{References}

Barr V, Stephenson C (2011) Bringing Computational Thinking to K-12: What is Involved and what is the Role of the Computer Science Education Community? ACM Inroads 2(1): 48-54.

Baytak A, Land SM (2011) An Investigation of the Artifacts and Process of Constructing Computer Games about Environmental Science in a Fifth Grade Classroom. Educational Technology Research and Development 59(765-782): 48-54.

Blikstein P, Wilensky U (2009) An Atom is known by the Company it Keeps: A Constructionist Learning Environment for Materials Science using Agent-Based Modeling. International Journal of Computers for Mathematical Learning 14(2): 81119.

Bloom BS, Krathwohl DR, Masia BB (1956) Taxonomy of Educational Objectives, Classification of Educational Goals, Handbook I: Cognitive Domain. New York: McKay.

Calao LA, Moreno-Lé on J, Correa HE, Robles G (2015) Developing Mathematical Thinking with Scratch an Experiment with $6^{\text {th }}$ Grade Students. In Design for Teaching and Learning in a Networked World. Springer International Publishing, 1727.

Cole K, Simkins M, Penuel WR (2002) Learning to Teach with Technology: Strategies for Inservice Professional Development. Journal of Technology and Teacher Education 10(3): 431-455.

Common Core State Standards Initiative - CCSSI (2010) Common Core State Standards for Mathematics (CCSSM). Washington, DC: National Governors Association Center for Best Practices and the Council of Chief State School Officers. Retrieved from http://www.corestandards. org/wp-content/uploads/Math_Standards.pdf.

Di Sessa AA (2000) Changing Minds: Computers, Learning, and Literacy. Cambridge, MA: MIT Press.

Gal-Ezer J, Stephenson C (2010) Computer Science Teacher Preparation is Critical. ACM Inroads 1(1) Doi>10.1145/1721933.1721953.

Hambrusch S, Hoffmann C, Korb JT, Haugan M, Hosking AL (2009) A Multidisciplinary Approach towards Computational Thinking for Science Majors. Proceedings of the $40^{\text {th }}$ ACM Technical Symposium on Computer Science Education (SIGCSE '09). New York, NY, USA: ACM, 183-187.

Hord SM, Rutherford WL, Huling-Austin L, Hall GE (1987) Taking Charge of Change. Alexandria, Va.: Association for Supervision and Curriculum Development.

ISTE (2011) Operational Definition of Computational Thinking for K-12 Education. https://bit.ly/2IbefQg.

Jona K, Wilensky U, Trouille L, Horn MS, Orton K, Weintrop D, Beheshti E (2014) Embedding Computational Thinking in Science, Technology, Engineering, and Math (CT-STEM). Presented at the Future Directions in Computer Science Education Summit Meeting, Orlando.

Kanaya T, Light D, Culp KM (2005) Factors Influencing Outcomes from a Technology Focused Professional Development Program. Journal of Research on Technology in Education 37(3): 313-329.

Kynigos C (2007) Using Half-Baked Microworlds to Challenge Teacher Educators' Knowing. Journal of Computers for Math Learning 12(2): 87-111.

Lambert L, Guiffre H (2009) Computer Science Outreach in an Elementary School. Journal of Computing Sciences in Colleges 24(3): 118-124. 
Lye SY, Koh JH (2014) Review on Teaching and Learning of Computational Thinking through Programming - What is Next for K-12? Computers in Human Behavior 41(Dec): 51-61.

National Research Council (2011) Report of a Workshop of Pedagogical Aspects of Computational Thinking. Washington, DC: The National Academies Press.

National Research Council (2013) Next Generation Science Standards: For States, By States. Washington, DC: The National Academies Press. https://doi.org/10.17226/ 18290.

Ottenbreit-Leftwich AT (2007) Expert Technology-Using Teachers: Visions, Strategies, and Development. Unpublished Dissertation. Purdue University, West Lafayette.

Pólya G (1957) How to Solve it: A New Aspect of Mathematical Method. Princeton, N.J.: Princeton University Press.

Putnam RT, Borko H (2000) What do New Views of Knowledge and Thinking have to Say about Research on Teacher Learning? Educational Researcher 29(1): 4-15.

Repenning A, Webb D, Ioannidou A (2010) Scalable Game Design and the Development of a Checklist for Getting Computational Thinking into Public Schools. In Proceedings of the $41^{\text {st }}$ ACM Technical Symposium on Computer Science Education, 265-269.

Sengupta P, Kinnebrew JS, Basu S, Biswas G, Clark D (2013) Integrating Computational Thinking with K-12 Science Education using Agent-Based Computation: A Theoretical Framework. Education and Information Technologies 18(2): 1-30.

Sherin B (2001) A Comparison of Programming Languages and Algebraic Notation as Expressive Languages for Physics. International Journal of Computers for Mathematics Learning 6(1): 1-61.

Snoeyink R, Ertmer PA (2001/2002) Thrust into Technology: How Veteran Teachers Respond. Journal of Educational Technology Systems 30(1): 85-111.

Somekh B (2008) Factors Affecting Teachers' Pedagogical Adoption of ICT. In J. Voogt and G. Knezek (ed), International Handbook of Information Technology in Primary and Secondary Education, 449-460. New York: Springer.

Weintrop D, Beheshti E, Horn M et al. (2016) Defining Computational Thinking for Mathematics and Science Classrooms. Journal of Science Education and Technology 25(Oct): 127-147.

Wilensky U, Reisman K (2006) Thinking Like a Wolf, a Sheep, or a Firefly: Learning Biology through Constructing and Testing Computational Theories-An Embodied Modeling Approach. Cognition and Instruction 24(2): 171-209.

Wing JM (2006) Computational Thinking. Communications of the ACM 49(3): 33-35.

Wozney L, Venkatesh V, Abrami PC (2006) Implementing Computer Technologies: Teachers' Perceptions and Practices. Journal of Technology and Teacher Education 14(1): 173-207.

Yadav A, Zhou N, Mayfield C, Hambrusch S, Korb JT (2011) Introducing Computational Thinking in Education Courses. In Proceedings of ACM Special Interest Group on Computer Science Education, Dallas, TX.

Yadav A, Mayfield C, Zhou N, Hambrusch S, Korb JT (2014) Computational Thinking in Elementary and Secondary Teacher Education. ACM Transactions on Computing Education 14(1): 1-16. Doi: 10.1145/2576872.

Zhao Y, Cziko GA (2001) Teacher Adoption of Technology: A Perceptual Control Theory Perspective. Journal of Technology and Teacher Education 9(1): 5-30. 


\section{APPENDIX 1: Sample Discussion Board Question Prompts}

1. How do you currently make connections between mathematics and science?

2. Which of the activities mentioned have you done in your classroom?

3. Which of the activities mentioned do you want to do in your classroom? Why?

4. How does Computational Thinking relate to the Standards for Mathematical Practice?

5. How does Computational Thinking relate to the Next Generation Science Standards?

6. What kinds of models do you currently use in your teaching?

7. What kinds of computer models can be helpful in your teaching?

8. What are the benefits of students not just using computer models, but being able to modify and create models?

9. What are your concerns with teaching computer modeling in the science classroom?

10. Which part(s) of your current curriculum can be replaced or supplemented with unit(s) on computer modeling?

\section{APPENDIX 2: Survey \#1}

Q1: The PD sessions throughout the project constituted meaningful and important skill/knowledge.

Q2: Activities and discussions at PD sessions enhanced my knowledge and understanding of related content

Q3: Activities and discussions during the PD sessions I attended have positively influenced my teaching of related content.

Q4: The information learned from participating in this project has/will positively impact the achievement of my students.

Q5: Project activities and discussions were engaging.

Q6: Approximately, how often do you believe you have applied the information learned from the PD sessions with your students?

Q7: Participating in the project workshops has been a worthwhile and valuable professional development experience for me.

Q8: What was the most beneficial/meaningful experience you had during the workshops?

Q9: Please provide any additional comments/feedback. 


\section{APPENDIX 3: Survey \#2 Semi-Structured Interview \& Focus Group Questions}

Thanks for your participation. The purpose of the Focus Group/Interview is to evaluate the CT for All project, not the participants. I will be creating an audio recording of the conversation, and a typewritten transcript of the interview will be created. I will review the transcript to try and understand what impressions you have about the program to understand whether and how well it worked, and how future programs might be improved. Pseudonyms will be used in place of your names to maintain confidentiality. Please feel free to be candid as you share your thoughts.

There are two broad elements I would like to ask about: 1) the content, computational thinking; and 2) your thoughts about the implementation of the professional development. This includes the materials, the sessions, or the professional learning community online. I am interested in any impressions you care to share about your experience in the CT for All program.

What have you gained from participating in this project?

How do you feel your participation in this project has impacted your students' learning and performance?

How have your thoughts and perceptions of your role in teaching computational thinking in your content area changed? How have they remained the same?

What were the most beneficial components of the project?

What suggestions/recommendations would you make for future projects with a similar focus to this one?

How has your participation in this project impacted other teachers at your school?

What feedback have you received from your administrators around your participation in the project?

What are your perceptions toward computational thinking, specifically, how is computational thinking implemented? How well do you think computational thinking can be integrated? How have your perceptions changed from before ITQ until now? 


\section{APPENDIX 4: Lesson Plan Rubric Computational Thinking Rubric for CT for All Participant's Lesson Plans}

Lesson Plan:

\begin{tabular}{|c|c|c|c|}
\hline & 0 & 1 & $\#$ \\
\hline Decomposition & $\begin{array}{l}\text { No example of } \\
\text { decomposition learning } \\
\text { activities in the lesson plan }\end{array}$ & $\begin{array}{l}\text { Lesson plan contains at least one } \\
\text { example of a learning activity on } \\
\text { decomposition }\end{array}$ & \\
\hline Pattern recognition & $\begin{array}{l}\text { No example of pattern } \\
\text { recognition learning } \\
\text { activities in the lesson plan }\end{array}$ & $\begin{array}{l}\text { Lesson plan contains at least one } \\
\text { example of a learning activity on } \\
\text { pattern recognition }\end{array}$ & \\
\hline Abstraction & $\begin{array}{l}\text { No example of abstraction } \\
\text { learning activities in the } \\
\text { lesson plan }\end{array}$ & $\begin{array}{l}\text { Lesson plan contains at least one } \\
\text { example of a learning activity on } \\
\text { abstraction }\end{array}$ & \\
\hline Algorithmic thinking & $\begin{array}{l}\text { No example of } \\
\text { algorithmic thinking } \\
\text { learning activities in the } \\
\text { lesson plan }\end{array}$ & $\begin{array}{l}\text { Lesson plan contains at least one } \\
\text { example of a learning activity on } \\
\text { algorithmic thinking }\end{array}$ & \\
\hline Optimization & $\begin{array}{l}\text { No example of } \\
\text { optimization learning } \\
\text { activities in the lesson plan }\end{array}$ & $\begin{array}{l}\text { Lesson plan contains at least one } \\
\text { example of a learning activity } \\
\text { on optimization }\end{array}$ & \\
\hline Generalization & $\begin{array}{l}\text { No example of } \\
\text { generalization learning } \\
\text { activities in the lesson plan }\end{array}$ & $\begin{array}{l}\text { Lesson plan contains at least one } \\
\text { example of a learning activity on } \\
\text { generalization }\end{array}$ & \\
\hline
\end{tabular}

\section{Category Descriptions}

Computational thinking is defined as "a problem-solving process that includes (but is not limited to) the following characteristics:

- Formulating problems in a way that enables the use of a computer and other tools to help solve them.

- Logically organizing and analyzing data.

- Representing data through abstractions such as models and simulations.

- Automating solutions through algorithmic thinking (a series of ordered steps).

- Identifying, analyzing, and implementing possible solutions with the goal of achieving the most efficient and effective combination of steps and resources.

- Generalizing and transferring this problem solving process to a wide variety of problems".

Based on the authors' working definition of computational thinking, there are six skill sets that are essential with respect to computational thinking: 
1. Decomposition: Decomposition is defined as "the ability to break a large problem down into many smaller problems". Decomposition helps formulate the problem in such a way that computers or other tools can be used in the solution process. For example, evidence of decomposition in a lesson plan can be that the students are asked to "identify parts", or to make a "list of examples" of the elements of a specific activity.

2. Pattern Recognition: Pattern recognition is defined as "the ability to notice similarities or common differences in data". For example, evidence of pattern recognition in a lesson plan can be that "order matters", or that the students are asked to determine "similarities and/or differences" between and among cases/scenarios.

3. Abstraction: Abstraction is defined as the process of "deciding what details are needed and which details can be ignored". The process of abstraction is often used when creating models or the simplified versions of complex systems. For example, evidence of abstraction in a lesson plan can be that the students are asked to "describe", "illustrate", or "use model(s)".

4. Algorithmic Thinking: Algorithmic thinking is defined as "a way of getting to a solution through the clear definition of the steps needed". Developing an algorithm means creating a step-by-step solution to solve a problem. For example, evidence of algorithmic thinking in a lesson plan can be that students are asked to create a "step-by-step" process for making a ham and cheese sandwich.

5. Optimization: Optimization is defined as "identifying, analyzing, and implementing possible solutions with the goal of achieving the most efficient and effective combination of steps and resources". For example, evidence of optimization in a lesson plan can be that students are asked to identify "limitations" in a solution process, or to think of how to make a solution process more efficient.

6. Generalization: Generalization is defined as "generalizing and transferring the problem solving process to a wide variety of problems". For example, evidence of generalization in a lesson plan can be that the students are asked to consider two or more contexts for a given task.

\section{APPENDIX 5: Sample Lesson Plans}

Grade Level: Kindergarten

Standards:

- Common Core State Standards

○ Literacy

- R.K.1; W.K.1; W.K.2; W.K.3; W.K.7; SL.K.5

○ Math

- MP 2; MP 4

- K.CC; K.MD.A.2

- Next Gen Science

○ K.LS.1-1 and K.ESS.3-1 
Objectives: Today we will decompose large activities into a series of smaller events. Today we will arrange sequential events into their logical order.

Vocabulary: algorithm

Lesson Plan: (selected from the unit plan)

* First discuss with your students the vocabulary algorithm. Show them the word. You say the word, they say the word. Explain to students the definition of an algorithm. An algorithm is a precise sequence of instructions for processes that can be executed by a computer. Have definition posted with a picture. Refer to this frequently throughout the lesson. Have students continuously practice saying the word.

- Extension: Algorithm comes from the Greek word arithmos which means number

* Explain to students that today we will be learning about the concepts of algorithms and how we follow algorithms in real life every day.

* Go over the objective for today.

* Have a class discussion about the steps that they take to get ready for school in the morning. As students are saying things they do to get ready write them up on the board. Once finished writing out the ideas, put numbers next to their responses to indicate order. Be sure to point out places where order matters and where order does not matter. Explain to students how we just created an algorithm for how they get ready for school in the morning. Refer back to the definition of algorithm. Introduce that it is possible to create algorithms for things we do every day.

- Extra Support: Create an algorithm for another every day activity such as making a peanut butter jelly sandwich, how to walk through the door and return, or making chocolate milk.

* Next day in class we are going to create an algorithm for planting a seed. Refer back to the definition of algorithm. Have the students watch the brainpop video on plant life cycle in order to gain background knowledge on how to plant a seed. As the video is playing feel free to stop the video and ask students questions in order to continue their engagement and motivation for watching the video.

* Once the video ends have the students split up into small groups/pairs. In the small groups/pairs each will need a plant a seed worksheet, scissors, glue, and a sentence strip. Option for choice: have this in an electronic format (wixie/interactive whiteboard lesson). Students will cut out each of the 9 squares. Their job is to determine which 6 of them you will utilize in order to plant a seed, so they will not use 3 squares

- Extra Support: Pull students who may need a little extra support at a small group with the teacher to help them with the activity. Pair the students up with a stronger person who can help them with the activity. Instead of giving the group/pair of students all 9 give them just the 6 that they need to sequence. If needed complete activity as a whole class. 
- Fine Motor: Students who may struggle to cut them out have the squares already pre-cut so they just have to focus on gluing.

* Once groups are finished their sequence of events (algorithm) to plant a seed they will swap sentence strips (or electronic formats) and follow the sequence of steps the other group created in order to actually plant a seed.

* After all groups have planted a seed following their algorithm have a class discussion about the process. What did you learn? How many of you were able to follow your algorithms to plant your seeds? Did the exercise leave anything out? What would you have added to make the algorithm even better? What if the algorithm had been only one step: plant the seed? Would that have been easier or harder? What is it were forty steps? What was your favorite part of the activity?

\section{Intro to Computational Thinking}

\begin{tabular}{|l|l|l|l|}
\hline Date & Aug 18,2017 & $\begin{array}{l}\text { Time } \\
\text { Frame }\end{array}$ & 50 minutes \\
\hline Unit & Computational Thinking & $\begin{array}{l}\text { Unit } \\
\text { Theme }\end{array}$ & \\
\hline
\end{tabular}

\begin{tabular}{|c|c|}
\hline $\begin{array}{l}\text { NGSS } \\
\text { Standards }\end{array}$ & $\begin{array}{l}\text { Developing and Using Models } \\
\text { Modeling in 9-12 builds on K-8 and progresses to using, } \\
\text { synthesizing, and developing models to predict and show relationships } \\
\text { among variables between systems and their components in the natural } \\
\text { and designed worlds. } \\
\text { Develop a model based on evidence to illustrate the } \\
\text { relationships between systems or between components of a system. } \\
\text { (HS-PS1-4),(HS-PS1-8) }\end{array}$ \\
\hline $\begin{array}{l}\text { Disciplinary } \\
\text { Core Ideas }\end{array}$ & $\begin{array}{l}\text { ETS1.C: Optimizing the Design Solution } \\
\text { Criteria may need to be broken down into simpler ones that } \\
\text { can be approached systematically, and decisions about the priority } \\
\text { of certain criteria over others (trade-offs) may be } \\
\text { needed. (secondary to HS-PS1-6) }\end{array}$ \\
\hline Object & $\begin{array}{l}\text { Students will be able to draw pixels into a grid in order to demonstrate } \\
\text { how a computer can create an image from a set of numbers. }\end{array}$ \\
\hline Usefu & $\begin{array}{l}\text { http://csunplugg } \\
\text { content/uploads }\end{array}$ \\
\hline
\end{tabular}

Drill: (5 min.)

Propose the following questions to the class. Have them write their :

In what situations would computers need to store pictures? (A drawing program, a game with graphics, or a multi-media system.)

How can computers store pictures when they can only use numbers? 


\begin{tabular}{|c|c|}
\hline \multicolumn{2}{|c|}{ Engagement (not boring): 5 minutes } \\
\hline $\begin{array}{l}\text { Captures students' } \\
\text { attention? } \\
\text { Activates students' } \\
\text { prior knowledge? } \\
\text { Connects to a } \\
\text { complex question, } \\
\text { global issue, or real } \\
\text { world problem? }\end{array}$ & $\begin{array}{l}\text { Provide time for students to discuss their thoughts about } \\
\text { the above discussion. Some students may know a lot, } \\
\text { others may need help. } \\
\text { If students are aware of what a fax machine does, that can } \\
\text { help in the explanation. To go even further, a fax machine } \\
\text { could be brought into the classroom. }\end{array}$ \\
\hline \multicolumn{2}{|c|}{ Exploration (think labs, hands-on, student driven): 10 minutes } \\
\hline $\begin{array}{l}\text { Analyzes other } \\
\text { disciplines to answer a } \\
\text { complex question, } \\
\text { global issue, or real } \\
\text { world problem? } \\
\text { _Applies a systematic } \\
\text { approach to address the } \\
\text { real world connection? } \\
\text { _Selects and employs } \\
\text { relevant technological } \\
\text { tools? }\end{array}$ & $\begin{array}{l}\text { Students will be given the handout with the "a" letter } \\
\text { drawn in pixelated form. Students will need to draw this } \\
\text { image and then to the side of the image write the coded } \\
\text { numbers that correspond to the pixels. Students can help } \\
\text { each other to understand and ask questions as needed. } \\
\text { Most students will catch on to this very quickly and begin } \\
\text { to move onto the next part. }\end{array}$ \\
\hline
\end{tabular}

Explanation (multi-sensory): 15 minutes

\begin{tabular}{l|l} 
_Analyzes data and & There are numbers and a grid on the next page of the \\
draws conclusions? & worksheet. Using the numbers, the students need to figure \\
Communicates & out which pixels to shade in. The result will be an image of \\
understandings and & a little picture. Students will know if they are getting the \\
possible solutions? & answers correct if their picture makes sense.
\end{tabular}

Extension/Elaboration (building complexity, real world application, frequent review): Remaining time in lesson.

\begin{tabular}{l|l|}
\hline _Modifies & Students can now create their own picture, turn it to code, and
\end{tabular} experimental procedures, prototypes, models, or solutions? Analyzes related STEM careers? then trade with a classmate who will have to decipher the picture. Students can draw their favorite character or emoji in order to make it unique and personalized to their interests. There is also an included extension activity where the students can include color to their picture, again using numbers to indicate the colors being used.

Evaluation (multiple modalities): During/After class

UDL Connections: Students are taking a picture and turning it into a number. Then students take a number and turn it into a picture. Abstract concepts are explained through this process.

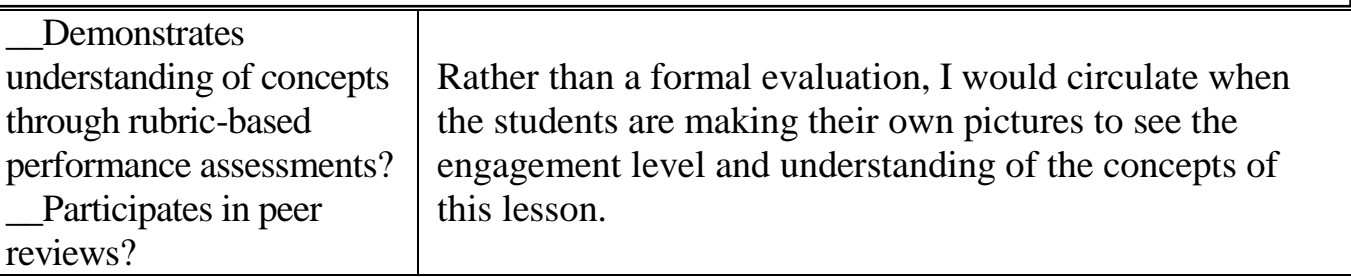




\begin{tabular}{|c|c|c|c|}
\hline \multicolumn{4}{|c|}{ AVID Strategies } \\
\hline Writing to Learn & Inquiry & Collaboration & Reading to Learn \\
\hline $\begin{array}{l}\text { _Cornell Notes } \\
\text { Notes (Right } \\
\text { Hand) } \\
\text { _Other }\end{array}$ & $\begin{array}{l}\text { _X_Analyze } \\
\text { _Extend } \\
\text { _X_Apply } \\
\text { _Seek } \\
\text { Clarification } \\
\text { _Other }\end{array}$ & $\begin{array}{l}\text { X_Problem } \\
\text { Solve } \\
\text { X_Work } \\
\text { together } \\
\text { Other }\end{array}$ & $\begin{array}{l}\text { _Pre-Reading } \\
\text { Activities } \\
\text { _ Summarize/Reflectiv } \\
\text { _ Highlight/Underline } \\
\text { _Other }\end{array}$ \\
\hline
\end{tabular}




\title{
The Phytoplankton and Water Quality of Sennar and Roseires Reservoirs, Sudan
}

\author{
By Faisal Abdalla Sinada ${ }^{*} \&$ Manal Elsayed Abdelrahman ${ }^{\dagger}$
}

The aim of the study was to evaluate the effect of heightening of Roseires Dam on the phytoplankton and physico-chemical characteristics of Sennar reservoir $\left(13^{\circ} 32^{\prime} 55^{\prime \prime}\right.$ and

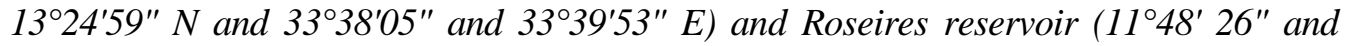
$11^{\circ} 32^{\prime} 45^{\prime \prime} N$ and $34^{\circ} 26^{\prime} 46^{\prime \prime}$ and $34^{\circ} 28^{\prime} 33^{\prime \prime} E$ ) on the Blue Nile, Sudan. The heightening project that was completed in 2013 increased the storage capacity of Roseires reservoir from $3.0 \times 10^{9} \mathrm{~m}^{3}$ to $7.4 \times 10^{9} \mathrm{~m}^{3}$. The study provides baseline data before the completion of the Grand Ethiopian Renaissance Dam (GERD) on the Blue Nile. No studies on the phytoplankton of Sennar or Roseires reservoir have been undertaken since late 1960s because of accumulating deficit of trained research personnel and the very low level of scientific research funding. Present water analyses include Secchi transparency, electrical conductivity, $\mathrm{pH}$, alkalinity, nitrate-nitrogen, phosphate-phosphorus, calcium, potassium, sodium, cadmium, cobalt, chromium, copper, iron, lead, magnesium, manganese, and zinc. Statistical analysis shows that there were no significant differences between the samples taken from Sennar and Roseires reservoirs. The quality of the water of the two reservoirs has not changed since 1960s, still being within allowable limits set by the Sudanese Standards and Metrology Organization and WHO for drinking. Strikingly, algal biomass remained extremely low in the two reservoirs during the present study. Visual observations and analysis of water samples collected from the two reservoirs and from the Blue Nile at Khartoum showed that the recurrent peaks reported by previous workers did not appear, while turbidity and concentrations of nutrients remained unexpectedly high with no signs of any algal growth during December 2015 - December 2017. Environmentalists are alarmed that pollution in the Blue Nile within Sudan will become a problem after the completion of GERD when regulation of water flow downstream will result in only a fraction of the Blue Nile water reaches Sudan throughout the year allowing for the accumulation of pollutants.

Keywords: Blue Nile, Phytoplankton, Roseires Dam, Sennar Dam, Water Quality.

\section{Introduction}

Published work on assessment of possible contamination or development of any degree of pollution of the Blue Nile is non-existent. In view of the social progress, industrial and population explosion and active urbanization that took place within the last fifty years and which shall continue in the coming years, pollution of the Blue Nile is inevitable unless certain measures are undertaken.

Attention is focused on the detection of unwelcome enrichments which cause deterioration of water quality. These undesirable contaminants might reach the course of the river as a result of (i) introduction of industrial contaminants from the many factories built along the Blue Nile, (ii) sewage effluent and urban runoff

\footnotetext{
*Associate Professor, University of Khartoum, Sudan.

${ }^{\dagger}$ Assistant Professor, University of Khartoum, Sudan.
} 
from expanding towns adjacent to the Blue Nile and/or (iii) diffusion of agrochemicals from Sudan Gezira agriculture scheme and other farms.

The Blue Nile after leaving Lake Tana, quickly descends into a deep gorge until it enters the Sudan south of Roseires with average annual flow of $46.2 \times 10^{9}$ $\mathrm{m}^{3} \mathrm{yr}^{-1}$. Before entering the Sudan plains, the Blue Nile receives 14 major torrential tributaries which supply most of the silty river water received at Roseires reservoir (Omer et al. 2015).

The discharge of the Blue Nile is primarily affected by the seasonality of torrential rains on the Ethiopian highlands where a wet season extends from July to October, with maximum rainfall and river flow during August-September, and a dry season from November to June.

The natural flow of the Blue Nile has been altered by artificial hydrological regimes within Sudan. Sennar and Roseires dams were built across the Blue Nile in 1925 and 1966 respectively. Roseires reservoir $(629 \mathrm{~km}$ upstream Khartoum, $11^{\circ} 48^{\prime} 26^{\prime \prime}$ and $11^{\circ} 32^{\prime} 45^{\prime \prime} \mathrm{N}$ and $34^{\circ} 26^{\prime} 46^{\prime \prime}$ and $\left.34^{\circ} 28^{\prime} 33^{\prime \prime} \mathrm{E}\right)$ is located in southeast of Sudan in Blue Nile State. Sennar reservoir $(345 \mathrm{~km}$ upstream Khartoum, $13^{\circ} 32^{\prime} 55^{\prime \prime}$ and $13^{\circ} 24^{\prime} 59^{\prime \prime} \mathrm{N}$ and $33^{\circ} 38^{\prime} 05^{\prime \prime}$ and $33^{\circ} 39^{\prime} 53^{\prime \prime} \mathrm{E}$ ) is located north of Roseires in Sennar State (Figure 1).

These two dams altered the natural flow of the river. A heightening of Roseires Dam was completed in January 2013. The project added $10 \mathrm{~m}$ in height and $12 \mathrm{~km}$ in length to the existing dam, increasing its storage capacity from $3.0 \times 10^{9} \mathrm{~m}^{3}$ to $7.4 \times 10^{9} \mathrm{~m}^{3}$ and its storage time from 45 to 60 days. The reservoir has a maximum depth of $45 \mathrm{~m}$. The storage capacity of Sennar Dam is $1 \times 10^{9} \mathrm{~m}^{3}$ with a retention time of 32 days. Sennar reservoir has a maximum depth of $17 \mathrm{~m}$. In 2017 Roseires reservoir reached its full capacity by late-December (Roseires and Sennar dams Engineers, Personal communication).

Figure 1. Map of the Blue Nile within Sudan Plains Showing Locations of Roseires and Sennar Dams

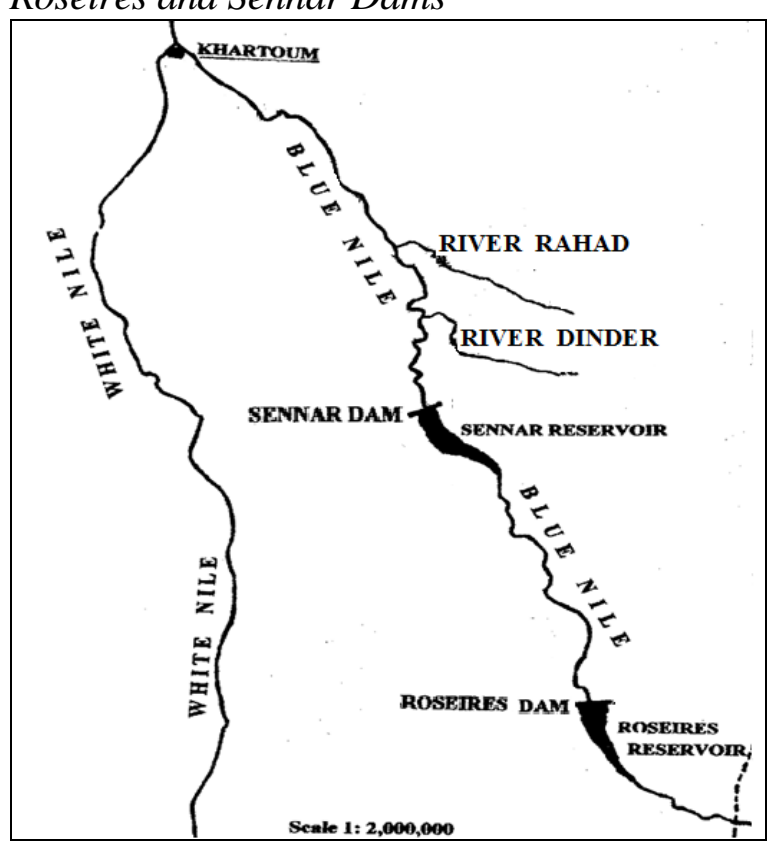




\section{Literature Review}

\section{The Blue Nile Upstream of Roseires before Construction of the Dam}

Before the completion of Roseires Dam, Hammerton (1970a, b, 1971a), in three different surveys carried out during February 1964, February 1965 and February 1966 reported an extremely sparse plankton population in $400 \mathrm{~km}$ section of the river upstream of Sennar reservoir. He found within this stretch of the Nile that the diatom Aulacoseira (formerly Melosira) granulata and the cyanobacterium Anabaena flos-aquae - two principal components of the Blue Nile plankton north of Sennar reservoir - were present in very small numbers (around 20 cells $\mathrm{mL}^{-1}$ ). All samples collected during 1964 - 1966 contained visible quantities of silt and fine sand and some organic detritus with a Secchi disc visibility less than $50 \mathrm{~cm}$. Poor light penetration coupled with relatively high current velocity might be the sole factor checking the development of phytoplankton within this stretch of the Blue Nile before the construction of Roseires Dam (Hammerton 1970a, b, 1971a, Talling and Rźoska 1967).

\section{Sennar Reservoir before Construction of Roseires Dam}

Hammerton (1970a, b, 1971a) confirming the findings of Talling and Rźoska (1967) found that as the water enters Sennar reservoir, most of the silt settled out. The Secchi disc visibility increased considerably resulting in a dense phytoplankton development within the reservoir. The diatom Aulacoseira granulata increased from around 20 cells $\mathrm{mL}^{-1}$ before entering Sennar reservoir to $2.1 \times 10^{3}$ cells $\mathrm{mL}^{-1}$ in the reservoir. There was a similar increase in numbers of the cyanobacterium Anabaena flos-aquae.

Roseires Reservoir: The Development of Phytoplankton after Construction of the Dam in 1966

According to Hammerton (1971a, b, c) the phytoplankton in Roseires reservoir during the first three years of its filling (1966 - 1970) showed considerably heavy growth with Aulacoseira granulata, Microcystis flos-aquae, Anabaena flos-aquae, Phormidium mucicola, Volvox aureus, and Pediastrum simplex var. duodenarium dominating the plankton at one time or another. The diatom Aulacoseira granulata increased from around 20 cells $\mathrm{mL}^{-1}$ before entering Roseires reservoir to $5.2 \times 10^{3}$ cells $\mathrm{mL}^{-1}$ cells $\mathrm{mL}^{-1}$ in the reservoir.

\section{Sennar Reservoir after Construction of Roseires Dam}

Hammerton (1971c, d, 1972a) followed the seasonal cycles of the phytoplankton in Sennar reservoir for three consecutive seasons. During 1968 1970 Aulacoseira granulata and co-dominant Anabaena flos-aquae dominated the phytoplankton in the reservoir. The total algal densities in Sennar reservoir were higher than those in Roseires. 
The fluctuations in the densities of Aulacoseira and Anabaena within Sennar reservoir during 1968 - 1970 closely reflected the seasonal changes of the numbers of these organisms in Roseires reservoir. The Roseires reservoir shortly after its creation greatly influenced the phytoplankton composition and density within Sennar reservoir, and subsequently downstream.

The Development of Phytoplankton at Khartoum (latitude $16^{\circ} \mathrm{N}$ ) before and after Construction of the Dam

For logistic reasons, studies of the phytoplankton of the Blue Nile during 1950s were confined to Khartoum. Prior to the establishment of Roseires Dam, Brook (1954), Rźoska et al. (1955), Talling and Rźoska (1967) reported a definite cycle and seasonal peaks of the major phytoplankton species that could be faithfully predicted at Khartoum. Later, after the construction of Roseires Dam, Sinada and Abdel Karim, (1984a), Yousif (2004) and Sinada and Yousif (2012) confirmed the recurrent substantial increase in algal densities which always appeared in the Blue Nile at Khartoum after the flood period in late October/early November when the current subsided and most of the silt settled out. These recurrent algal peaks were no different from those reported at Khartoum before the construction of Roseires Dam by previous workers except for the appearance of new records, with the dominant algal species remaining the same.

\section{Materials and Methods}

\section{Study Period}

The two reservoirs were visited every two - four months, thus, December 2015, February 2016, April 2016, November 2016, April 2017 and December 2017. No attempt was made to sample the reservoirs during the rainy flood season between June - October 2016 and June - October 2017 since no alga was expected to be encountered in any numbers in the expected highly turbid flood waters. To assess spatial distribution of phytoplankton communities and water quality, surface samples only were collected on one occasion from five randomly chosen stations covering only the central sector of each reservoir. The vertical distribution of phytoplankton populations and physico-chemical variables were assessed only in Roseires reservoir at the central station. A 2-L Ruttner water sampler connected to a $45 \mathrm{~m}$ steel cable was lowered from the side of a tugboat using a manual winch with automatic brake to collect water from the surface, $15 \mathrm{~m}$ and near the bottom. All water samples were collected between 09:00 and 10:00 am. Only surface samples were collected from Sennar reservoir because it was not safe to use the heavy winch to retrieve the $2-\mathrm{L}$ Ruttner sampler from the side of a small powermotorized fishing boat. 


\section{Water and Phytoplankton Sampling}

Surface water samples were collected from each reservoir in polyethylene bottles. Depth profiles were studied only in Roseires reservoir. $\mathrm{pH}$ and electric conductivity were recorded in situ onboard using handheld Jenway digital field instruments. Water temperature was measured using a mercury thermometer. Water transparency was measured using a Secchi disc. Alkalinity was determined by titration with $0.1 \mathrm{~N} \mathrm{HCl}$ in the field using bromcresol green-methyl red mixed indicators as described by Mackereth et al. (1978).

For analysis of dissolved nitrate-nitrogen $\left(\mathrm{NO}_{3}-\mathrm{N}\right)$, phosphate-phosphorus $\left(\mathrm{PO}_{4}-\mathrm{P}\right)$ and heavy metals, water samples were collected in clean polyethylene bottles and transported to the laboratory. Silica $\left(\mathrm{SiO}_{2}\right)$ was determined on one occasion only (20.3 and $23.1 \mathrm{mg} \mathrm{SiO}_{2} \mathrm{~L}^{-1}$ in Sennar and Roseires reservoirs respectively). Water samples were analyzed by the spectrophotometric procedure as described in Allen (1989) using Apel Spectrophotometer, Japan, fitted with a 1 $\mathrm{cm}$ path length cuvette. The absorbance was measured at 540,880, and $810 \mathrm{~nm}$, for the $\mathrm{NO}_{3}, \mathrm{PO}_{4}$, and $\mathrm{SiO}_{2}$, respectively. Sodium and potassium were determined following the flame photometer method. Calcium was measured following the EDTA titration method. Cadmium, cobalt, chromium, copper, iron, lead, magnesium, manganese, and zinc were measured on three occasions. Analysis was performed on AA-6800 Shimadzu Atomic Absorption Spectrophotometer (Shimadzu Corporation, Japan). A linear calibration curve for each trace metal was drawn by preparing sets of external standards diluted from $1000 \mathrm{ppm}$ certified single element reference solutions supplied by Romil (Romil, Ltd, Cambridge, UK). A standard QC solution was analyzed after 10 samples for each of the nine trace metals.

\section{Qualitative and Quantitative Analyses of Phytoplankton}

For qualitative taxonomic analysis, phytoplankton samples were collected with plankton net (mesh size $25 \mu \mathrm{m}$ ). The net samples were transferred into plastic containers with screw caps. Each sample was preserved in $4 \%$ formalin and stored in the laboratory until analysis.

For quantitative analysis of the phytoplankton, unstrained water samples were collected from below the surface. They were fixed and preserved with $10 \%$ Lugol's solution. Depending on the density of the phytoplankton, aliquots of 1-10 $\mathrm{mL}$ were sedimented in chambers by standing for $2-5 \mathrm{~h}$ following the procedure described by Lund et al. (1958). Algae present were enumerated on a Zeiss inverted microscope at a magnification of $\times 200$. Each filament was counted as a unit. The average number of cells per filament was determined from a large number of specimens. Results of phytoplankton biomass were expressed as cells $\mathrm{mL}^{-1}$.

Phytoplankton biomass was measured in terms of Chlorophyll-a (Chl-a) as described in Strickland and Parsons (1977). For the estimation of total chlorophyll- $a$ a known amount of surface water was filtered through GF/C filter. The filter was removed and the chlorophyll was extracted in a flask with $14 \mathrm{~mL}$ of 
$90 \%$ acetone for $24 \mathrm{~h}$ at $4^{\circ} \mathrm{C}$ in the dark. The clear extract was transferred to a 1 $\mathrm{cm}$ path length cuvette using Apel Spectrophotometer, Japan, to measure the absorbance at 665 and $750 \mathrm{~nm}$.

\section{Identification of Planktonic Algae}

Algae collected in the net samples were identified up to genus or species level according to the standard works and keys of Cleve-Euler (1951), Desikachary (1959), Prescott (1962), Krammer (1991a, b), Wehr et al. (2015).

\section{Statistical Analysis}

The differences in physical and chemical variables between the two reservoirs were tested using $\mathrm{T}$ test at $95 \%$ Confidence Intervals. The homogeneity of water in each reservoir was tested by calculating the coefficient of variation.

\section{Results and Discussion}

\section{Water Quality: Physical and Chemical Variables}

The waters of Sennar and Roseires reservoirs are of excellent quality for drinking and domestic use, irrigation, industrial use, navigation, tourism, bathing and recreation. In Sennar and Roseires reservoirs the water quality and heavy metal concentrations in terms of cadmium, chromium, copper, iron, lead, manganese, and zinc were well within allowable limits set by the Sudanese Standards and Metrology Organization (SSMO 2008) and are within permissible limits set by WHO for drinking water (WHO 2011).

The concentrations of heavy metals were more or less the same in the two reservoirs except for slightly higher but not alarming value of chromium recorded once in Roseires reservoir. Conversely, manganese was slightly higher in Sennar reservoir than in Roseires. The source of the heavy metals detected in waters of the two reservoirs is more likely to be natural since no anthropogenic polluting activities such as factories occur in the vicinity of the two reservoirs.

Physical and chemical variables measured in water samples collected from the sampling sites in both reservoirs are presented in Tables 1 and 2. The statistical analysis using t-test with $95 \%$ Confidence Intervals shows that there were no significant differences between the samples taken from Sennar and Roseires reservoirs as regards the following environmental variables: electrical conductivity, alkalinity, nitrate-nitrogen, and phosphate-phosphorus. Similarly, $\mathrm{pH}$ which was neither acidic nor highly alkaline was more or less the same in both reservoirs.

Table 1 shows the results of physico-chemical analysis in both reservoirs. The concentrations of $\mathrm{NO}_{3}-\mathrm{N}$ and $\mathrm{PO}_{4}-\mathrm{P}$ measured in both reservoirs during the present study were persistently higher than those recorded by previous workers at Khartoum. For instance in April 2016 and April 2017 the concentrations of $\mathrm{NO}_{3}$ 
$\mathrm{N}$ and $\mathrm{PO}_{4}-\mathrm{P}\left(326-550 \mu \mathrm{g} \mathrm{NO} \mathrm{NO}_{3}-\mathrm{N} \mathrm{L}^{-1}\right.$ and $\left.80-160 \mu \mathrm{g} \mathrm{PO}_{4}-\mathrm{P} \mathrm{L}^{-1}\right)$ were exceptionally high to be monitored during this time of the year. In the past 60 years $\mathrm{NO}_{3}-\mathrm{N}$ and $\mathrm{PO}_{4}-\mathrm{P}$ in the Blue Nile at Khartoum during April were severely depleted by heavy phytoplankton growth to less than $29 \mu \mathrm{g} \mathrm{NO} \mathrm{NO}_{3}-\mathrm{N} \mathrm{L}^{-1}$ and undetectable $\mathrm{PO}_{4}-\mathrm{P}$ levels (Talling and Rźoska 1967, Hammerton 1972b, Sinada and Abdel Karim 1984b, Sinada and Yousif 2013). The high concentrations of nutrients measured in the two reservoirs during the present study is attributed to the paucity of phytoplankton which was indicated by very low numbers of algal counts in the two reservoirs (see later).

Vertical Distribution of the Physical and Chemical Variables in the Roseires Reservoir

Water samples were retrieved from the surface, $15 \mathrm{~m}$ and from near the bottom $(\sim 44 \mathrm{~m})$ in the Roseires reservoir only. The three depths were sampled on five occasions during the present study. As Table 2 shows, a weak, possibly unstable, thermal stratification was detected on 26 April 2016. No stratification was observed during the other sampling visits. Temperature, $\mathrm{pH}$, alkalinity, and conductivity remained more or less uniformly distributed throughout the water column. Absence of stratification is attributable to the small water temperature difference between summer and winter in Roseires area. Perhaps wind action was strong enough to mix the water and destroy any stratification.

\section{Spatial Distribution of the Physical and Chemical Variables in the Two Reservoirs}

An attempt was made to determine the spatial distribution of the physical and chemical variables in the two reservoirs by sampling five locations in each reservoir. The Coefficient of variation values of $<0.3$ indicate that there are no significant differences in physical and chemical variables among the sampling sites in Sennar or those in Roseires reservoir. The environmental variables measured were more or less evenly distributed in the various sampling sites in each reservoir (not shown here).

\section{Phytoplankton Species Diversity}

\section{Qualitative Results}

List of algae present in the plankton of Sennar and Roseires reservoirs and their occurrence at different sampling dates are given in Table 3. Five phytoplankton groups were represented in the two reservoirs though in very small numbers. These groups were Bacillariophyta, Cyanobacteria, Chlorophyta, Euglenophyta, and Pyrrophyta. Bacillariophyta were qualitatively dominant, while Cyanobacteria were subdominant in the two reservoirs.

A total of 39 taxa were encountered in the plankton of the two reservoirs during the present study. In terms of species, Bacillariophyta were the richest taxonomic group with 17 taxa, followed by Cyanobacteria (11 taxa), Chlorophyta (7 taxa), Euglenophyta (3 taxa), and Pyrrophyta (1 taxon). As expected, the species composition was more or less similar in both reservoirs. 
Table 1. Physical and Chemical Variables Recorded in Surface Waters Collected from Sennar and Roseires Reservoirs during the Study Period

\begin{tabular}{|c|c|c|c|c|c|c|c|c|c|c|}
\hline \multirow[b]{2}{*}{ Physico-chemical variables } & \multicolumn{5}{|c|}{ Sennar reservoir } & \multicolumn{5}{|c|}{ Roseires reservoir } \\
\hline & $\begin{array}{c}\text { Feb } \\
2016\end{array}$ & $\begin{array}{c}\text { Apr } \\
2016\end{array}$ & $\begin{array}{l}\text { Nov } \\
2016\end{array}$ & $\begin{array}{c}\text { Apr } \\
2017\end{array}$ & $\begin{array}{c}\text { Dec } \\
2017\end{array}$ & $\begin{array}{c}\mathrm{Feb} \\
2016\end{array}$ & $\begin{array}{c}\text { Apr } \\
2016\end{array}$ & $\begin{array}{l}\text { Nov } \\
2016\end{array}$ & Apr 2017 & Dec 2017 \\
\hline Temperature $\left({ }^{\circ} \mathrm{C}\right)$ & 22.0 & 30.0 & 27.6 & 29.8 & 24.8 & 26.6 & 29.2 & 30.3 & 27.8 & 26.3 \\
\hline Secchi transparency $(\mathrm{cm})$ & 15 & 45 & 15 & 70 & 60 & 30 & 100 & 35 & 100 & 85 \\
\hline Conductivity $\left(\mu \mathrm{Scm}^{2}\right)$ & 113 & 122 & 110 & 159 & 120 & 111 & 120 & 101 & 155 & 121. \\
\hline $\mathrm{pH}$ (Units) & 8.4 & 7.8 & 7.9 & 7.8 & 8.0 & 8.4 & 8.0 & 7.9 & 7.7 & 8.5 \\
\hline Alkalinity (meq L ${ }^{-1}$ ) & 3.20 & 3.12 & 3.20 & 2.00 & 1.3 & 3.12 & 3.20 & 3.04 & 1.90 & 1.2 \\
\hline $\mathrm{NO}_{3}-\mathrm{N}\left(\mu \mathrm{g} \mathrm{L}^{-1}\right)$ & 350 & 520 & 442 & 355 & 500 & 377 & 550 & 348 & 326 & 440 \\
\hline $\mathrm{PO}_{4}-\mathrm{P}\left(\mu \mathrm{g} \mathrm{L}^{-1}\right)$ & 160 & 140 & 110 & 90 & 50 & 150 & 160 & 70 & 80 & 70 \\
\hline Sodium (mg/L) & - & 6.8 & 6.4 & 7.4 & - & 6.5 & 6.3 & 6.4 & 7.1 & - \\
\hline Potassium (mg/L) & - & 4.9 & 2.6 & 4.5 & - & 2.9 & 4.7 & 2.2 & 4.7 & - \\
\hline Calcium $(\mathrm{mg} / \mathrm{L})$ & 15.7 & - & 16.7 & 19.4 & 7.5 & 12.9 & - & 14.7 & 18.2 & 5.9 \\
\hline Magnesium (mg/L) & 34.4 & - & - & 24.0 & 22.9 & 33.2 & - & - & 32.0 & 30.8 \\
\hline Cadmium $\left(\mu \mathrm{g} \mathrm{L}^{-1}\right)$ & 1.0 & - & - & ND & ND & 0.5 & - & - & ND & ND \\
\hline Chromium $\left(\mu \mathrm{g} \mathrm{L}^{-1}\right)$ & 22.8 & - & - & ND & 12.5 & 32.6 & - & - & ND & 58.3 \\
\hline Cobalt $\left(\mu \mathrm{g} \mathrm{L}^{-1}\right)$ & 18.0 & - & - & 60.0 & ND & 21.6 & - & - & 79.0 & ND \\
\hline Copper $\left(\mu \mathrm{g} \mathrm{L}^{-1}\right)$ & 24.2 & - & - & 7.0 & 18.2 & 24.2 & - & - & 6.0 & 18.2 \\
\hline Ferrous (mg/L) & 0.2 & - & - & 0.38 & 0.29 & 0.1 & - & - & 0.20 & 0.64 \\
\hline Lead $\left(\mu \mathrm{g} \mathrm{L}^{-1}\right)$ & ND & - & - & ND & ND & ND & - & - & 8 & ND \\
\hline Manganese $\left(\mu \mathrm{g} \mathrm{L}^{-1}\right)$ & 4.2 & - & - & ND & 8.9 & 13.6 & - & - & ND & $\mathbf{1 1 . 5}$ \\
\hline Zinc $\left(\mu \mathrm{g} \mathrm{L}^{-1}\right)$ & 2.1 & - & - & 1.2 & ND & 2.9 & - & - & ND & 3.9 \\
\hline Chlorophyll-a $\left(\mu \mathrm{g} \mathrm{L}{ }^{-1}\right)$ & ND & ND & ND & ND & $>1$ & ND & ND & ND & ND & ND \\
\hline
\end{tabular}

ND= Not Detected. 
Table 2. Physical and Chemical Data Recorded in Waters Collected from Three Depths in Roseires Reservoir during the Periods February 2016, April 2016, November 2016, April 2017 and December 2017

\begin{tabular}{|c|c|c|c|c|c|c|}
\hline \multirow{2}{*}{$\begin{array}{c}\text { Environmental } \\
\text { variables }\end{array}$} & \multirow{2}{*}{$\begin{array}{c}\text { Depth } \\
(\mathbf{m})\end{array}$} & \multicolumn{5}{|c|}{ Roseires reservoir } \\
\cline { 2 - 7 } & & $\begin{array}{c}\text { Feb } \\
2016\end{array}$ & $\begin{array}{c}\text { Apr } \\
2016\end{array}$ & $\begin{array}{c}\text { Nov } \\
2016\end{array}$ & $\begin{array}{c}\text { Apr } \\
2017\end{array}$ & $\begin{array}{c}\text { Dec } \\
2017\end{array}$ \\
\hline \multirow{3}{*}{ Temperature $\left({ }^{\circ} \mathrm{C}\right)$} & surface & $\mathbf{2 6 . 6}$ & $\mathbf{2 9 . 2}$ & $\mathbf{3 0 . 3}$ & $\mathbf{2 7 . 8}$ & $\mathbf{2 6 . 3}$ \\
\cline { 2 - 7 } & 15 & $\mathbf{2 8 . 2}$ & $\mathbf{2 9 . 1}$ & $\mathbf{3 0 . 0}$ & $\mathbf{2 7 . 8}$ & $\mathbf{2 6 . 4}$ \\
\cline { 2 - 7 } & 44 & $\mathbf{2 5 . 1}$ & $\mathbf{2 8 . 5}$ & $\mathbf{2 9 . 7}$ & $\mathbf{2 8 . 0}$ & $\mathbf{2 7 . 8}$ \\
\hline \multirow{3}{*}{$\begin{array}{c}\text { Conductivity } \\
\left(\mu \mathrm{Scm}^{2}\right)\end{array}$} & surface & $\mathbf{1 1 1}$ & $\mathbf{1 2 0}$ & $\mathbf{1 0 1}$ & $\mathbf{2 7 6}$ & $\mathbf{2 1 3}$ \\
\cline { 2 - 7 } & 15 & $\mathbf{1 1 1}$ & $\mathbf{1 2 0}$ & $\mathbf{1 1 5}$ & $\mathbf{2 7 6}$ & $\mathbf{2 1 4}$ \\
\cline { 2 - 7 } & 44 & $\mathbf{1 1 3}$ & $\mathbf{1 2 2}$ & $\mathbf{1 1 7}$ & $\mathbf{2 8 1}$ & $\mathbf{2 1 5}$ \\
\hline \multirow{3}{*}{$\mathrm{pH}($ Units) } & surface & $\mathbf{8 . 4}$ & $\mathbf{8 . 0}$ & $\mathbf{7 . 9}$ & $\mathbf{7 . 7}$ & $\mathbf{8 . 5}$ \\
\cline { 2 - 7 } & 15 & $\mathbf{8 . 2}$ & $\mathbf{8 . 1}$ & $\mathbf{7 . 9}$ & $\mathbf{7 . 1}$ & $\mathbf{8 . 1}$ \\
\cline { 2 - 7 } & 44 & $\mathbf{8 . 5}$ & $\mathbf{8 . 0}$ & $\mathbf{7 . 8}$ & $\mathbf{7 . 2}$ & $\mathbf{8 . 1}$ \\
\hline \multirow{3}{*}{$\begin{array}{c}\text { Alkalinity } \\
\left(\text { meq L }{ }^{-1}\right)\end{array}$} & surface & $\mathbf{3 . 1 2}$ & $\mathbf{3 . 2 0}$ & $\mathbf{3 . 0 4}$ & $\mathbf{1 . 9 0}$ & $\mathbf{1 . 2 0}$ \\
\cline { 2 - 7 } & 15 & $\mathbf{3 . 0}$ & $\mathbf{1 . 9 5}$ & $\mathbf{1 . 5 0}$ & $\mathbf{1 . 9 0}$ & $\mathbf{1 . 3 0}$ \\
\cline { 2 - 7 } & 44 & $\mathbf{3 . 0}$ & $\mathbf{3 . 3 8}$ & $\mathbf{1 . 5 0}$ & $\mathbf{1 . 9 0}$ & $\mathbf{1 . 4 0}$ \\
\hline
\end{tabular}

Aulacoseira was represented by A. distans, A. granulata, A. granulata var. angustissima, A. agassizii, and a species identified tentatively as $A$. ambigua?. The diatom community structure is similar to that observed by Sinada and Yousif (2012) in the Blue Nile at Khartoum. This may indicate that the inocula of the recurrent annual Aulacoseira peaks recorded at Khartoum originate from the upper reaches of the Blue Nile. Other diatoms recorded in the two reservoirs were also rarely seen in the net samples during the present study (Table 3).

Cyanobacteria were represented in the two reservoirs by Anabaena flos-aquae f. spiroides, Aphanocapsa sp., Aphanotheca sp., Chroococcus sp., Gloeotrichia sp., Merismopedia sp., Microcystis aeruginosa, Microcystis incerta, Oscillatoria spp., and Rivularia sp. These Cyanobacteria were rarely seen in the net samples collected from both reservoirs. Anabaena flos-aquae f. spiroides and Microcystis aeruginosa were common in the Blue Nile at Khartoum often developing profuse growth during December - February (Sinada unpublished data, Sinada and Yousif 2012). Gloeotrichia echinulata and Rivularia sp. which occurred on different occasions in the two reservoirs were not reported before in the Nile within Sudan.

Chlorophyta was represented by seven taxa in the plankton. These species were rarely seen in the net samples.

Euglenophyta was represented by two species of Trachelomonas and one species of Euglena while Pyrrophyta was represented by one species of Glenodinium (Table 3).

\section{Quantitative Results}

Unlike conditions observed during 1967 - 1970 by Hammerton (1971c, d, 1972a) no single algal species was dominant during the present study. Algal numbers were present in extremely unexpected low numbers in both Reservoirs throughout the study period. Although encountered in very small numbers, it is striking to record 15 algal taxa in Sennar reservoir at the end of the study in December 2017, while no alga was seen in the net samples collected from 
Roseires reservoir during the same visit. In general, more algal taxa were collected from Sennar reservoir (32 taxa) than from Roseires reservoir (22 taxa). Although needs to be verified by intensive sampling in selected stretches of the Blue Nile between the tail of Sennar reservoir and Roseires Dam, it may be assumed that not all inocula of algal taxa in Sennar Dam and downstream to Khartoum originate from Roseires reservoir.

Glenodinium sp. appeared only in Sennar reservoir in December 2017 exhibiting the highest count of 36 cells $\mathrm{mL}^{-1}$ exceeding those of Aulacoseira granulata. The same species of Glenodinium was reported in the Blue Nile at Khartoum by Sinada (1972) and Sinada and Yousif (2012) though in negligible numbers.

Aulacoseira granulata which was dominant in the two reservoirs throughout the growth seasons (November - May) of 1966 - 1970 showing peaks in the range of $1.5 \times 10^{3}-1.2 \times 10^{4}$ cells $\mathrm{mL}^{-1}$ (Hammerton 1971c, d, 1972a), rarely exceeded 20 cells $\mathrm{mL}^{-1}$ during the present study. Similarly, Table 3 shows that Anabaena flosaquae, which co-dominated the phytoplankton in the two reservoirs throughout much of the growing seasons during 1966-1970 was rarely seen during the present study. The conditions during the present study were reminiscent of the phytoplankton population in $400 \mathrm{~km}$ section of the river upstream of Sennar reservoir reported by Talling and Rźoska (1967) before the construction of Roseires Dam where Aulacoseira granulata and Anabaena flos-aquae, numbers did not exceed 20 cells $\mathrm{mL}^{-1}$ before entering Sennar reservoir.

The scarcity of planktonic algae in Sennar and Roseires reservoirs during the study period, despite of high nutrient concentrations may be attributed to the unusual high silt content. It is obvious that poor light penetration is the sole factor checking the development of phytoplankton in the two reservoirs during the present study. These conditions in the two reservoirs were no different from those reported in the Blue Nile at Khartoum during the annual phase of the flood period by several workers including Sinada and Abdel Karim (1984a, b) and Sinada and Yousif (2012).

According to Hammerton (1971c, d, 1972a), Roseires reservoir shortly after its construction greatly influenced the phytoplankton composition and density within Sennar reservoir; the total algal biomass in Sennar reservoir was higher than that in Roseires reservoir. However, in the present study the meagre data show that more algal taxa and relatively higher algal counts occurred in Sennar than in Roseires reservoir. No influence is exerted by Roseires Dam on Sennar reservoir during the present study except perhaps the discharge of silty water which decreased Secchi transparency in Sennar reservoir preventing the development of phytoplankton. 
Table 3. List of the Planktonic Algae Encountered in Net Samples Collected from Sennar and Roseires Reservoirs: (+) Rare, and (-) Absent. Numbers Indicate Algal Biomass in terms of Cells or Coils per mL Encountered in Surface Samples Collected from the Central Stations in Sennar and Roseires Reservoirs

\begin{tabular}{|c|c|c|c|c|c|c|c|c|c|c|c|c|}
\hline \multirow[b]{2}{*}{ Species } & \multicolumn{6}{|c|}{ Sennar reservoir } & \multicolumn{6}{|c|}{ Roseires reservoir } \\
\hline & $\begin{array}{c}\text { Dec } \\
2015 \\
\end{array}$ & $\begin{array}{l}\mathrm{Feb} \\
2016\end{array}$ & $\begin{array}{c}\text { Apr } \\
2016\end{array}$ & $\begin{array}{l}\text { Nov } \\
2016\end{array}$ & $\begin{array}{c}\text { Apr } \\
2017\end{array}$ & $\begin{array}{c}\text { Dec } \\
2017\end{array}$ & $\begin{array}{c}\text { Dec } \\
2015\end{array}$ & $\begin{array}{l}\text { Feb } \\
2016\end{array}$ & $\begin{array}{c}\text { Apr } \\
2016\end{array}$ & $\begin{array}{l}\text { Nov } \\
2016\end{array}$ & $\begin{array}{c}\text { Apr } \\
2017\end{array}$ & $\begin{array}{c}\text { Dec } \\
2017\end{array}$ \\
\hline Pandorina morum (O. Müller) Bory & - & - & - & - & - & - & - & + & - & - & - & - \\
\hline P. simplex var. duodenarium (Bailey) Rabenhorst & + & - & - & - & + & - & - & - & - & - & - & - \\
\hline Pediastrum obtusum Lucks & - & - & - & - & - & + & - & - & - & - & - & - \\
\hline Scenedesmus sp. & - & - & - & - & - & 4 & - & - & - & - & - & - \\
\hline Schroederia setigera (Schröder) Lemmermann & - & - & - & - & - & 4 & - & - & - & - & - & - \\
\hline Staurastrum sp. & - & - & + & - & + & - & - & - & - & - & - & - \\
\hline Volvox aureus Ehrenberg & - & - & - & - & - & - & - & - & - & + & - & - \\
\hline Aulacoseira ambigua? (Grunow) Simonsen & + & + & + & + & + & + & - & - & - & + & - & - \\
\hline Aulacoseira distans (Ehrenberg) Simonsen & - & + & - & + & + & 16 & - & + & - & + & - & - \\
\hline Aulacoseira granulata (Ehrenberg) Simonsen & - & 2 & 2 & - & + & 24 & - & + & 4 & + & + & - \\
\hline A. granulata var. angustissima (O. Müller) Simonsen & + & + & + & - & + & + & + & - & + & + & + & - \\
\hline Aulacoseira agassizii (Ostenfeld) Simonsen & - & - & - & - & - & + & - & - & - & - & - & - \\
\hline Cyclotella meneghiniana Kuetz & - & 1 & - & - & - & 4 & - & + & - & - & - & - \\
\hline Gomphonema sp. & - & - & - & + & - & 4 & - & - & - & + & - & - \\
\hline Caloneis amphisbaena (Bory) Cleve & - & + & - & + & - & - & - & - & - & - & - & - \\
\hline Navicula spp & + & - & - & - & - & 4 & + & + & - & - & - & - \\
\hline Nitzschia sp. & - & - & - & - & - & - & - & + & - & - & - & - \\
\hline Pleurosigma sp. & - & - & - & + & - & - & - & - & - & - & + & - \\
\hline $\begin{array}{l}\text { Rhopalodia gibba (Ehrenberg) O. Müller } \\
\text { Ulnaria(formerly Synedra) acus(Kützing) M. Aboal }\end{array}$ & - & - & + & + & - & - & - & - & - & - & + & - \\
\hline Ulnaria acus (Kützing) M. Aboal & - & - & + & - & - & 4 & - & - & - & - & + & - \\
\hline Ulnaria ulna (Nitzsch) Compère & - & - & - & - & - & + & - & - & - & - & - & - \\
\hline Nitzschia sp. & - & - & - & - & - & - & - & + & - & - & - & - \\
\hline Surirella tenera Gregory. & - & - & - & + & - & - & - & - & - & + & - & - \\
\hline Cymatopleurasolea (Bréb.) W. Smith & - & - & - & + & - & - & - & - & - & - & - & - \\
\hline
\end{tabular}




\begin{tabular}{|c|c|c|c|c|c|c|c|c|c|c|c|c|}
\hline Anabaena flos-aquae (Lyngbye) Brébisson f. spiroides & + & - & 2 & - & - & 8 & - & + & - & - & - & - \\
\hline Anabaena spp. & - & - & - & + & - & - & - & - & - & - & - & - \\
\hline Aphanocapsa sp. & - & + & - & - & + & - & - & ++ & - & - & + & - \\
\hline Aphanotheca sp. & - & - & - & - & + & - & - & + & - & - & + & - \\
\hline Chrococcus sp. & - & - & - & - & - & + & - & - & - & - & - & - \\
\hline Merismopedia tenuissima Lemmer & - & - & - & + & - & - & - & + & - & - & - & - \\
\hline Gloeotrichia echinulata P.G.Richter & - & - & + & - & - & - & - & + & - & - & - & - \\
\hline Microcystis aeruginosa( Kützing) Elenkin & - & - & - & - & - & - & - & + & - & - & - & - \\
\hline Microcystis incerta(Lemmer.) Lemmerman & - & - & - & - & - & 4 & - & - & - & - & - & - \\
\hline Oscillatoria spp. & - & + & - & + & - & - & - & ++ & - & - & - & - \\
\hline Rivularia sp. & - & - & + & - & - & - & - & - & + & - & - & - \\
\hline Euglena sp. & - & - & - & - & - & 4 & - & - & - & - & - & - \\
\hline Trachelomonas volvocina (Ehrenb.) Ehrenberg & - & - & - & - & - & 4 & - & - & - & - & - & - \\
\hline Trachelomonas sp. & - & - & - & - & - & + & - & - & - & - & - & - \\
\hline Glenodinium sp. & - & - & - & - & - & 36 & - & - & - & - & - & - \\
\hline
\end{tabular}




\section{Discussion}

The construction of Roseires Dam in 1966, as expected, had its influence upon the ecology of the Blue Nile within Sudan by changing the hydrological regime of the river and creating a reservoir in which current velocity was much reduced and lake conditions were initiated. Previous workers reported major changes in the species composition of the phytoplankton at Khartoum after the construction of Roseires Dam when certain taxa, which dominated the phytoplankton in the 1950s, disappeared and new species appeared in appreciable numbers in early 1970 s and by the turn of the century.

Shortly after the construction of Roseires Dam in 1966, seasonal peaks of the major phytoplankton species were well established and a definite annual cycle could be faithfully predicted at Khartoum. The recurrent annual biological cycles of events in the Blue Nile are greatly influenced by the flood regime and the storage of water in Roseires and Sennar reservoirs, which are controlled by the natural regime of rainfall in the catchment area on the Ethiopian Plateau.

Rźoska et al. (1955), Talling and Rźoska (1967), Sinada (1972), Sinada and Abdel Karim (1984a, b) and Yousif (2004) showed that the annual flood of the Blue Nile is the most important factor limiting the growth of the phytoplankton at Khartoum. The scarcity of planktonic algae during the flood between late June and late October despite of high nutrient concentrations is attributable to the high silt content and poor light penetration. It has been well established that at Khartoum, diatoms (Aulacoseira spp.) were the first to appear in appreciable numbers after the flood, and dominate the phytoplankton during November-December to be replaced successively by peaks of profuse growth of Microcystis and Anabaena during January-February. During March-April green algae preponderated, followed by the recurrent summer maximum of Aulacoseira and Anabaena in May to mid-June before being washed out by the new brown floodwater (Rźoska et al. 1955, Talling and Rźoska 1967, Sinada 1972, Sinada and Abdel Karim 1984a, b, Yousif 2004). We assumed that similar cycles of phytoplankton succession would continue to occur every year in Roseires and Sennar reservoirs and along the whole stretch of the Blue Nile from Sennar to Khartoum as long as the hydrological regime of the river was not significantly altered.

Indeed, throughout the years since the construction of Roseires Dam in 1966 no unusual incidence, which could be confirmed by microscopic examination and sediment load, has been reported except in May 2003 and January 2009. In these two incidents, unprecedented profuse growth of the cyanobacterium Anabaena flos-aquae, attributed with caution to incipient eutrophication, occurred in the Blue Nile at Khartoum and along the whole stretch of the Blue Nile from Khartoum to Sennar Dam. Otherwise, there was a definite highly predictable phytoplankton cycle which almost faithfully repeated itself every year since the construction of Roseires Dam in 1966.

However, an unusual event, which was a deviation from the repeated and predictable cycle, occurred during the present study in 2016-2017. We expected that algae in Roseires and Sennar dams and at Khartoum should have started to appear in late October-early November 2015 (when most of the silt should have 
settled downs and water should have become clear) as they faithfully did for the last fifty years since the construction of Roseires Dam. Nevertheless, algae did not appear let alone in large numbers as we expected. Unlike conditions observed by Hammerton (1971a, b, c, 1972a) after the construction of Roseires Dam, throughout the period of the present study, visible quantities of silt and fine sand remained suspended in the water column of the two reservoirs as well as water samples collected from the Blue Nile at Khartoum. The river at Khartoum did not support any appreciable algal growth while turbidity and concentrations of nutrients remained unexpectedly high and continued to be high with no signs of any algal growth during 2016 and 2017. These conditions, which prevailed throughout the present study, are reminiscent of the annual flood season at Khartoum during late June-early October. A plausible explanation for the paucity of algae in Sennar, Roseires, and at Khartoum during December 2015-April 2016 was deduced from briefings given by the engineers of Roseires Dam. They briefed us of a different filling system they had adopted during 2015 flood season (JulySeptember) because of low magnitude of flow at El Deim (a monitoring station upstream Roseires reservoir near the Sudanese-Ethiopian border) due to little rainwater received in Ethiopia- the lowest annual rainfall in 30 years. The filling of the reservoir of Roseires Dam started unusually as early as August 2015 - a deviation from operation rules under normal climatic conditions in which filling never started before 1st September or after 26th September each year when most of the silty water was allowed to flow downstream. Possibly the unusual early damming of the highly turbid water in August 2015 contributed to storage of unprecedented large volumes of water, which contain large amounts of silt. Engineers at Roseires and Sennar dams opened the spillways during November and December 2015 to allow the highly turbid water stored in the Roseires reservoir to pass downstream to compensate for shortage of water at Merowe Dam $350 \mathrm{~km}$ north of Khartoum. This seems to be a plausible explanation for the unprecedented turbid water reaching Khartoum during December 2015 - April 2106. The absence of algae in the Blue Nile at Khartoum during November 2015 April 2016 was attributed to the flow of turbid water which did not allow silt to settle out of suspension thus preventing the growth of algae.

Similar conditions of paucity of algae were observed during sampling visits to Sennar and Roseires reservoirs in April 2017 and December 2017. By late December 2017, the Roseires reservoir reached a full supply level of $490.00 \mathrm{~m}$ a.s.l. (Roseires dam Resident Engineer, Personal Communication, 2017). The full supply level before the heightening of the dam never exceeded $481.00 \mathrm{~m}$ a.s.l. No explanation can be given for the paucity of algae in the reservoirs and at Khartoum during November-December 2017 except perhaps the relatively high content of suspended silt, which prevented the development of phytoplankton.

\section{Conclusions}

In conclusion, the physical and chemical characteristics of the water of Sennar and Roseires reservoirs did not change during the past fifty years. No unwelcome 
enrichment, which might occur because of introduction of industrial contaminants or diffusion of agrochemicals into Sennar and Roseires reservoirs and into the course of the Blue Nile upstream the two dams, was detected. It is pleasing that the waters of Sennar and Roseires reservoirs are of excellent quality for drinking being well within allowable limits set by the Sudanese Standards and Metrology Organization (SSMO 2008). The concentrations of heavy metals are within permissible limits set by WHO for drinking water (WHO 2011).

Fortunately, there was no regular build-up of heavy metal concentrations in the Blue Nile since pollutants entering the river, if any, are washed away with the annual flood. Environmentalists are alarmed that Nile pollution may become a problem after the completion of the Grand Ethiopian Renaissance Dam (GERD) when only a fraction of the Blue Nile water may reach Sudan allowing for the accumulation and regular build-up of pollutants. A similar problem of Nile pollution was reported in Egypt after the completion of Aswan High Dam when only $10 \%$ of River Nile water flows downstream Aswan High Dam failing to annually flush pollutants out of the Nile system within Egypt into the Mediterranean.

During the present study the impact of the heightening of Roseires Dam on the development of phytoplankton in the Blue Nile was detected. Visual observations as well as water samples collected from the two reservoirs and from the Blue Nile at Khartoum showed that recurrent peaks reported by previous workers did not appear in the Blue Nile while turbidity and concentrations of nutrients remained unexpectedly high with no signs of any algal bloom during 2016 - 2017. No explanation can be given for the scarcity of algae in the large masses of water stored in Roseires reservoir (full supply level of $490.00 \mathrm{~m}$ a.s.l.) during 2017 except perhaps for the effect of the high silt content which remained suspended for a longer time than usual after the flood subsided.

\section{Acknowledgments}

We gratefully acknowledge the funding of this work by the Ministry of higher Education and Scientific Research, Sudan. The authors would like to express appreciation for the support of the Sudanese Electricity Distribution Company Ltd. and Dams Implementation Unit for provision of accommodation in Damazin and Sennar during our field visits. Our thanks go to the top engineers of both Roseires and Sennar dams for providing a tugboat and a power-motorized fishing boat.

\section{References}

Allen SE (1989) Chemical Analysis of Ecological Materials. Second Edition. Oxford: Blackwell Scientific Publications.

Brook AJ (1954) A Systematic Account of the Phytoplankton of the Blue and White Nile. Annals and Magazine of Natural History 12(VII): 648-656. 
Cleve-Euler A (1951) Die Diatomeen von Schweden und Finland. [The Diatoms of Sweden and Finland.] Bibliotheca Phycologica Band 5. New York: 3301 Lehre Verlag von J Cramer.

Desikachary TV (1959) Cyanophyta. New Delhi: ICAR Monographs.

Hammerton D (1970a) Water Characteristics and Phytoplankton Production. Eleventh Annual Report. University of Khartoum: Hydrobiological Research Unit, 1963-1964, 5-12.

Hammerton D (1970b) Longitudinal Survey of the Blue Nile. Twelfth Annual Report. University of Khartoum: Hydrobiological Research Unit, 1964-1965, 5-8.

Hammerton D (1971a) Blue Nile Survey. Studies of Primary Production in the River Nile. Thirteenth Annual Report. University of Khartoum: Hydrobiological Research Unit, 1965-1966, 16-17.

Hammerton D (1971b) Blue Nile Survey. Fourteenth Annual Report. University of Khartoum: Hydrobiological Research Unit, 1966-1967, 3-9.

Hammerton D (1971c) Blue Nile Survey. Fifteenth Annual Report. University of Khartoum: Hydrobiological Research Unit, 1967-1968, 5-14.

Hammerton D (1971d) Blue Nile Survey. Sixteenth Annual Report. University of Khartoum: Hydrobiological Research Unit, 1968-1969, 5-9.

Hammerton D (1972a) Blue Nile Survey. Seventeenth Annual Report. University of Khartoum: Hydrobiological Research Unit, 1969-1970, 6-10.

Hammerton D (1972b) The Nile River: A Case History. In River Ecology and Man. Edited by RT Oglesby, CA Carlson, JA McCann. New York and London: Academic Press.

Krammer K (1991a) Morphology and Taxonomy in Some Taxa of the Genus Aulacoseira Thwaites (Bacillariophyceae) I. Aulacoseira distans and Similar Taxa. Nova Hedwigia 52(1-2): 89-112.

Krammer K (1991b) Morphology and Taxonomy in Some Taxa of the Genus Aulacoseira Thwaites (Bacillariophyceae) II. Taxa in the A. Granulata, Italica- and LirataGroups. Nova Hedwigia 53(3-4): 477-496.

Lund JWG, Le Cren ED, Kipling C (1958) The Inverted Microscope Method of Estimating Algal Numbers and the Statistical Basis of Estimation by Counting. Hydrobiologia 11(2): 143-170.

Mackereth FJ, Heron J, Talling JF (1978) Water Analysis: Some Revised Methods for Limnologists. Freshwater Biological Association Scientific Publication No. 36.

Omer AYA, Ali YSA, Roelvink JA, Dastgheib A, Paron P, Crosato A (2015) Modelling of Sedimentation Processes inside Roseires Reservoir (Sudan). Earth Surface Dynamics 3(Apr): 223-238.

Prescott GW (1962) Algae of the Western Great Lakes Area. Dubuque, Iowa: Wm C. Brown Co. Inc.

Rźoska J, Brook AJ, Prowse GA (1955) Seasonal Plankton Development in the White and Blue Nile near Khartoum. Verhandlungen der Internationalen Vereinigung fur Theoretische und Angewandte Limnologie 12(1): 327-334.

Sheath RG, Wehr JD (2015) Introduction to the Freshwater Algae. In Freshwater Algae of North America. Edited by JD Wehr, RG Sheath, JP Kociolek. San Diego: Academic Press, 2015, 1-11.

Sinada F (1972) Ecological and Productivity Studies on the Phytoplankton of the Blue and White Nile at Khartoum. M.Sc. Thesis. Khartoum: Faculty of Science, University of Khartoum.

Sinada F, Abdel Karim AG (1984a) Physical and Chemical Characteristics of the Blue Nile and the White Nile at Khartoum. Hydrobiologia 110(1): 21-32. 
Sinada F, Abdel Karim AG (1984b) A Quantitative Study of the Phytoplankton in the Blue and White Nile at Khartoum. Hydrobiologia 110(1): 47-55.

Sinada F, Yousif S (2012) An Updated Checklist of the Phytoplankton of the Blue Nile at Khartoum. Sudan Journal of Science 5(1). http://sciencejournal.uofk.edu.

Sinada F, Yousif S (2013) Water Chemistry and Quality of the Blue Nile at Khartoum. Sudan Journal of Science 5(2): 31-43.

SSMO - Sudanese Standards and Metrology Organization (2008) Drinking Water Guidelines Bulletin. Sudan.

Strickland JDH, Parsons TR (1977) A Practical Handbook of Seawater Analysis 167. Second Edition. Ottawa: Queen's Printer. Fisheries Research Board of Canada Bulletin.

Talling JF, Rźoska J (1967) The Development of Plankton in relation to Hydrological Regime in the Blue Nile. Journal of Ecology 55(3): 637-662.

WHO (2011) Guidelines for Drinking - Water Quality. Fourth Edition. Geneva Switzerland: World Health Organization.

Yousif S (2004) Observations on the Phytoplankton and Water Quality of the Blue Nile at Khartoum. M.Sc. Unpublished Thesis. Khartoum: University of Khartoum. 



\title{
Effect of Irrigation Canal Sediments, Humate Fertilizer and Irrigation Interval on Wheat Performance in Desert Soils
}

\author{
By Ali Abdalla Mohammed", Asim Osman Elzubeir ${ }^{*}$, \\ Muawia Elbedawi Hamad ${ }^{\ddagger}$ \& Abdalla Ibrahim Elhagwa
}

A field study was conducted for two successive winter seasons; 2013/14 and 2014/15, at the Research Farm of the National Institute of Desert Studies (University of Gezira), New Hamdab Scheme, Northern State of Sudan. The objective was to investigate the effect of treatments interactions of application of irrigation canal sediments, humate fertilizer and irrigation interval on wheat (Triticum aestivum L.) growth and yield attributes in high terrace soils. Treatments were arranged in a split-split plot design with four replicates. Application of irrigation canal sediments constituted three rates $(0,30$ and 60 ton/ha), three rates of humate fertilizer were used $(0,2$ and $4 \mathrm{~kg} / \mathrm{fed})$ and two levels of irrigation interval were imposed (10 and 15 days). The soil of the experimental site is characterized by high amount of sand and low chemical soil fertility and the climatic zone of the area is described as desert. The results showed significant differences $(P \leq 0.05)$ due to the interactions effect of these three factors on number of plants $/ \mathrm{m}^{2}$, plant height, number of spikes $/ \mathrm{m}^{2}$, number of seeds/spike, 1000-seeds weight, grain yield and straw yield for both seasons. Also, treatments interactions had highly significant effects $(P \leq 0.01)$ on number of tillers $/ \mathrm{m}^{2}$ and harvest index, and very highly significant differences $(P \leq 0.001)$ on biological yield of wheat in both seasons. The best combination of irrigation canal sediments, humate fertilizer and irrigation interval which gave the highest values of growth, yield and yield components of wheat for both seasons; except for number of plants $/ \mathrm{m}^{2}$ in the second season and straw yield in both seasons, was the interaction effect of application of 60 ton/ha irrigation canal sediments, $4 \mathrm{~kg} / f e d$ humate fertilizer and 10 days irrigation interval.

Keywords: Aridisols, Humic Substances, Irrigation Water Scheduling, Northern State (Sudan), Soil Reclamation, Triticum Aestivum L.

\section{Introduction}

Wheat (Triticum aestivum L.) is mainly grown in the Sudan under irrigation, during winter months; its cultivation has recently expanded into latitudes lower than $15^{\circ} \mathrm{N}$ (Ageeb et al. 1996, Almeu and Hazem 2011). Demand for wheat in the past was not very high because the nutritional habit of the majority of the Sudanese people was based mainly on sorghum. At present, wheat consumption has increased and the government is attempting to attain self-sufficiency in this commodity. In order to fulfill this objective, it is necessary to increase the

\footnotetext{
* National Institute of Desert Studies, University of Gezira, Sudan.

${ }^{\dagger}$ Professor, Faculty of Agricultural Science, University of Dongola, Sudan.

${ }^{\star}$ Faculty of Agricultural Sciences, University of Gezira, Sudan.

- Agricultural Research Corporation, Wad Medani, Sudan.
} 
cultivated area and obtain maximum output from each unit volume of water consumed.

Increasing wheat productivity is a national target in Sudan to fill the gap between wheat consumption and production. However, lack of yield stability over seasons and locations has remained a great challenge to both research and production management (Babiker and Faki 1994). Wheat production under semiarid conditions of Sudan is now a success. Grain yield of over five ton/ha were obtained with high irrigation, either from river flows or lifted from the River Nile and wells using diesel pumps (Farah et al. 1994).

New Hamdab Scheme (Northern State of Sudan) faces problems of mud accumulation in all irrigation canals. Enormous amounts of sediments are being removed during cleaning of these canals. Disposal of this sediment is a real problem. Sediments accumulated in irrigated canals contain high quantities of clay and might be a useful as a soil conditioner (Mubarak et al. 2014).

There is more interest in utilizing soils of low or marginal productivity (e.g., sandy soils) for crop production to match the demand for agricultural products (Tester 1990). The major constraints of these soils are their water retention, high water transmission and low nutrient content. The nutrients- poor sandy soils could be productive if their content of organic matter can be increased. The maintenance of proper soil organic matter levels to sustain soil productivity is important and humic acid probably being the largest single soil organic matter that may cope up with the objective.

In many of the arid and semi-arid regions in the world (including Sudan) water is likely to become the most critical resource and the most limiting factor of the production of food (Elquosy 1998). Also, Ageeb (1994) stated that, irrigation water and irrigation practices are factors which have always limited wheat productivity. Detection of crop water stress is critical for efficient irrigation water management, especially in the semi-arid regions. On the other hand, irrigation water is becoming increasingly scares; this highlights the importance of the effective and efficient use of this resource. In truly arid regions; such as the Northern State (Sudan), all water of crops must be met with irrigation. In these areas, all phases of crop production are adjusted for irrigation. Regardless of the method used to deliver water, irrigation must supply moisture to that part of the soil from which roots absorb it. The timing and amount of irrigation should be regulated to assure optimum crop yield.

Recent years have witnessed a great intensification of land and water use in an effort to increase agricultural production in many parts of the world. This involved application of modern techniques leading to an increased farming efficiency. Therefore, an experimental study was conducted at El Multaga area, Northern State (Sudan) under high terrace soils to evaluate the interaction effect of application of irrigation canal sediments, humate fertilizer and irrigation interval to improve wheat productivity in the area. 


\section{Materials and Methods}

\section{Description of the Experimental Site}

Field experiments were carried out during two consecutive winter seasons (2013/14 and 2014/15) at the National Institute of Desert Studies Research Farm (University of Gezira), New Hamdab Scheme, Northern State of Sudan which lies at latitude $17^{\circ} 55^{\prime} \mathrm{N}$ and longitude $31^{\circ} 10^{\prime} \mathrm{E}$. The climatic zone of the area is described as desert, which is characterized by high temperature in summer, low temperature in winter and low rainfall (Habiballa and Ali 2010). The soil of the experimental site belongs to El Multaga soil series, texture of the control section is fine loamy, its structure is strong wide columnar flat breaks into medium and fine subangular blocky. It is classified as Vertic Haplocambids, fine loamy, mixed, hyperthermic. Generally, the soil chemical fertility is low (Land and Water Research Centre 1999).

\section{Experimental Design and Treatments}

Three treatments were arranged in a split-split-plot design that completely randomized within four replicates. The experimental area for each replicate was divided into three blocks, each block was divided into two strip plots and each was further divided into three subplots. Three meters wide areas were left between blocks as buffer zones. The area of each sub- sub plot (experimental unit) was 42 $\mathrm{m}^{2}(6 \times 7 \mathrm{~m})$. The experimental units were two meter apart from each other, with a total number of 18 experimental units. The main plots were assigned to irrigation interval with two levels, the sub- plots were assigned to irrigation canal sediments application with three rates and sub- sub plots were assigned to humate fertilizer application with three rates. This setup was replicated four times. The experimental procedures were the same for both seasons. The applied treatments and their abbreviations are illustrated in Table 1. The experiment was part of research study to investigate the effects of applied treatments and their interactions on wheat performance and soil physical and chemical properties in the area.

Table 1. Treatments Application and their Abbreviations

\begin{tabular}{|c|c|c|}
\hline Treatment & Operation & Abbreviation \\
\hline \multirow{2}{*}{$\begin{array}{l}\text { Irrigation interval } \\
\text { (I) }\end{array}$} & 10 days & $\mathrm{I}_{1}$ \\
\hline & 15 days & $\mathrm{I}_{2}$ \\
\hline \multirow{3}{*}{$\begin{array}{l}\text { Irrigation canal sediments } \\
\text { (S) }\end{array}$} & 0 ton/ha & $\mathrm{S}_{1}$ \\
\hline & 30 ton/ha & $\mathrm{S}_{2}$ \\
\hline & 60 ton/ha & $\mathrm{S}_{3}$ \\
\hline \multirow{3}{*}{$\begin{array}{l}\text { Humate fertilizer } \\
\text { (H) }\end{array}$} & $0 \mathrm{~kg} / \mathrm{fed}$ & $\mathrm{H}_{1}$ \\
\hline & $2 \mathrm{~kg} / \mathrm{fed}$ & $\mathrm{H}_{2}$ \\
\hline & $4 \mathrm{~kg} / \mathrm{fed}$ & $\mathrm{H}_{3}$ \\
\hline
\end{tabular}

$\mathrm{I}_{1} \times \mathrm{S}_{1} \times \mathrm{H}_{1}=$ as the controlled treatments.

fed=Feddan $(1 \mathrm{fed}=0.42 \mathrm{ha})$. 


\section{Cultural Practices}

The land after the site had been selected and before the application of the treatments, was freed from weeds and crop residues. The soil amendment materials; irrigation canal sediments, and humate fertilizer were spread at rates mentioned before, incorporated with the soil. Land preparation was done with tractor-mounted disc plough to ensure satisfactory seedbed. Also, site of study area was levelled to facilitate irrigation and ensure uniform soil moisture content distribution.

Wheat variety Wadi Elneel was used in this study. Sowing was done manually by digging on $20^{\text {th }}$ of November (winter season) for both agricultural seasons, with seed rate of $120 \mathrm{~kg} / \mathrm{ha}$, at $0.2 \mathrm{~m}$ inter-row spacing. Nitrogen and Phosphorus were added as recommended by Agricultural Research Corporation (Sudan). Harvest started when signs of maturity of wheat crop were observed. The crop was harvested on $21^{\text {st }}$ of March for both seasons. The irrigation was carried out every 10 and 15 days intervals; the ten days was considered the conventional practice, whereas the fifteen days was considered mild stress. According to Erneo (2007) who concluded that, wheat water requirements per season was $635 \mathrm{~mm}$, therefore, irrigation was applied with rate of $5.9 \mathrm{~mm} /$ day. Irrigation water was measured at the plot level by Parshall flume with its calibration curve. Water delivered to plots with constant water head. The source of water supply for farm irrigation system was River Nile.

\section{Collection of Data}

Plant samples were collected randomly from each experimental unit (sub- sub plot) and then growth and yield parameters were determined.

\section{$\underline{\text { Number of Plant } / \mathrm{m}^{2}}$}

Number of plants $/ \mathrm{m}^{2}$ were counted for each season at 10 days after sowing in three different positions in each sub- sub plot using a steel frame of one meter square. Then the mean number of plant $/ \mathrm{m} 2$ with respect to each treatment was calculated.

\section{$\underline{\text { Plant Height }}$}

Ten whole plant samples were selected randomly from each sub- sub plot at maturity stage, each season. Plant height as expressed in $\mathrm{cm}$ was measured from the tip of the spike to the soil surface, and then the mean was calculated.

Number of Spike/m²

Using steel frame of one meter square, the number of spikes $/ \mathrm{m}^{2}$ was calculated at harvest time for each sub- sub plot as an average number of three readings. 
$\underline{\text { Number of Tillers } / \mathrm{m}^{2}}$

Number of tillers $/ \mathrm{m}^{2}$ was obtained by subtracting the number of plants $/ \mathrm{m}^{2}$ at 10 days after sowing from the number of spikes $/ \mathrm{m}^{2}$ at harvest time, each season.

\section{Spike Length}

Ten spikes samples were selected randomly from each sub- sub plot at maturity stage and the spike length $(\mathrm{cm})$ was measured, and then the mean spike length was obtained for each treatment.

\section{Number of Seeds/Spike}

Samples of ten spikes were selected randomly from each sub- sub plot at maturity stage and seeds per spike were counted, and then the mean number of seeds/spike was obtained.

\section{0 - Seeds Weight}

A number of thousand seeds were picked randomly from seeds of each subsub plot. The seeds were weighed with a sensitive balance, and mean 1000-seeds weight $(\mathrm{g})$ was obtained for each treatment.

\section{Biological Yield per Unit Area}

Plants of the net area of one meter square (using steel frame of one meter square) were cut at the soil surface at harvest time in three different positions in each sub- sub plot, tied in bundles and left to dry by air. After drying, the harvested plants were weighted to obtain the biological yield $(\mathrm{kg} / \mathrm{ha})$ (dry matters plus grains).

\section{Grain Yield per Unit Area}

The biological yield samples were manually threshed and the grain yield as expressed in $\mathrm{kg} / \mathrm{ha}$ was obtained.

\section{Straw Yield per Unit Area}

Also, straw yield (kg/ha) was determined as mentioned by Imran (2010): Straw yield $(\mathrm{kg} / \mathrm{ha})=$ Biological yield $(\mathrm{kg} / \mathrm{ha})-$ Grain yield $(\mathrm{kg} / \mathrm{ha})$

\section{$\underline{\text { Harvest Index }}$}

Harvest index (\%) was obtained using the following formula (Imran 2010):

$$
\text { Harvest index }=\frac{\text { Total grain yield }(\mathrm{kg} / \mathrm{ha})}{\text { Total boilogical yield }(\mathrm{kg} / \mathrm{ha})} \times 100
$$




\section{Statistical Analysis and Interpretation of Data}

Statistical analysis was carried out using a computer software package (MSTAT). Significance of differences among the various characters under study was compared using Duncan's Multiple Range Test (DMRT). Results were presented in tabular forms.

\section{Results and Discussion}

Table 2 shows the mean values of number of plant $/ \mathrm{m}^{2}$ and plant height of wheat crop as affected by treatments interactions for both seasons. The results of the statistical analysis indicated that the interaction of irrigation interval, irrigation canal sediments and humate fertilizer had significant effects $(\mathrm{P} \leq 0.05)$ on number of plants $/ \mathrm{m}^{2}$ when checked early in both seasons. Since the number of plant $/ \mathrm{m}^{2}$ was counted at 10 days after sowing and at that time all experimental units had the same irrigation, therefore, the significant effect of the interaction of the applied treatments on number of plants $/ \mathrm{m}^{2}$ might be due to irrigation canal sediments and humate fertilizer. Also, the effect of interaction of irrigation interval, irrigation canal sediments and humate fertilizer on plant height at maturity stage was checked in both seasons. There were significant effects $(\mathrm{P} \leq 0.05)$ due to the interaction of these three factors on plant height in both seasons.

Table 2. The Mean Effect of Irrigation Interval, Irrigation Canal Sediments and Humate Fertilizer on Wheat Growth Parameters for Both Seasons

\begin{tabular}{|c|c|c|c|c|c|c|}
\hline \multirow{2}{*}{\multicolumn{3}{|c|}{$\begin{array}{c}\text { Treatment } \\
\text { combinations }\end{array}$}} & \multicolumn{2}{|c|}{ No. of plants $/ \mathrm{m}^{2}$} & \multicolumn{2}{|c|}{ Plant height (cm) } \\
\hline & & & $1^{\text {st }}$ Season & $2^{\text {nd }}$ Season & $1^{\text {st }}$ Season & $2^{\text {nd }}$ Season \\
\hline \multirow{9}{*}{$\mathbf{I}_{1}$} & \multirow{3}{*}{$\mathbf{S}_{\mathbf{1}}$} & $\overline{H_{1}}$ & $181^{\operatorname{tg}}$ & $206^{1}$ & $67^{e}$ & $72^{\mathrm{ef}}$ \\
\hline & & $\mathbf{H}_{2}$ & $183^{\text {ef }}$ & $210^{\mathrm{hi}}$ & $71^{\mathrm{d}}$ & $75^{\mathrm{de}}$ \\
\hline & & $\mathbf{H}_{3}$ & $184^{\mathrm{ef}}$ & $227^{f}$ & $74^{\mathrm{bc}}$ & $79^{\mathrm{bcd}}$ \\
\hline & \multirow{3}{*}{$\mathbf{S}_{\mathbf{2}}$} & $\mathrm{H}_{1}$ & $165^{i}$ & $234^{\mathrm{e}}$ & $72^{\mathrm{cd}}$ & $69^{\mathrm{fg}}$ \\
\hline & & $\mathrm{H}_{2}$ & $193^{\mathrm{d}}$ & $242^{\mathrm{d}}$ & $73^{\mathrm{cd}}$ & $80^{\mathrm{bc}}$ \\
\hline & & $\mathrm{H}_{3}$ & $197^{b c d}$ & $269^{\mathrm{a}}$ & $74^{\mathrm{bc}}$ & $81^{\mathrm{bc}}$ \\
\hline & \multirow{3}{*}{$\mathbf{S}_{\mathbf{3}}$} & $\mathrm{H}_{1}$ & $187^{\mathrm{e}}$ & $210^{\mathrm{hi}}$ & $68^{\mathrm{e}}$ & $69^{\mathrm{fg}}$ \\
\hline & & $\mathrm{H}_{2}$ & $199^{\mathrm{bcd}}$ & $234^{\mathrm{e}}$ & $76^{\mathrm{b}}$ & $82^{b}$ \\
\hline & & $\mathbf{H}_{3}$ & $207^{\mathrm{a}}$ & $263^{b}$ & $83^{\mathrm{a}}$ & $89^{\mathrm{a}}$ \\
\hline \multirow{9}{*}{$\mathbf{I}_{2}$} & \multirow{3}{*}{$\mathbf{S}_{1}$} & $\mathrm{H}_{1}$ & $201^{b}$ & $231^{\mathrm{ef}}$ & $53^{h}$ & $60^{\mathrm{h}}$ \\
\hline & & $\mathbf{H}_{2}$ & $206^{\mathrm{a}}$ & $219^{g}$ & $53^{\mathrm{h}}$ & $59^{h}$ \\
\hline & & $\mathbf{H}_{3}$ & $196^{\mathrm{cd}}$ & $229^{\mathrm{ef}}$ & $61^{g}$ & $67^{g}$ \\
\hline & \multirow{3}{*}{$\mathbf{S}_{\mathbf{2}}$} & $\mathrm{H}_{1}$ & $172^{\mathrm{h}}$ & $247^{\mathrm{C}}$ & $49^{i}$ & $58^{\text {hi }}$ \\
\hline & & $\mathrm{H}_{2}$ & $177^{\mathrm{g}}$ & $201^{j}$ & $55^{\mathrm{h}}$ & $54^{1}$ \\
\hline & & $\mathrm{H}_{3}$ & $168^{\text {hi }}$ & $211^{\text {hi }}$ & $62^{\mathrm{fg}}$ & $68^{\mathrm{fg}}$ \\
\hline & \multirow{3}{*}{$\mathbf{S}_{\mathbf{3}}$} & $\mathrm{H}_{1}$ & $200^{\mathrm{bc}}$ & $221^{\mathrm{g}}$ & $53^{\mathrm{h}}$ & $58^{\mathrm{hi}}$ \\
\hline & & $\mathrm{H}_{2}$ & $182^{f}$ & $212^{\text {hi }}$ & $67^{\mathrm{e}}$ & $72^{\text {ef }}$ \\
\hline & & $\mathrm{H}_{3}$ & $184^{\mathrm{ef}}$ & $219^{\mathrm{g}}$ & $71^{\mathrm{d}}$ & $77^{\mathrm{cd}}$ \\
\hline & \multicolumn{2}{|c|}{ DMRT } & $*$ & $*$ & $*$ & $*$ \\
\hline
\end{tabular}

Abbreviations of I, S and $\mathrm{H}$ and their operations as explained in Table 1.

Means followed by the same letter(s) in column are not significantly different at $\mathrm{P} \leq 0.05$.

$*=$ Significantly different at $\mathrm{P} \leq 0.05$. 
Table 3 summarizes the mean effect of irrigation interval, irrigation canal sediments and humate fertilizer on wheat yield components parameters on both seasons. The results indicated that the interaction of these three factors had significant effects $(\mathrm{P} \leq 0.05)$ on number of spike $/ \mathrm{m}^{2}$, number of seeds/spike and 1000 -seeds weight in both seasons. The analysis of variances for both seasons evident that the number of tillers $/ \mathrm{m}^{2}$ was highly significantly affected $(\mathrm{P} \leq 0.01)$ by the interaction of the studied treatments. However, treatments interaction were failed to show any significant differences $(\mathrm{P} \leq 0.05)$ on spike length in the two seasons.

The mean values of wheat yield parameters as affected by the interactions of the applied treatments for both seasons are shown in Table 4. It was found that the interaction of the tested treatments showed very highly significant differences $(\mathrm{P} \leq$ 0.001) on biological yield in both seasons. Biological yield is a combined contribution of yield components such as number of tillers $/ \mathrm{m}^{2}$, plant height, number of seeds/spike and 1000-seeds weight. The biological yield is significantly charged by any change in these components. It was found that the interaction of irrigation interval, irrigation canal sediments and humate fertilizer had significant effects $(\mathrm{P} \leq 0.05)$ on grain yield and straw yield of wheat in both seasons. But, harvest index had highly significant differences $(\mathrm{P} \leq 0.01)$ due to interaction effects of applied treatments in both seasons.

The results clarified that the application of 60 ton/ha of irrigation canal sediments and addition of $4 \mathrm{~kg} / \mathrm{fed}$ humate fertilizer when wheat was irrigated every ten days recorded the highest means values; compare to the controlled treatment and other treatments combinations, of all examined wheat growth and yield attributes in both seasons, except for number of plant $/ \mathrm{m}^{2}$ and straw yield which failed to show clearly the best combination of these three factors. Generally, the results showed highest values of the examined parameters of wheat crop in the second season than that of the first season. This could be attributed to the variations in climatic conditions between the two seasons, i.e. the second season was characterized by lower temperature in December and January and higher relative humidity percentage in all months compared to the first season, and the first season was characterized by higher temperature in February and March compared to the second season. High temperature is a major environmental constraint that limits wheat production in the Sudan (Ageeb 1994). Table 5 shows the mean temperature and relative humidity during growing seasons of wheat in both agricultural seasons as recorded by National Institute of Desert Studies Meteorological Station. 
Table 3. The Mean Effect of Irrigation Interval, Irrigation Canal Sediments and Humate Fertilizer on Wheat Yield Components Parameters on Both Seasons

\begin{tabular}{|c|c|c|c|c|c|c|c|c|c|c|c|c|}
\hline \multirow{2}{*}{\multicolumn{3}{|c|}{$\begin{array}{c}\text { Treatment } \\
\text { combinations }\end{array}$}} & \multicolumn{2}{|c|}{ No. of spikes $/ \mathrm{m}^{2}$} & \multicolumn{2}{|c|}{ No. of tillers $/ \mathrm{m}^{2}$} & \multicolumn{2}{|c|}{ Spike length $(\mathrm{cm})$} & \multicolumn{2}{|c|}{ No. of seeds/spike } & \multicolumn{2}{|c|}{ 1000-seeds weight (g) } \\
\hline & & & $\mathbf{1}^{\text {st }}$ Season & $2^{\text {nd }}$ Season & $1^{\text {st }}$ Season & $2^{\text {nd }}$ Season & $1^{\text {st }}$ Season & $2^{\text {nd }}$ Season & $\mathbf{1}^{\text {st }}$ Season & $2^{\text {nd }}$ Season & $\mathbf{1}^{\text {st }}$ Season & $2^{\text {nd }}$ Season \\
\hline \multirow{9}{*}{$\mathbf{I}_{1}$} & \multirow{3}{*}{$\mathbf{S}_{1}$} & $\overline{\mathbf{H}_{1}}$ & $264^{\mathrm{hi}}$ & $234^{\mathrm{fg}}$ & $58^{\mathrm{fg}}$ & $53^{\text {ef }}$ & 6.4 & 6.4 & $32^{\text {def }}$ & $32^{\text {defg }}$ & $33^{\text {cdef }}$ & $32^{\mathrm{fg}}$ \\
\hline & & $\mathbf{H}_{2}$ & $271^{\text {gh }}$ & $237^{\mathrm{fg}}$ & $61^{\text {ef }}$ & $54^{\mathrm{e}}$ & 6.7 & 5.3 & $33^{\text {cdef }}$ & $31^{\text {efg }}$ & $35^{\text {bcde }}$ & $35^{\mathrm{bc}}$ \\
\hline & & $\mathrm{H}_{3}$ & $289^{\mathrm{e}}$ & $239^{\mathrm{e}}$ & $62^{\mathrm{e}}$ & $55^{\mathrm{e}}$ & 6.4 & 5.5 & $34^{\text {cdef }}$ & $34^{\mathrm{de}}$ & $35^{\text {bcde }}$ & $35^{\mathrm{bc}}$ \\
\hline & \multirow{3}{*}{$\mathbf{S}_{\mathbf{2}}$} & $\mathrm{H}_{1}$ & $308^{\mathrm{d}}$ & $243^{\mathrm{e}}$ & $74^{\mathrm{d}}$ & $78^{\mathrm{d}}$ & 6.3 & 6.1 & $35^{\text {bcde }}$ & $33^{\text {def }}$ & $32^{\text {def }}$ & $32^{\mathrm{fg}}$ \\
\hline & & $\mathrm{H}_{2}$ & $320^{\mathrm{c}}$ & $283^{\mathrm{c}}$ & $78^{\mathrm{d}}$ & $90^{\mathrm{c}}$ & 6.3 & 6.7 & $36^{\mathrm{abcd}}$ & $35^{\mathrm{c}}$ & $36^{\mathrm{abc}}$ & $35^{\mathrm{bc}}$ \\
\hline & & $\mathbf{H}_{3}$ & $344^{\mathrm{b}}$ & $294^{\mathrm{b}}$ & $75^{\mathrm{d}}$ & $97^{\mathrm{b}}$ & 6.1 & 5.9 & $37^{\mathrm{abc}}$ & $38^{\mathrm{b}}$ & $37^{\mathrm{abc}}$ & $36^{\mathrm{b}}$ \\
\hline & \multirow{3}{*}{$\mathbf{S}_{\mathbf{3}}$} & $\mathrm{H}_{1}$ & $293^{\mathrm{e}}$ & $274^{\mathrm{d}}$ & $83^{c}$ & $87^{\mathrm{c}}$ & 6.4 & 6.0 & $38^{\mathrm{ab}}$ & $37^{\mathrm{bc}}$ & $35^{\text {bcde }}$ & $35^{\mathrm{bc}}$ \\
\hline & & $\mathbf{H}_{2}$ & $322^{\mathrm{c}}$ & $297^{\mathrm{b}}$ & $88^{\mathrm{b}}$ & $98^{\mathrm{b}}$ & 6.3 & 6.9 & $37^{\mathrm{abc}}$ & $38^{\mathrm{b}}$ & $37^{\mathrm{abc}}$ & $36^{\mathrm{b}}$ \\
\hline & & $\mathbf{H}_{3}$ & $357^{\mathrm{a}}$ & $317^{\mathrm{a}}$ & $94^{\mathrm{a}}$ & $110^{\mathrm{a}}$ & 7.0 & 7.2 & $40^{\mathrm{a}}$ & $48^{\mathrm{a}}$ & $39^{a}$ & $39^{a}$ \\
\hline \multirow{9}{*}{$\mathbf{I}_{2}$} & \multirow{3}{*}{$\mathbf{S}_{1}$} & $\mathrm{H}_{1}$ & $241^{\mathrm{k}}$ & $221^{\mathrm{jk}}$ & $30^{j}$ & $20^{j}$ & 6.1 & 5.0 & $22^{\mathrm{h}}$ & $23^{\mathrm{h}}$ & $31^{\mathrm{ef}}$ & $30^{\mathrm{hi}}$ \\
\hline & & $\mathrm{H}_{2}$ & $253^{\mathrm{ij}}$ & $230^{i}$ & $34^{\mathrm{ij}}$ & $24^{i}$ & 5.8 & 5.3 & $27^{\mathrm{g}}$ & $24^{\mathrm{h}}$ & $33^{\text {cdef }}$ & $32^{\text {fg }}$ \\
\hline & & $\mathbf{H}_{3}$ & $262^{\text {hi }}$ & $218^{\mathrm{jk}}$ & $33^{\mathrm{ij}}$ & $22^{i j}$ & 5.6 & 5.6 & $30^{\mathrm{fg}}$ & $29^{\mathrm{g}}$ & $35^{\text {bcde }}$ & $32^{\mathrm{fg}}$ \\
\hline & \multirow{3}{*}{$\mathbf{S}_{\mathbf{2}}$} & $\mathrm{H}_{1}$ & $282^{\mathrm{ef}}$ & $197^{\mathrm{m}}$ & $35^{\mathrm{i}}$ & $25^{\mathrm{i}}$ & 6.3 & 5.2 & $32^{\text {def }}$ & $31^{\text {efg }}$ & $30^{f}$ & $29^{i}$ \\
\hline & & $\mathrm{H}_{2}$ & $247^{\mathrm{jk}}$ & $227^{1}$ & $46^{\mathrm{h}}$ & $50^{\mathrm{fg}}$ & 6.0 & 5.4 & $30^{\mathrm{fg}}$ & $31^{\mathrm{efg}}$ & $36^{\mathrm{abc}}$ & $32^{\mathrm{fg}}$ \\
\hline & & $\mathrm{H}_{3}$ & $268^{g h}$ & $218^{\mathrm{jk}}$ & $57^{\mathrm{fg}}$ & $50^{\mathrm{fg}}$ & 6.5 & 5.3 & $33^{\text {cdef }}$ & $32^{\text {defg }}$ & $34^{\text {bcde }}$ & $34^{\text {cde }}$ \\
\hline & \multirow{3}{*}{$\mathbf{S}_{\mathbf{3}}$} & $\mathrm{H}_{1}$ & $263^{\mathrm{hi}}$ & $243^{\mathrm{e}}$ & $42^{\mathrm{h}}$ & $43^{h}$ & 5.6 & 5.9 & $31^{\text {efg }}$ & $30^{\mathrm{fg}}$ & $34^{\text {bcde }}$ & $33^{\text {def }}$ \\
\hline & & $\mathrm{H}_{2}$ & $267^{\mathrm{h}}$ & $234^{\mathrm{fg}}$ & $55^{\mathrm{g}}$ & $52^{\text {ef }}$ & 6.5 & 5.5 & $32^{\mathrm{def}}$ & $31^{\text {efg }}$ & $35^{\text {bcde }}$ & $34^{\text {cde }}$ \\
\hline & & $\mathrm{H}_{3}$ & $278^{\mathrm{fg}}$ & $232^{\mathrm{h}}$ & $59^{\mathrm{efg}}$ & $48^{g}$ & 6.7 & 6.5 & $32^{\text {def }}$ & $34^{\mathrm{de}}$ & $36^{\mathrm{abc}}$ & $35^{\mathrm{bc}}$ \\
\hline \multicolumn{3}{|c|}{ DMRT } & $*$ & $*$ & $* *$ & $* *$ & N.S. & N.S. & $*$ & $*$ & $*$ & $*$ \\
\hline
\end{tabular}

Abbreviations of I, S and $\mathrm{H}$ and their operations as explained in Table 1.

Means followed by the same letter(s) in column are not significantly different at $\mathrm{P} \leq 0.05$.

N.S. $=$ Not significantly different at $\mathrm{P} \leq 0.05$.

$* * *=$ Significantly different at $\mathrm{P} \leq 0.05$ and $\mathrm{P} \leq 0.01$, respectively. 
Table 4. The Mean Effect of Interactions of the Applied Treatments on Yield Parameters of Wheat in Both Seasons

\begin{tabular}{|c|c|c|c|c|c|c|c|c|c|c|}
\hline & reat & & Biologic & d (kg/ha) & Grain & (kg/ha) & Straw & (kg/ha) & Harve & ex $(\%)$ \\
\hline & nDIn & & $1^{\text {st }}$ Season & $2^{\text {nd }}$ Season & $\mathbf{1}^{\text {st }}$ Season & $2^{\text {nd }}$ Season & $\mathbf{1}^{\text {st }}$ Season & $2^{\text {nd }}$ Season & $1^{\text {st }}$ Season & $2^{\text {nd }}$ Season \\
\hline & & $\mathbf{H}_{1}$ & $7591^{\text {bcdef }}$ & $7236^{\circ}$ & $2353^{j}$ & $2301^{\mathrm{q}}$ & $5238^{\mathrm{k}}$ & $4935^{\circ}$ & $31^{\text {hi }}$ & $32^{\text {efgh }}$ \\
\hline & $\mathbf{S}_{1}$ & $\mathbf{H}_{2}$ & $8012^{\text {abcdef }}$ & $8067^{1}$ & $2564^{\mathrm{h}}$ & $2693^{\mathrm{m}}$ & $5448^{g}$ & $5374^{1}$ & $32^{\text {gh }}$ & $33^{\text {defg }}$ \\
\hline & & $\mathbf{H}_{3}$ & $9431^{\mathrm{ab}}$ & $8415^{\mathrm{k}}$ & $3112^{d}$ & $2887^{j}$ & $6319^{c}$ & $5528^{i}$ & $33^{\text {efg }}$ & $34^{\text {cdef }}$ \\
\hline & & $\mathrm{H}_{1}$ & $8114^{\text {abcdef }}$ & $8446^{j}$ & $2840^{\mathrm{g}}$ & $2994^{\mathrm{h}}$ & $5274^{j}$ & $5452^{j}$ & $35^{\text {cde }}$ & $35^{\mathrm{bcd}}$ \\
\hline $\mathbf{I}_{1}$ & $\mathbf{S}_{2}$ & $\mathrm{H}_{2}$ & $8879^{\mathrm{abc}}$ & $9818^{d}$ & $3017^{f}$ & $3518^{\mathrm{c}}$ & $5862^{\mathrm{e}}$ & $6300^{e}$ & $34^{\text {defg }}$ & $36^{\mathrm{bc}}$ \\
\hline & & $\mathrm{H}_{3}$ & $8751^{\mathrm{abcd}}$ & $8485^{i}$ & $3326^{b}$ & $3065^{g}$ & $5425^{\mathrm{h}}$ & $5420^{\mathrm{k}}$ & $38^{\mathrm{ab}}$ & $36^{\mathrm{bc}}$ \\
\hline & & $\mathrm{H}_{1}$ & $9189^{\mathrm{abc}}$ & $10310^{c}$ & $2848^{g}$ & $3312^{\mathrm{e}}$ & $6341^{b}$ & $6998^{c}$ & $31^{\mathrm{hi}}$ & $32^{\text {efgh }}$ \\
\hline & $\mathbf{S}_{\mathbf{3}}$ & $\mathbf{H}_{2}$ & $9535^{\mathrm{abc}}$ & $11530^{b}$ & $3050^{\mathrm{e}}$ & $3838^{b}$ & $6485^{\mathrm{a}}$ & $7692^{a}$ & $32^{\text {gh }}$ & $33^{\text {defg }}$ \\
\hline & & $\mathbf{H}_{3}$ & $9931^{\mathrm{a}}$ & $12330^{\mathrm{a}}$ & $3955^{\mathrm{a}}$ & $4660^{\mathrm{a}}$ & $5976^{d}$ & $7670^{b}$ & $40^{\mathrm{a}}$ & $38^{\mathrm{a}}$ \\
\hline & & $\mathrm{H}_{1}$ & $6125^{\mathrm{f}}$ & $7042^{p}$ & $1838^{1}$ & $2052^{p}$ & $4287^{p}$ & $4990^{n}$ & $30^{i}$ & $29^{\mathrm{h}}$ \\
\hline & $\mathbf{S}_{1}$ & $\mathbf{H}_{2}$ & $7730^{\text {bcdef }}$ & $9574^{\mathrm{e}}$ & $2473^{j}$ & $2725^{1}$ & $5257^{j}$ & $6849^{c}$ & $32^{\mathrm{gh}}$ & $28^{\mathrm{h}}$ \\
\hline & & $\mathbf{H}_{3}$ & $7208^{\text {cdef }}$ & $7791^{\mathrm{m}}$ & $2561^{\mathrm{h}}$ & $2808^{\mathrm{k}}$ & $4647^{n}$ & $4983^{n}$ & $36^{\mathrm{cd}}$ & $36^{\mathrm{bc}}$ \\
\hline & & $\mathrm{H}_{1}$ & $6717^{\text {ef }}$ & $7743^{\mathrm{n}}$ & $2280^{k}$ & $2654^{n}$ & $4437^{\circ}$ & $5089^{m}$ & $34^{\text {defg }}$ & $34^{\text {cdef }}$ \\
\hline $\mathbf{I}_{2}$ & $\mathbf{S}_{2}$ & $\mathbf{H}_{2}$ & $6780^{\mathrm{def}}$ & $7265^{\circ}$ & $2507^{i}$ & $2540^{\circ}$ & $4273^{p}$ & $4725^{\mathrm{p}}$ & $37^{\mathrm{bc}}$ & $35^{\text {bcd }}$ \\
\hline & & $\mathrm{H}_{3}$ & $7206^{\text {cdef }}$ & $8793^{h}$ & $2519^{i}$ & $3064^{\mathrm{g}}$ & $4687^{\mathrm{m}}$ & $5729^{h}$ & $35^{\text {cde }}$ & $35^{\text {bcd }}$ \\
\hline & & $\mathrm{H}_{1}$ & $7353^{\text {cdef }}$ & $9349^{g}$ & $2277^{k}$ & $2948^{i}$ & $5076^{1}$ & $6401^{\mathrm{d}}$ & $31^{\mathrm{hi}}$ & $32^{\text {efgh }}$ \\
\hline & $\mathbf{S}_{\mathbf{3}}$ & $\mathbf{H}_{2}$ & $7873^{\text {bcdef }}$ & $9431^{f}$ & $2577^{h}$ & $3130^{f}$ & $5296^{i}$ & $6301^{\mathrm{e}}$ & $33^{\text {efg }}$ & $33^{\text {defg }}$ \\
\hline & & $\mathbf{H}_{3}$ & $8631^{\text {abcd }}$ & $9327^{\mathrm{g}}$ & $3117^{\mathrm{c}}$ & $3465^{d}$ & $5514^{\mathrm{f}}$ & $5862^{\mathrm{g}}$ & $36^{\mathrm{cd}}$ & $37^{b}$ \\
\hline DI & & & $* * *$ & $* * *$ & $*$ & $*$ & $*$ & $*$ & $* *$ & $* *$ \\
\hline
\end{tabular}

Abbreviations of I, S and $\mathrm{H}$ and their operations as explained in Table 1.

Means followed by the same letter(s) in column are not significantly different at $\mathrm{P} \leq 0.05$.

$*, * *, * * *=$ Significantly different at $\mathrm{P} \leq 0.05, \mathrm{P} \leq 0.01$ and $\mathrm{P} \leq 0.001$, respectively. 
Table 5. The Mean Temperature and Relative Humidity in the Experimental Site in Both Seasons

\begin{tabular}{|l|c|c|c|c|}
\hline \multirow{2}{*}{ Month } & \multicolumn{2}{|c|}{ Mean Temp $\left({ }^{\mathbf{0}} \mathbf{C}\right)$} & \multicolumn{2}{c|}{ Relative Humidity (\%) } \\
\cline { 2 - 5 } & $\mathbf{1}^{\text {st }}$ Season & $\mathbf{2}^{\text {nd }}$ Season & $\mathbf{1}^{\text {st }}$ Season & $\mathbf{2}^{\text {nd }}$ Season \\
\hline November & 22.1 & 24.9 & 40 & 46 \\
\hline December & 22.0 & 20.7 & 46 & 50 \\
\hline January & 19.7 & 19.2 & 44 & 51 \\
\hline February & 23.9 & 21.3 & 35 & 43 \\
\hline March & 27.3 & 26.3 & 25 & 34 \\
\hline
\end{tabular}

Figures 1 and 2 illustrate the appearance of wheat crop under the controlled treatments $\left(\mathrm{I}_{1} \times \mathrm{S}_{1} \times \mathrm{H}_{1}\right)$ and the best combination of treatments interactions $\left(\mathrm{I}_{1} \times \mathrm{S}_{3} \times \mathrm{H}_{3}\right)$, respectively. It clear that the growth and appearance of wheat crop grown under treatments interactions $\mathrm{I}_{1} \times \mathrm{S}_{3} \times \mathrm{H}_{3}$ was more better than under the controlled treatments $\left(\mathrm{I}_{1} \times \mathrm{S}_{1} \times \mathrm{H}_{1}\right)$.

Since the sand loamy soil of the study area have weakly developed profiles and a loose consistency, so the use of irrigation canal sediments as soil an amendment by incorporation with the soil this could be a good source for soil reclamation for its availability and low cost. It was clarified that application of irrigation canal sediments improved wheat productivity. Mubarak et al. (2015) concluded that, short-term application of irrigation canal sediments could be useful practice in amelioration of poor quality desert soils (Aridisols) through improving physical and chemical properties.

Figure 1. Appearance of Wheat Crop Grown under the Controlled Treatments

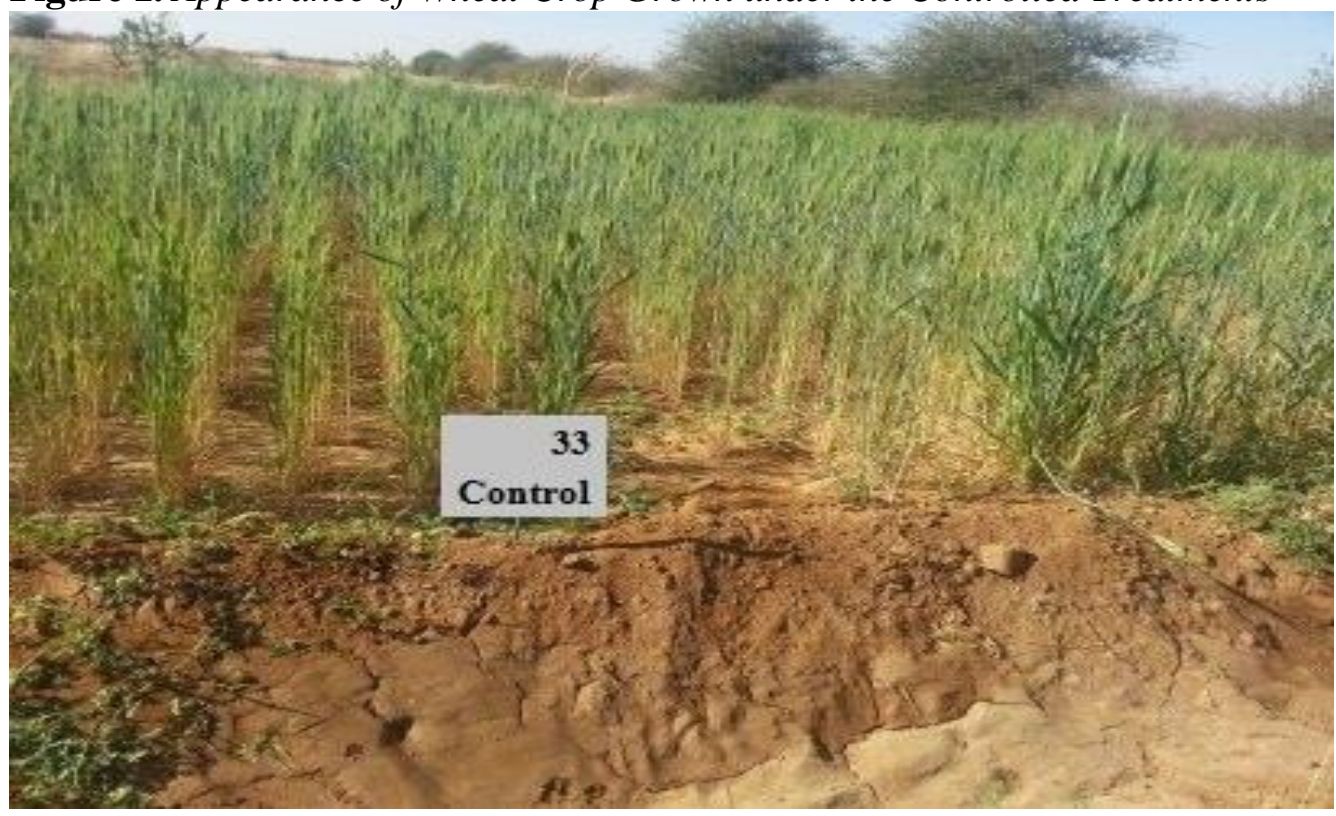


Figure 2. Appearance of Wheat Crop Grown under Application of 60 ton/ha Irrigation Canal Sediment, $4 \mathrm{~kg} / \mathrm{fed}$ Humate Fertilizer and 10 Days Irrigation Interval

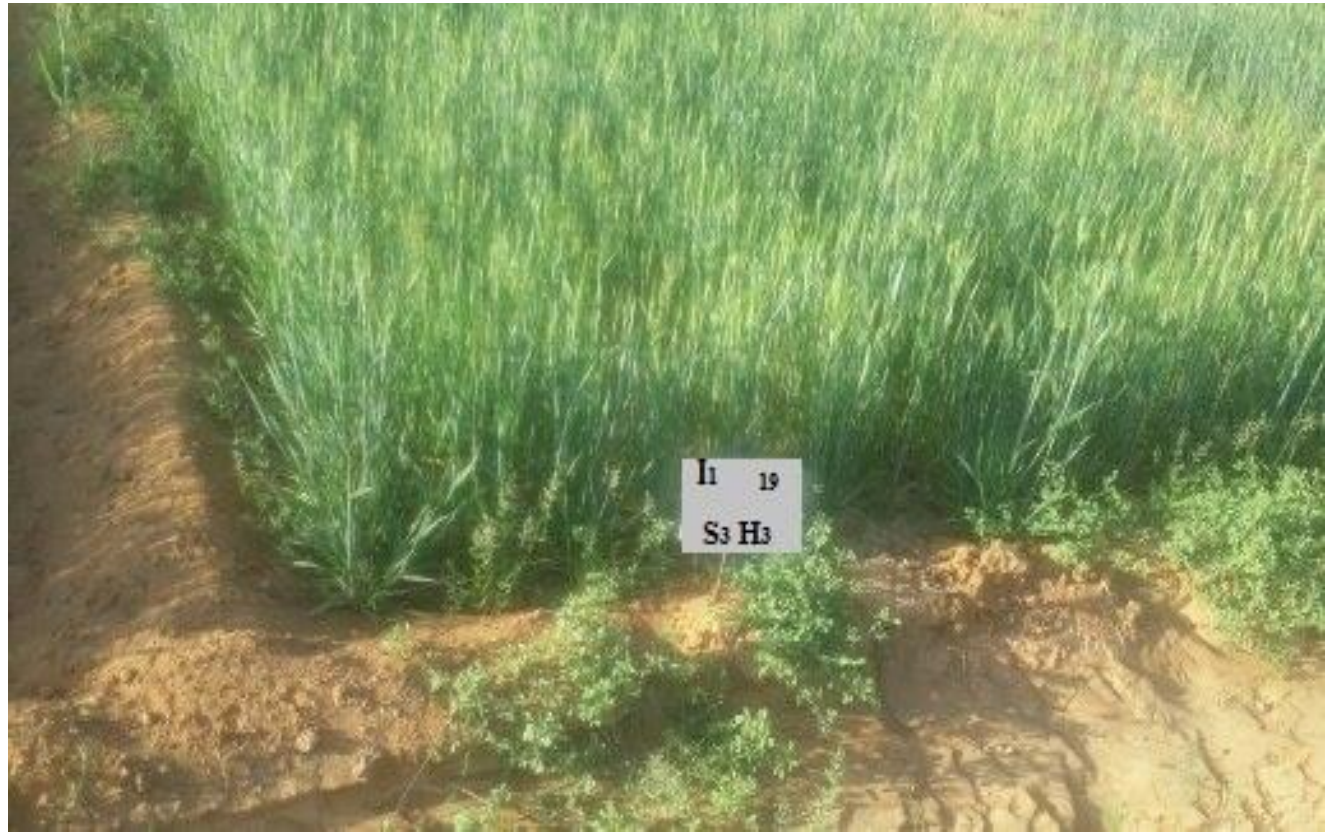

The desert plain soils of the Northern State of Sudan are characterized by high amount of sand and low chemical soil fertility and mostly are deficient in Nitrogen, Phosphorus and Organic Carbon for optimum yield production of different cultivated crops (Land and Water Research Centre 1999). Humate fertilizer, as humic acid in its solid state, is a good healthy and cheap solution for the poor and infertile soil of the study area. The results of this study showed that the application of humic acid improved growth and yield of wheat. As mentioned by Rasool et al. (2015) and Dudley (2018), humic acid is very economical product which increased the fertility status of soil; especially in light and sandy soils which typically are poor in humans, thus, provide conditions which are favourable to plant growth and ultimately increase yield of crop. Also, the results is in agreement with that of Shahryari et al. (2009) who stated that, humic substance is a beneficial natural substance for increasing the quality and the quantity of wheat. In the same manner, Babar Iqbal et al. (2016) concluded that wheat yield increased by increasing the application of humic acid. According to Petti (2004), plants grown on soils which contain adequate humin, humic acids, and fulvic acids are less subject to stress, are healthier, produce higher yields; and the nutritional quality of harvested foods and feeds are superior.

Irrigation is an expensive input, therefore, farmer, agronomist, economist and engineer need to know the response of growth and yield of wheat to irrigation. Several investigations from different parts of the world reported that growth and yield attributes of wheat; plant height, number of tillers $/ \mathrm{m}^{2}$, number of spike/ $/ \mathrm{m}^{2}$, spike length, number of seeds/spike, 1000-seeds weight, biological yield, grain yield, straw yield and harvest index, increased with more frequent irrigation and decrease with less frequent irrigation (Hussain et al. 2004, Zeidan et al. 2009, 
Akram 2011, El Hwary and Yagoub 2011, Seleiman et al. 2011, Ali and Ahmed 2012, Ngwako and Mashiqa 2013, Rahman 2014, Shrief and Abdel-Mohsen 2015).

\section{Conclusions}

The results obtained shown that wheat production in soil of low or marginal productivity (Aridisols) could be increased by maintenance of this soil to increase the cultivated area. In high terrace soils, as in the Northern State of Sudan, the application of sediments accumulated in irrigated canals might be a useful way to increase the wheat productivity and disposal of this sediment. Also, wheat production in poor quality desert soils could be increased by increasing the application of humate fertilizer. Furthermore, the effective and efficient use of irrigation water (less frequent irrigation) could increase the growth and yield attributes of wheat. As far as irrigation canal sediments and humate fertilizer applications and irrigation interval combination is concerned, it can be concluded that the higher values of the most growth and yield attributes of winter wheat cultivated in El Multaga soil series (Northern State of Sudan) were obtained under application of 60 ton/ha irrigation canal sediments, $4 \mathrm{~kg} / \mathrm{fed} \mathrm{humate} \mathrm{fertilizer} \mathrm{and}$ 10 days irrigation interval.

\section{References}

Ageeb OA (1994) Agronomic Aspects of Wheat Production in Sudan. In DA Saunders, GP Hettel (eds), Wheat in Heat- Stressed Environments: Irrigated, Dry Areas and Rice-Wheat Farming Systems, 67-74. Proceedings of the International Conference of Wheat in Hot, Dry, Irrigated Environments, 1-4 February 1993. Wad Medani, Sudan.

Ageeb OA, Elahmadi AB, Solh MB (1996) Wheat Production and Improvement in the Sudan. In MC Saxena (ed), Proceedings of the National Research Review Workshop, 27- 30 August 1995.Wad Medani, Sudan.

Akram M (2011) Growth and Yield Components of Wheat under Water Stress of Different Growth Stages. Bangladesh Journal of Agricultural Research 36(3): 455-468.

Ali AA, Ahmed SH (2012) Water Stress Effect on Yield and Water Use Efficiency of Two Wheat Varieties, 337-343. $3^{\text {rd }}$ RUFORUM Biennial Meeting, 24-28 September 2012. Entebbe, Uganda.

Almeu A, Hazem A (2011) Government of Sudan and FAO/WFP Crop and Food Security Assessment Mission to the 15 Northern States of Sudan. Retrieved from https://bit. ly/2XU8oEh.

Babiker EA, Faki H (1994) Evaluation of Farmers' Attitudes and their Effect on Wheat Productivity and Input Use in Rahad Scheme. Wad Medani, Sudan: ICARDA/ARC.

Dudley D (2018) Humate, A Farmer's Best Friend. Retrieved from https://bit.ly/2V $\mathrm{Z7g} 0 \mathrm{~F}$.

El Hwary EB, Yagoub SO (2011) Effect of Different Irrigation Intervals on Wheat (Triticum Aestivum L.) in Semi-Arid Regions of Sudan. Journal of Science and 
Technology 12(3): 75- 83.

Elquosy D (1998) Demand Management Policies, 1-8. International Conference on Water Problem in Africa, 26-27 October 1998. Cairo University, Egypt.

Erneo DB (2007) Impact of Irrigation Method and Variety on Water Requirement of Wheat (Triticum Aestivum L.) in the Upper Terrace of Northern Sudan. PhD Thesis. Sudan: University of Juba.

Farah SM, Ahmed SH, Salih AA, Ishag HM, Badr Eldin AM (1994) Effect of Skipping Irrigation at Different Developmental Stages of Wheat, 1-5. Nile Valley Regional Coordination Meeting, 1-4 October 1994. Cairo, Egypt.

Habiballa AM, Ali AM (2010) Classification of Climates Using Aridity Indices. Sudan Journal of Desertification Research 2: 62-75.

Hussain A, Chaudhry MR, Wajid A, Ahmed A, Rafiq M, Ibrahim M, Goheer AR (2004) Influence of Water Stress on Growth, Yield and Radiation Use Efficiency of Various Wheat Cultivars. International Journal of Agriculture \& Biology 6(6): 1074-1079.

Imran AA (2010) Effect of Tillage Methods, Green and Farmyard Manures on Wheat Yield and Properties of Desert Plain Soils, Northern State, Sudan. MSc Thesis. Wad Medani, Sudan: University of Gezira.

Iqbal B, Shazma A, Farjad I, Wajid A, Mohammad I, Shehryar KH (2016) Response of Wheat Crop to Humic Acid and Nitrogen Levels. EC Agriculture 3(1): 558-565.

Land and Water Research Centre (1999) Detailed Soil Survey and Land Suitability Classification of El Multaga Scheme. Wad Medani, Sudan: Agricultural Research Corporation.

Mubarak AA, Hassan AA, Ahmed IA, Eltilib AMA (2014) Use of Dry Sewage Sludge and Clay based Ameliorant for Production of Wheat (Triticum Aestivum L.) in a Desert Soil II: Effects on Yield and Nutrient Content. Sudan Journal of Desertification Research 6(1): 67-78.

Mubarak AA, Hassan AA, Ahmed IA, Eltilib AMA (2015) A Note on the Impact of Dry Sewage Sludge and Hamdab Irrigation Canal Sediment on Some Quality Attributes of an Aridisols, Northern State. Sudan Journal of Desertification Research 7(1): 132-141.

Ngwako S, Mashiqa PK (2013) The Effect of Irrigation on Growth and Yield of Winter Wheat (Triticum Aestivum L.) Cultivars. International Journal of Agriculture and Crop Sciences 5(9): 976-982.

Petti R (2004) Organic Matter, Humus, Humate, Humic Acid, Fulvic Acid and Humin: Their Importance in Soil Fertility and Plant Health. Retrieved from https://bit.ly/ 2TveUmy.

Rahman M (2014) Effects of Different Levels of Irrigation on the Yield and Yield Contributing Characters of Wheat. MSc Thesis. Bangladesh Agricultural University. Retrieved from https://bit.ly/2HeH7aD.

Rasool GH, Wahla AJ, Nawaz M, Abdur Rehman M (2015) Determination and Evaluation of the Effect of Different Doses of Humic Acid on the Growth and Yield of Wheat (Triticum Aestivum L.). Journal of Agriculture and Veterinary Science 8(2): 5-7.

Seleiman M, Abdel-aal S, Ibrahim M, Zahran G (2011) Productivity, Grain and Dough Quality of Bread Wheat Grown with Different Water Regimes. Journal of AcroCrop Science 2(1): 11-17.

Shahryari R, Gadimov A, Gurbanov E, Valizade M (2009) Application of Potassium Humate to Wheat for Organic Agriculture in Iran. Asian Journal of Food and Agro-Industry 2(Special Issue-ref. 12): 164-168.

Shrief SA, Abdel-Mohsen AA (2015) Regression Models to Describe the Influence of 
Different Irrigation Regimes on Grain Yield and Water Use Efficiency in Bread Wheat. Advance in Agriculture and Biology 4(1): 39-49.

Tester CF (1990) Organic Amendment Effects on Physical and Chemical Properties of a Sandy Soil. Soil Science Society of America Journal 54(3): 827-831.

Zeidan EM, Abd El-Hameed IM, Bassiouny AH, Waly AA (2009) Effects of Irrigation Intervals, Nitrogen and Organic Fertilization on Yield, Yield Attributes and Crude Protein Content of Some Wheat Cultivars under Newly Reclaimed Saline Soil, 298307. $4^{\text {th }}$ Conference on Recent Technologies in Agriculture. Retrieved from https://bit.ly/2CfMuCc. 